UNIVERSIDADE DE SÃO PAULO

FACULDADE DE ZOOTECNIA E ENGENHARIA DE ALIMENTOS

GRAZIELE GROSSI BOVI

Óleo de buriti (Mauritia flexuosa L.) nanoemulsionado: produção por método de baixa energia, caracterização físico-química das dispersões e incorporação em bebida isotônica

(Versão corrigida) 
GRAZIELE GROSSI BOVI

Óleo de buriti (Mauritia flexuosa $L$.) nanoemulsionado: produção por método de baixa energia, caracterização físico-química das dispersões e incorporação em bebida isotônica

Dissertação apresentada à Faculdade de Zootecnia e Engenharia de Alimentos da Universidade de São Paulo, como parte dos requisitos para a obtenção do Título de Mestre em Ciências.

Área de concentração: Ciências da Engenharia de Alimentos

Orientadora: Prof. ${ }^{a}$ Dr. ${ }^{a}$ Samantha Cristina de Pinho 
Dados Internacionais de Catalogação na Publicação

Serviço de Biblioteca e Informação da Faculdade de Zootecnia e Engenharia de Alimentos da Universidade de São Paulo

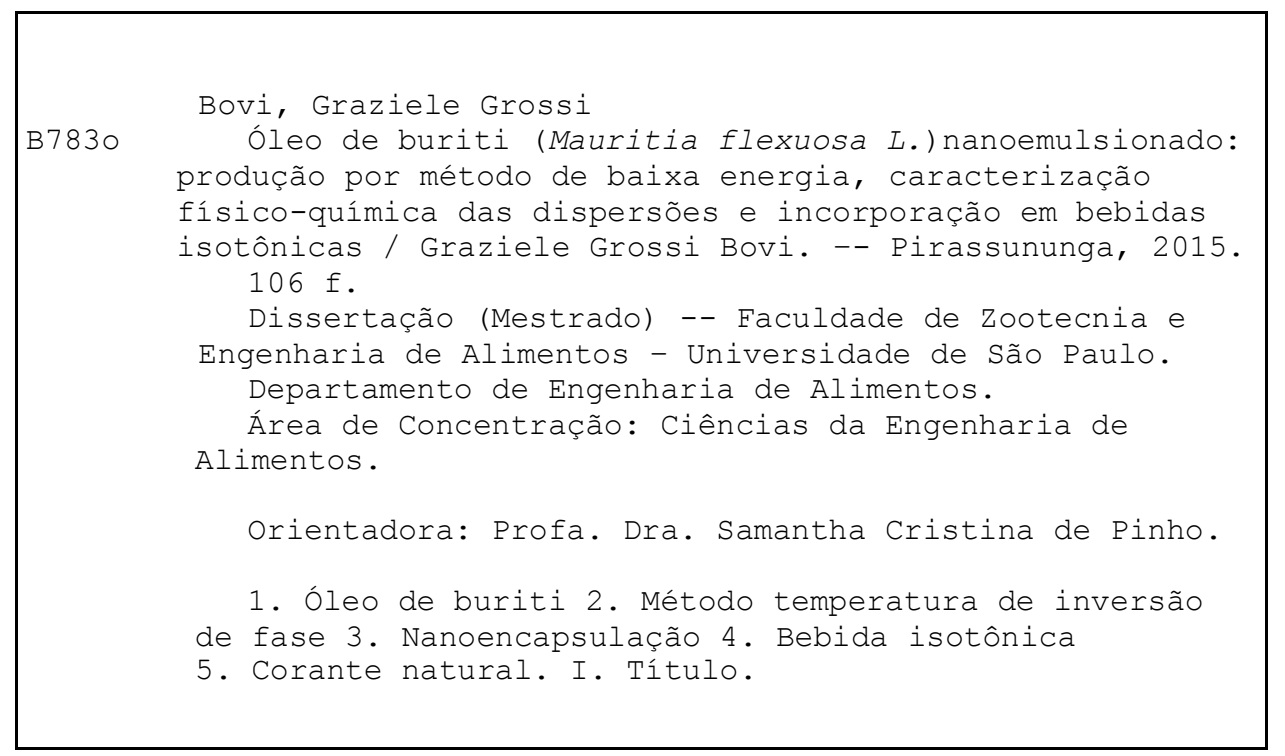

"Permitida a cópia total ou parcial deste documento, desde que citada a fonte - o autor" 


\title{
Óleo de buriti (Mauritia flexuosa $L$.) nanoemulsionado: produção por método de baixa energia, caracterização físico-química das dispersões e incorporação em bebida isotônica
}

\author{
Dissertação apresentada à Faculdade de \\ Zootecnia e Engenharia de Alimentos da \\ Universidade de São Paulo, como parte dos \\ requisitos para obtenção do título de Mestre \\ em Ciências do programa de Pós-Graduação \\ em Engenharia de Alimentos.
}

Área de Concentração: Ciências da Engenharia de Alimentos

Data de aprovação:

Banca Examinadora:

Prof $^{a}$. Dr ${ }^{\mathrm{a}}$. Samantha Cristina Pinho (Faculdade de Zootecnia e Engenharia de Alimentos/USP) (Orientadora)

Prof. Dr. Rodrigo Rodrigues Petrus

(Faculdade de Zootecnia e Engenharia de Alimentos/USP)

Prof $^{\mathrm{a}}$. Dr ${ }^{\mathrm{a}}$. Fabiana Perrechil Bonsanto

(Instituto de Ciências Ambientais, Químicas e Farmacêuticas/UNIFESP) 
Dedico essa dissertação de Mestrado aos meus pais, Juliane e Silvio, e à minha tia, Joceli, por todo apoio e incentivo aos estudos, sem vocês nada disso seria possível. 


\section{AGRADECIMENTOS}

À Prof ${ }^{\mathrm{a}}$. Samantha C. Pinho, minha orientadora, pela oportunidade, convivência, dedicação e paciência. Obrigada pelo tempo disponibilizado a este trabalho de Mestrado e pela experiência acadêmica que me transmitiu.

Ao Prof. Dr. Rodrigo Petrus e à Mestre em Engenharia de Alimentos Natali Knorr Valadão, pela co-orientação na etapa de produção da bebida isotônica.

À Faculdade de Zootecnia e Engenharia de Alimentos, pela oportunidade de realização do curso de Mestrado.

À minha família pela presença, carinho, conselhos, incentivo e apoio.

À Marcela Tedesco, que me auxiliou em diversas situações. Obrigada por me abrigar inúmeras vezes.

Ao Yusuf Nadi Karatay, que mesmo distante sempre se fez presente. Obrigada por todo amor, carinho e suporte em todas as horas que precisei.

Aos técnicos Guilherme Silva, Camila Molina, Carla Mônaco, Keila Aracava e Marcelo Thomazini pela disposição em ajudar. Em especial quero agradecer à Clara Mori (FMVZ/USP) pelas análises de osmolalidade e ao Fabinho (Fábio Gallo) pela imensa ajuda no dia do processamento.

A todos do Laboratório de Coloides e Funcionalidade de Macromoléculas pela boa vontade e disposição em ajudar. Em especial quero agradecer a Ivana Andrade, Marluci Ghiraldi, Nayla Souki e Taíse Toniazzo por toda ajuda no dia do processamento, à Marilia Moraes e à Graziela Veiga pelos ensinamentos na produção das nanoemulsões e também às alunas de graduação Silmara Y. Shimoda, Maria Souza Pacheco e Marina Zagria Vasconcelos pela ajuda nas análises no laboratório.

À Coordenação de Aperfeiçoamento de Pessoal de Nível Superior (CAPES) pela concessão da bolsa de Mestrado. 
"Seja a mudança que você quer ver no mundo"

Mahatma Gandhi 


\section{RESUMO}

BOVI, G. G. Óleo de buriti (Mauritia flexuosa L.) nanoemulsionado: produção por método de baixa energia, caracterização físico-química das dispersões e incorporação em bebida isotônica. 2015. 106 f. Dissertação (Mestrado) - Faculdade de Zootecnia e Engenharia de Alimentos, Universidade de São Paulo, Pirassununga, 2015.

O óleo de buriti (Mauritia flexuosa L.) é o óleo vegetal mais rico em $\beta$-caroteno encontrado na biodiversidade brasileira, além de possuir tocoferol e ácido graxo. Apesar do alto valor nutritivo, não é amplamente cultivado e seu processamento comercial é realizado em pequena escala. Sua encapsulação e posterior aplicação em produto alimentício representa uma alternativa para o aumento de seu consumo uma vez que nesta forma pode ser incorporado em produtos alimentares de base aquosa. Este estudo objetivou a produção, caracterização e avaliação da estabilidade de nanoemulsões encapsulando óleo de buriti para posterior aplicação em bebida isotônica visando a substituição de corante artificial, especialmente o amarelo crepúsculo, por corante natural. As nanoemulsões foram produzidas por método de baixa energia (temperatura de inversão de fases - PIT) e o melhor resultado foi obtido usando uma proporção de óleo-tensoativo (SOR) de 2 (10\% óleo de buriti e Tween 80), água deionizada, $\alpha$ tocoferol e $\mathrm{NaCl}$. As nanoemulsões foram avaliadas em termos de tamanho médio de gotícula, oxidação lipidica e quantificação de carotenoides totais. Estas apresentaram boa estabilidade físico-química, porém a quantificação de carotenoides totais mostrou diminuição de $73 \%$ após 60 dias de armazenamento. Duas formulações de nanoemulsão foram escolhidas $(2,5 \mathrm{M}$ e $3 \mathrm{M}$ de $\mathrm{NaCl}$, ambas na proporção de 1:1 de carotenoides totais: $\alpha$-tocoferol) e aplicadas em um sitema modelo de bebida isotônica e pasteurizadas a $80{ }^{\circ} \mathrm{C} / 15 \mathrm{~s}$. A caracterização da bebida isotônica se deu em termos de $\mathrm{pH}$ (3), osmolalidade (302 mOsmol / kg), acidez titulável total $(0,171 \mathrm{~g} / 100 \mathrm{~mL})$ e sólidos solúveis ( $5^{\circ}$ Brix), além de análises microbiologicas e avaliação sensorial. Os resultados mostraram que é possível incorporar óleo de buriti nanoemulsionado em bebida isotônica e por meio da realização de análise sensorial, observou-se que a incorporação de nanoemulsão em bebida isotônica foi relativamente satisfatório.

Palavras-chave: óleo de buriti, método temperatura de inversão de fase, nanoencapsulação, bebida isotônica, corante natural 


\begin{abstract}
BOVI, G. G. Buriti oil (Mauritia flexuosa L.) in nanoemulsions: production by low energy method, physico-chemical characterization of the dispersions and incorporation in isotonic beverage. 2015. 106 f. M. Sc. Dissertation - Faculdade de Zootecnia e Engenharia de Alimentos, Universidade de São Paulo, Pirassununga, 2015.
\end{abstract}

Buriti (Mauritia flexuosa L.) oil is the richest vegetable oil in beta-carotene found in Brazilian biodiversity, it is also rich in tocopherol and fatty acid. Despite its high nutritional value, buriti is not widely cultivated and its commercial fruit processing is carried out on a small scale. The encapsulation of buriti oil and subsequent application in food products represents an alternative to increase its consumption, since in this form it can be incorporated in aqueous-based food products. This project aimed the production, characterization and stability evaluation of nanoemulsions encapsulating buriti oil for subsequent incorporation in isotonic beverage, aiming to replace artificial colorant, especially sunset yellow, by natural colorant. The nanoemulsions were produced by low energy method -phase inversion temperature (PIT) method- and the best result was obtained using a surfactant-oil ratio (SOR) of 2.0 (10\% buriti oil and $20 \%$ polysorbate 80 ), deionized water, alpha-tocopherol and $\mathrm{NaCl}$. The nanoemulsions were evaluated in terms of storage stability (60 days), average droplet size, quantification of lipid oxidation and total carotenoids. The system showed good physical-chemical stability, however the quantification of total encapsulated carotenoids showed a decrease of $73 \%$ after 60 days of storage. Two formulations of nanoemulsions were chosen $(2,5 \mathrm{M}$ and $3 \mathrm{M}$ of $\mathrm{NaCl}$, both in the proportion of total carotenoids: $\alpha$ tocopherol of 1:1) and incorporated in an isotonic beverage model system, and pasteurized at $80^{\circ} \mathrm{C} / 15 \mathrm{~s}$. The beverage was characterized in terms of $\mathrm{pH}(3)$, osmolality (302 mosmol $/ \mathrm{kg})$, total titratable acidity $(0.171 \mathrm{~g} / 100 \mathrm{~mL})$ and soluble solids (5 ${ }^{\circ}$ Brix); microbiology and sensory evaluation of the isotonic drinks were also carried out. The results showed that it is possible to incorporate nanoemultionated buriti oil in isotonic beverage. In the sensory analysis, it was verified that the incorporation of nanoemulsion in isotonic beverage was relatively satisfactory.

Keywords: buriti oil, phase inversion temperature method, nanoencapsulation, isotonic beverage, natural colorant 


\section{LISTA DE FIGURAS}

Figura 1 - Palmeira Mauritia flexuosa L. (buritizeiro). .............................................. 21

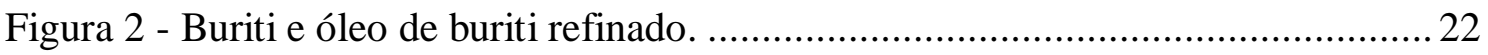

Figura 3 - Estruturas de alguns carotenoides...................................................... 25

Figura 4 - Mecanismos de instabilidade das nanoemulsões........................................ 30

Figura 5 - Etapas do processo PIT. (A) $\mathrm{T}<\mathrm{T}_{\text {PIT }}$ e os tensoativos são principalmente hidrofílicos, (B) T é aumentada, o tensoativo se torna lipofílico e é solubilizado pela FO, (C) $\mathrm{T}=\mathrm{T}_{\mathrm{PIT}}$, microemulsões bicontinuas se formam e (D) A emulsão é invertida e então a água é dispersa em uma mistura de óleo e tensoativo lipofílico. O sistema é então resfriado, fazendo com que de repente o tensoativo fique hidrofílico e induza uma migração rápida e espontânea para a fase aquosa, gerando as nanoemulsões................. 31 Figura 6 - Protocolo método EIP e mapa típico de formulação vs. composição para um sistema contendo óleo/água/tensoativo. 33

Figura 7 - Algumas etapas do protocolo utilizado para produção do óleo de buriti nanoemulsionado: (A) processo de aquecimento da nanoemulsão sobre agitação mecânica, (B) aparência da nanoemulsão após retirada do aquecimento e (C) processo de resfriamento da nanoemulsão sobre aquecimento magnético. 50 Figura 8 - Planta Piloto de Processamento de Alimentos Fluidos da FZEA/USP: (A) recepção (alimentação), (B) trocador de calor a placas isotérmico, (C) tanque para produto pasteurizado, (D) cabina de fluxo de ar unidirecional ISO classe 5 e (E)

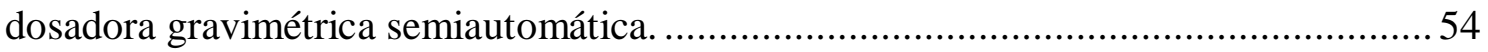

Figura 9 - Fluxograma do processamento da bebida isotônica sabor tangerina. .56 Figura 10 - Ponto de viragem acidez titulável: (A) representação do ponto de viragem e (B) aspectos visual da solução antes da análise.

Figura 11 - Aspectos das dispersões : (A) nanoemulsão após o primeiro ciclo de aquecimento e resfriamento e (B) nanoemulsão após o segundo ciclo de aquecimento e resfriamento.

Figura 12 - Curva de condutividade da nanoemulsão durante o aquecimento (A) 2,5 M de $\mathrm{NaCl}$, (B) $3 \mathrm{M}$ de $\mathrm{NaCl}$, (C) 3,5 $\mathrm{M}$ de $\mathrm{NaCl}$ e (D) $4 \mathrm{M}$ de $\mathrm{NaCl}$.

Figura 13 - Aspecto visual do sal decantado na nanoemulsão produzida com 3,5 M $\mathrm{NaCl}$

Figura 14 - Aspecto visual das dispersões de nanoemulsões contendo 2,5 e 3,0 M de $\mathrm{NaCl}$ na proporção $(1: 1,5)$ durante o primeiro dia após a produção. 
Figura 15 - Curvas de distribuição de tamanho de gota das nanoemulsões produzidas com 2,5 M de NaCl: (A) proporção CT:AT de (1: sem $\alpha$-tocoferol) e (B) proporção CT:AT de (1:0,5) e (C) proporção CT:AT de (1:1)...

Figura 16 - Curvas de distribuição de tamanho de gota das nanoemulsões produzidas com $3 \mathrm{M}$ de $\mathrm{NaCl}$. (A) Proporção CT:AT de (1: sem $\alpha$-tocoferol) e (B) proporção CT:AT de (1:0,5) e (C) Proporção CT:AT de (1:1)

Figura 17 - Diâmetro médio hidrodinâmico ao longo de um período de 60 dias das seis formulações testadas 72

Figura 18 - Quantificação de carotenoides totais em 60 dias de estocagem. (A) 2,5 M de

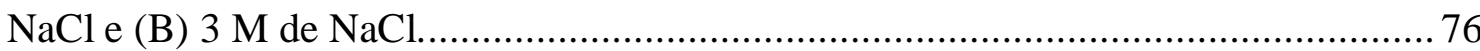

Figura 19 - Óleo de buriti nanoemulsionado em diferentes dias de estocagem. ............ 77 Figura 20 - Comparação entre o aspecto visual da bebida isotônica formulada e as bebidas disponíveis comercialmente 80

Figura 21 - Aspecto visual das diferentes porcentagens de substituição de corante por nanoemulsão de óleo de buriti. 81

Figura 22 - Etapas do processo da produção da bebida isotônica: (A) assepsia das embalagens, (B) formulação I1 no tanque de recepção, (C) formulação I2 no tanque de recepção, (D) pasteurizador, (E) cabina de fluxo de ar unidirecional, (F)envase

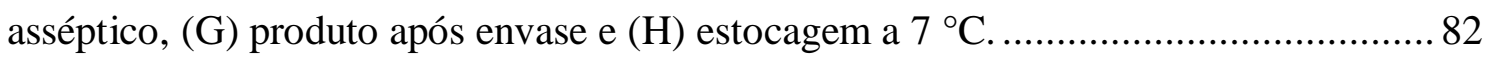

Figura 23 - Formulação 3 com uma leve separação de fase no dia 38. 83 Figura 24 - Diagrama CIELAB com sequência de nuances de cores e orientação do ângulo de Hue. 87

Figura 25 - Intenção de compra das formulações de bebida isotônica sabor tangerina.. 92 


\section{LISTA DE TABELAS}

Tabela 1 - Parâmetros físico-químicos típicos do óleo de buriti. 22

Tabela 2 - Composição do óleo de buriti em termos de seus componentes principais... 23 Tabela 3 - Diferentes variedades e quantidades de carotenoides presentes no óleo de buriti.

Tabela 4 - Quantidade de carotenoides totais presentes no óleo de buriti de acordo com diferentes estudos

Tabela 5 - Conteúdo de tocoferois no óleo de buriti (valores expressos em mg.kg ${ }^{-1}$ )... 26

Tabela 6 - Composição em ácidos graxos do óleo de buriti (valores em porcentagem). 28

Tabela 7 - Comparação da composição, em ácidos graxos, entre o óleo de buriti e outros óleos vegetais. 28

Tabela 8 - Estudos de produção de nanoemulsões por método de baixa energia relatados na literatura $(\mathrm{O}=$ óleo; $\mathrm{T}=$ tensoativo; $\mathrm{CS}=$ co-solvente e $\mathrm{CE}=$ composto encapsulado $)$.

Tabela 9 - Estudos com bebida isotônica relatados na literatura. 39

Tabela 10 - Propriedades dos corantes utilizados no Brasil (IDA expresso em mg/kg do peso corpóreo, limite máximo expresso em mg/100g e solubilidade expressa em $\mathrm{g} / 100 \mathrm{~mL}$ a $\left.25^{\circ} \mathrm{C}\right)$. 42

Tabela 11 - Corantes naturais mais utilizados pelas indústrias alimentícias. 46

Tabela 12 - As proporções utilizadas na nomenclatura se referem a proporção entre carotenoides totais (CT) presentes no óleo de buriti e $\alpha$-tocoferol (AT) (CT:AT). Massa total de amostra: $200 \mathrm{~g}$.

Tabela 13 - Ingredientes utilizados nas formulações das bebidas isotônicas sabor tangerina.

Tabela 14 - Resultados qualitativos dos testes para as nanoemulsões produzidas com o tensoativo polisorbato $80, \mathrm{NaCl}$, água deionizada e óleo de buriti $(\mathrm{T}=$ tensoativo, $\mathrm{O}=$ óleo e SOR = razão entre $\mathrm{T}$ e $\mathrm{O}$ ).

Tabela 15 - Resultados qualitativos dos testes para as nanoemulsões produzidas com o tensoativo Tween $80, \mathrm{NaCl}$, água deionizada e óleo de buriti para $\mathrm{SOR}=2,0(\mathrm{~T}=$ tensoativo e $\mathrm{O}=$ óleo).

Tabela 16 - Determinação da temperatura de inversão de fases 64

Tabela 17 - Diâmetros hidrodinâmicos médios de gota das nanoemulsões produzidas com 2,5 M de $\mathrm{NaCl}$. 
Tabela 18 - Diâmetros hidrodinâmicos médios de gota das nanoemulsões produzidas com $3 \mathrm{M}$ de $\mathrm{NaCl}$ .70

Tabela 19 - Polidispersidade das nanoemulsões produzidas com 2,5 $\mathrm{M}$ de $\mathrm{NaCl}$. ........ 73

Tabela 20 - Polidispersidade das nanoemulsões produzidas com $3 \mathrm{M}$ de $\mathrm{NaCl}$. .73

Tabela 21 - Carotenoides totais encapsulados na nanoemulsão produzidas com 2,5 M de $\mathrm{NaCl}$. 74

Tabela 22 - Carotenoides totais encapsulados na nanoemulsão produzida com $3 \mathrm{M}$ de $\mathrm{NaCl}$. 75

Tabela 23 - Oxidação lipídica quantificada por TBARS para as nanoemulsões produzidas com $2,5 \mathrm{M}$ de $\mathrm{NaCl}$.

Tabela 24 - Oxidação lipídica quantificada por TBARS para as nanoemulsões produzidas com $3 \mathrm{M}$ de $\mathrm{NaCl}$.

Tabela 25 - Características físico-químicas do isotônico sabor tangerina recémpasteurizado (dia 0$)(\mathrm{I} 2=25 \%$ nanoemulsão $3 \mathrm{M}$ de $\mathrm{NaCl}$ e I3 = 30\% nanoemulsão 2,5 $\mathrm{M}$ de $\mathrm{NaCl}$ ).

Tabela 26 - Resultados das determinações de pH para as três formulações de bebida isotônica ( $\mathrm{I} 2=25 \%$ nanoemulsão $3 \mathrm{M}$ de $\mathrm{NaCl}$ e $\mathrm{I} 3=30 \%$ nanoemulsão $2,5 \mathrm{M}$ de $\mathrm{NaCl})$.

Tabela 27 - Resultados das determinações de sólidos solúveis ( ${ }^{\circ}$ Brix) para as três formulações de bebida isotônica ( $\mathrm{I} 2=25 \%$ nanoemulsão $3 \mathrm{M}$ de $\mathrm{NaCl}$ e $\mathrm{I} 3=30 \%$ nanoemulsão 2,5 $\mathrm{M}$ de $\mathrm{NaCl})$. 85

Tabela 28 - Resultados das determinações de acidez total titulável para as três formulações de bebida isotônica ( $\mathrm{I} 2=25 \%$ nanoemulsão $3 \mathrm{M}$ de $\mathrm{NaCl}$ e I3 $=30 \%$ nanoemulsão 2,5 $\mathrm{M}$ de $\mathrm{NaCl})$.

Tabela 29 - Resultados das determinações de cor instrumental para as três formulações de bebida isotônica ( $\mathrm{I} 2=25 \%$ nanoemulsão $3 \mathrm{M}$ de $\mathrm{NaCl}$ e I3 $=30 \%$ nanoemulsão 2,5 $\mathrm{M}$ de $\mathrm{NaCl})$ 88

Tabela 30 - Resultados dos testes microbiológicos (I2 = 25\% nanoemulsão $3 \mathrm{M}$ de $\mathrm{NaCl}$ e $\mathrm{I} 3=30 \%$ nanoemulsão $2,5 \mathrm{M}$ de $\mathrm{NaCl})$.

Tabela 31 - Teste diferença de controle realizado nas formulações controle e I2 (I2= $25 \%$ nanoemulsão $3 \mathrm{M}$ de $\mathrm{NaCl}$ ).

Tabela 32 - Resultados teste escala hedônica realizado nas formulações controle e I2 (I2= 25\% nanoemulsão $3 \mathrm{M}$ de $\mathrm{NaCl}$ ). 


\section{LISTA DE SIGLAS E ABREVIATURAS}

A/O - Água em óleo

ANOVA - Análise de variância

BHT - Di-terc-butil metil fenol

DRBC - Ágar dicloran rosa de bengala cloranfenicol

EPI - Emulsion point inversion (ponto de inversão da emulsão)

FA - Fase aquosa

FO- Fase oleosa

IDR - Ingestão diária recomendada

LDL - Low density lipoproteins (lipoproteínas de baixa densidade)

MAPA - Ministério da agricultura, pecuária e abastecimento

MDA - Malonaldeído

MUFA - Monounsaturated fatty acids (ácidos graxos monoinsaturados)

O/A - Óleo em água

O/A/O - Emulsão múltipla óleo/água/ óleo

PCA - Plate count agar

PCS - Photon corrrelation spectroscopy (espectroscopia de correlação de fótons)

PEAD - Polietileno de alta densidade

PIT - Phase inversion temperature (temperatura de inversão de fases)

PIZ - Phase inversion zone

PUFA - Polyunsaturated fatty acids

rpm - Rotações por minuto

SOR - Surfactant:oil ratio (razão tensoativo:óleo)

TBA - Ácido tricloroacético

TBARS - TBA reactive substances

TCA - Ácido tiobarbitúrico

TEP - 1,1,3,3 - tetraetoxipropano

TPIT- Temperatura de inversão de fases 


\section{LISTA DE SÍMBOLOS}

$a^{*}$ - cromaticidade no eixo variando do vermelho/verde

$b^{*}$ - cromaticidade no eixo variando do amarelo/azul

$\mathrm{C}_{\mathrm{ab}}^{*}$ - croma

$\mathrm{L}^{*}$ - luminosidade 


\section{SUMÁRIO}

1 INTRODUÇÃO

2 REVISÃO BIBLIOGRÁFICA ….......................................................................... 21

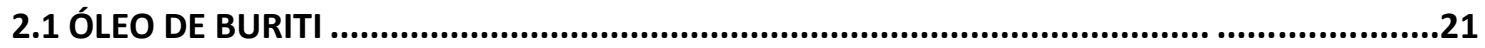

2.2 NANOEMULSÕES: ESTRUTURA E PRODUÇÃO POR MÉTODOS DE BAIXA ENERGIA ...........29

2.3 SUPLEMENTOS HIDROELETROLÍTICOS (BEBIDAS ISOTÔNICAS) .....................................36

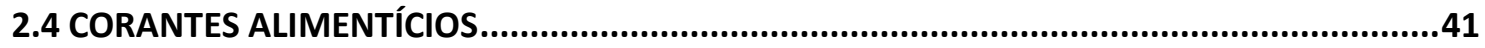

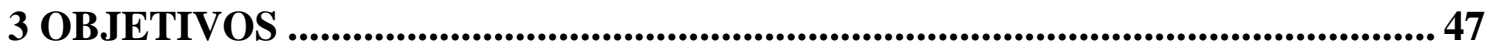

4 MATERIAIS E MÉTODOS .................................................................................. 48

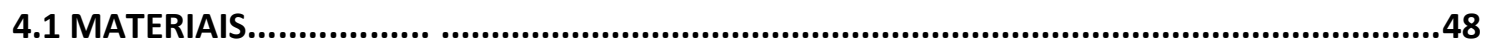

4.1.1 Produção e caracterização de óleo de buriti nanoemulsionado ........................... 48

4.1.2 Produção e caracterização da bebida isotônica ................................................... 48

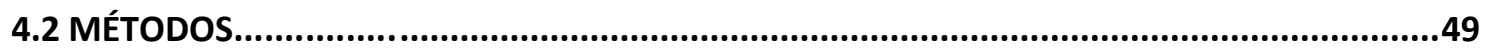

4.2.1 Determinação da temperatura de inversão de fases ......................................... 49

4.2.2 Produção de óleo de buriti nanoemulsionado pelo método da temperatura de

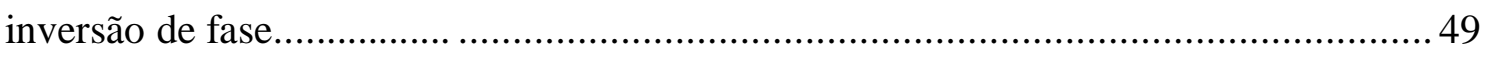

4.2.3 Avaliação da estabilidade físico-química das nanoemulsões ..............................52

4.2.3.1 Distribuição e diâmetro médio de tamanho de gota e polidispersidade ..............52

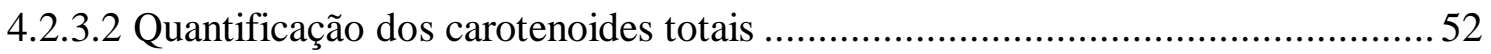

4.2.3.3 Avaliação da oxidação lipídica ............................................................... 53

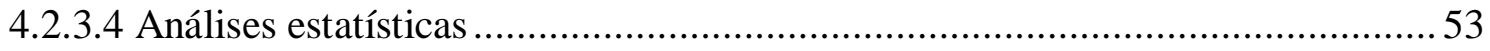

4.2.4 Incorporação do óleo de buriti nanoemulsionado em bebida isotônica .................54

4.2.4.1 Produção da bebida isotônica sabor tangerina adicionada de óleo de buriti

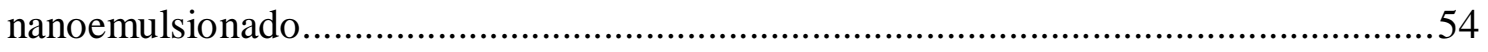

4.2.4.2 Caracterização da bebida isotônica sabor tangerina adicionada de nanoemulsões

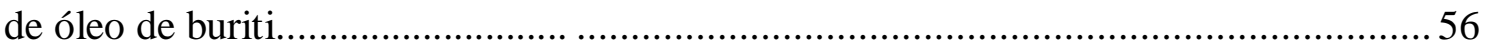

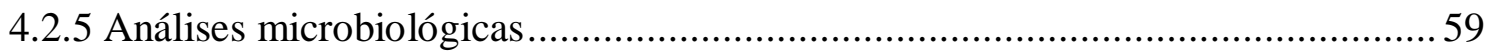


4.2.6 Análise sensorial

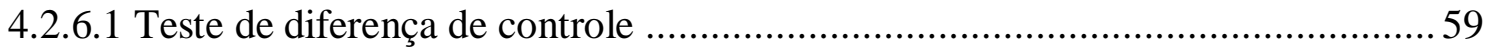

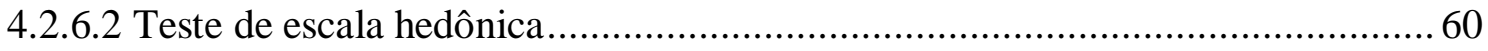

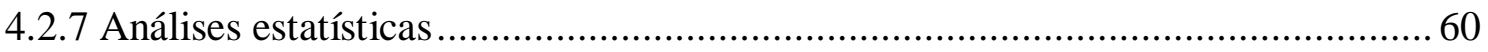

5 RESULTADOS E DISCUSSÃO .................................................................61

5.1 DETERMINAÇÃO DAS CONDIÇÕES DE PROCESSO PARA PRODUÇÃO DE ÓLEO DE BURITI

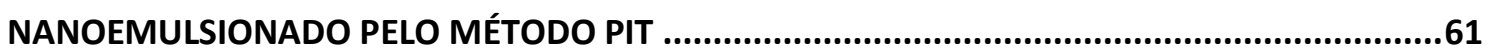

5.2 DETERMINAÇÃO DA TEMPERATURA DE INVERSÃO DE FASES.......................................63

5.3 PRODUÇÃO DE ÓLEO DE BURITI NANOEMULSIONADO PELO MÉTODO DA TEMPERATURA

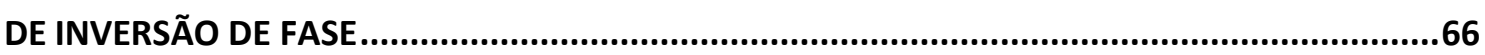

5.4 AVALIAÇÃO DA ESTABILIDADE FÍSICO-QUÍMICA DAS NANOEMULSÕES ...........................67

5.4.1 Distribuição e diâmetro médio de tamanho de gota e polidispersidade .................67

5.4.2 Quantificação dos carotenoides totais ........................................................... 74

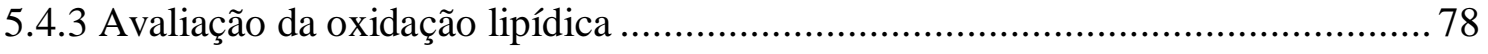

5.5 INCORPORAÇÃO DAS NANOEMULSÕES DE ÓLEO DE BURITI EM BEBIDA ISOTÔNICA .......80

5.5.1 Produção da bebida isotônica adicionada de nanoemulsões de óleo de buriti .......80

5.5.2 Caracterização da bebida isotônica adicionada de nanoemulsões de óleo de

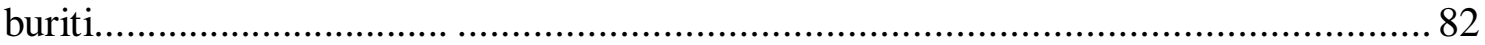

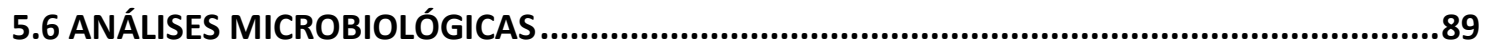

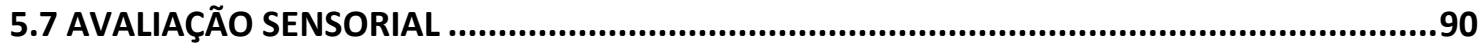

5.7.1 Teste de diferença de controle .................................................................. 90

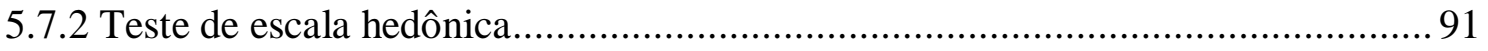

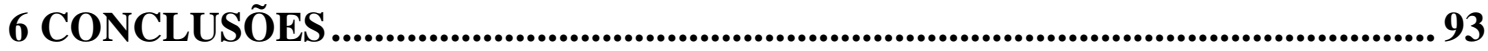

7 SUGESTÕES PARA TRABALHOS FUTUROS ................................................94

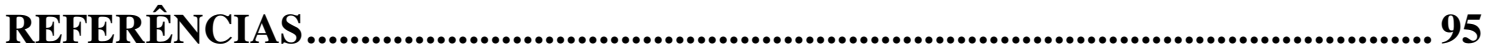

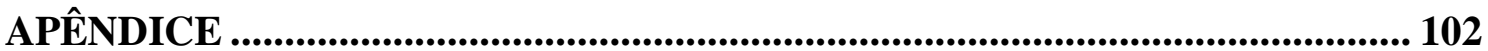

APÊNDICE A Termo de consentimento e livre esclarecido para o teste diferença do controle................................................................................................. 102 
APÊNDICE B Modelo da ficha de avaliação sensorial utilizada no teste de diferença do controle

APENNDICE C Termo de consentimento e livre esclarecido para o teste de escala hedônica.

APÊNDICE D Modelo da ficha de avaliação sensorial utilizada no teste de escala hedônica.

ANEXO

ANEXO A Laudo do óleo de buriti utilizado neste trabalho de Mestrado

(fornecido pelo fabricante)

ANEXO B Laudo do aroma de tangerina utilizado neste trabalho de Mestrado

(fornecido pelo fabricante).

ANEXO C Parecer do Comitê de Ética em Pesquisa da Escola de Enfermagem da Universidade de São Paulo (EEUSP) 


\section{INTRODUÇÃO}

Impulsionada pela crescente demanda dos consumidores por alimentos mais saudáveis e seguros, a aplicação da nanotecnologia nas indústrias farmacêuticas e alimentícias têm recebido grande atenção da comunidade científica. As nanoemulsões são um dos campos de aplicação mais interessantes, uma vez que pode atuar como veículos ou sistemas de entrega para compostos lipofílicos, tais como drogas, nutracêuticos, sabores, antioxidantes e agentes antimicrobianos, além de ser capaz de encapsular, proteger e liberar compostos funcionais.

O buriti (Mauritia flexuosa L.) é uma fonte vegetal rica em tocoferois, carotenoides e em ácidos graxos. A presença de tocoferois na alimentação humana é importante pois além de terem atividade pró-vitamina E, são antioxidantes naturais sequestrantes de radicais livres. Os carotenoides, possuem ação corante no intervalo do amarelo ao vermelho, possuem ação antioxidante e, dependendo da variedade, são precursores da vitamina A. Com relação aos ácidos graxos presentes no óleo de buriti cerca de $73 \%$ a $78 \%$ é o ácido oleico, conhecido pela sua propriedade de redução do nível de colesterol no sangue. Devido à presença de grandes quantidades de ácido oleico, o óleo de buriti se mostra como um candidato em potencial para prevenir o colesterol.

Apesar de ter grande valor nutricional, o buriti é pouco cultivado e explorado e o processamento comercial dos frutos é realizado em uma escala muito pequena. Atualmente a indústria de cosméticos é a principal responsável pelo uso industrial do buriti. Ao realizar uma pesquisa de mercado, Galdino (2007) constatou uma carência de informação registrada sobre a comercialização de produtos derivados do buriti no mercado internacional e nacional. Porém, estimativas superficiais indicam que a produção potencial anual na região nordeste e norte do Brasil seja de aproximadamente 70 mil toneladas (frutas/safra). Portanto, devido à abundância do fruto nestas regiões e à sua riqueza nutricional, é de grande importância a investigação das possibilidades de utilização deste fruto como uma fonte de óleos vegetais e vitaminas. A encapsulação do óleo de buriti, e a posterior aplicação em um produto alimentício, representa uma alternativa para o aumento do consumo do mesmo.

Este projeto de Mestrado teve como objetivo a produção, caracterização e avaliação da estabilidade de nanoemulsões encapsulando óleo de buriti, sendo utilizado o método de baixa energia (temperatura de inversão de fases - PIT) para obtenção de 
tais sistemas coloidais. Para isso, foi necessária a determinação de parâmetros de processo, a caracterização das nanoemulsões em termos de diâmetro médio hidrodinâmico e distribuição de tamanho de gota, quantificação dos carotenoides totais encapsulados e avaliação da oxidação lipídica, além de um estudo da estabilidade por um período de 60 dias. Por fim, as nanoemulsões desenvolvidas foram aplicadas em bebida isotônica. A aplicação do óleo de buriti nanoemulsionado, rico em carotenoides, em bebidas isotônicas, visou a substituição dos corantes artificiais, especialmente o amarelo tartrazina e o amarelo crepúsculo, por corantes naturais, além de representar uma alternativa para o aumento da ingestão de agente pró-vitamina A e E em um produto com apelo de saudabilidade. Após a aplicação das nanoemulsões em bebida isotônica, avaliou-se suas propriedades físico-químicas, tais como $\mathrm{pH}$, acidez titulável, sólidos totais solúveis, teores de sódio e potássio, osmolalidade e cor instrumental, assim como a sua avaliação sensorial e microbiológica. 


\section{REVISÃO BIBLIOGRÁFICA}

\section{1 ÓLEO DE BURITI}

O buritizeiro (Mauritia flexuosa L.) é uma palmeira nativa da região amazônica, com ampla distribuição na região, e é encontrado no Brasil, Colômbia, Peru, Equador, Bolívia, Venezuela e Guianas. No Brasil está presente nas regiões Norte, Nordeste e Centro-Oeste (EMBRAPA, 2005). Pertence à família Arecaceae, de tronco reto e cilíndrico, podendo alcançar até $35 \mathrm{~m}$ de altura, conforme mostrado na Figura 1. Seu fruto, denominado buriti ou miriti, são castanho-avermelhado em forma de elipsoide, e possui uma superfície revestida por escamas brilhantes. A polpa amarela do fruto recobre uma semente oval dura, a qual é uma amêndoa comestível. A época de frutificação varia de uma região para a outra, porém geralmente ocorre entre os meses de dezembro a junho (LIMA et al., 2009; GALDINO, 2007; MORAIS; GUTJAHR, 2009).

Figura 1 - Palmeira Mauritia flexuosa L. (buritizeiro).

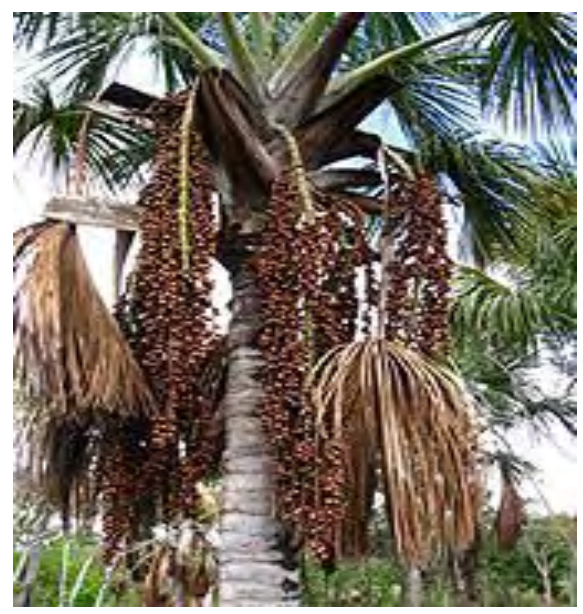

Fonte: SAMPAIO, M.B.; PERRI, A. Os muitos frutos da 'árvore da vida'. Campinas, 2012. Disponível em: <www.unicamp.br/unicamp/ju/532/ os-muitos-frutos-da- "árvore-da-vida">. Acesso em: 29 ago. 2015.

Do fruto do buriti é extraído o óleo de buriti, um óleo comestível que possui características organolépticas de aroma e sabor agradáveis, e ambos são mostrados na Figura 2. O óleo de buriti tem aplicações na indústria de alimentos como, por exemplo, corante natural de massas alimentícias, margarinas e queijos, além de ser empregado para fritura de alimentos (EMBRAPA, 2005). A Tabela 1 mostra os parâmetros físicoquímicos típicos do óleo de buriti. 
Figura 2 - Buriti e óleo de buriti refinado.

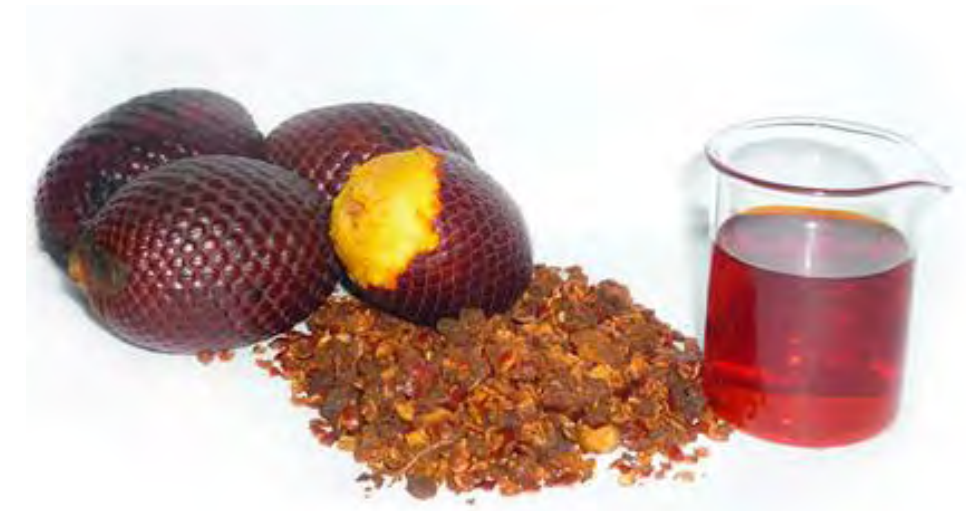

Fonte: AGROINDUSTRIA OSHO (NATURIK). Aguaje (Buriti) Fruit Oil. Callao, 2007. Disponível em: <www.agroindustriasosho.com/aguaje.html>. Acesso em: 29 ago. 2015.

Tabela 1 - Parâmetros físico-químicos típicos do óleo de buriti.

\begin{tabular}{lrr}
\hline Índices & Unidade & Valores de Referência \\
\hline Densidade & $\mathrm{g} / \mathrm{cm}^{-3}$ & 0,86 \\
Índice de refração $\left(\mathrm{a} 22^{\circ} \mathrm{C}\right)$ & - & 1,46 \\
Índice de iodo & $\mathrm{cg} \mathrm{I} / 100 \mathrm{~g}$ & 77,20 \\
Índice de saponificação & $\mathrm{mg} \mathrm{KOH} / \mathrm{g}$ & 169,90 \\
Ponto de fusão & ${ }^{\circ} \mathrm{C}$ & 12,00
\end{tabular}

Fonte: ALBUQUERQUE, M.L.S. et al. Characterization of Buriti (Mauritia flexuosa L.) Oil by Absorption and Emission Spectroscopies. Journal of the Brazilian Chemical Society, São Paulo, v. 16, n. 6A, p. 1113-1117, 2005.

O óleo de buriti é uma fonte vegetal rica em tocoferois e carotenoides, cuja importância nutricional é devido ao seu potencial pró-vitamina $\mathrm{A}$, e também em ácidos graxos, principalmente em ácido oleico, responsável pela prevenção do colesterol "ruim" (Low Density Lipoprotein, LDL) (ALBUQUERQUE et al., 2005; SILVA et al., 2009). Apesar de ter grande valor nutricional, o buriti ainda é relativamente pouco cultivado e explorado, e a produção do óleo é baixa ou insuficiente para atender a demanda do mercado (FRANÇA et al., 1999; CARVALHO et al., 2011).

Segundo Afonso e Ângelo (2011), as limitações identificadas na cadeia produtiva do buriti são: a presença de um mercado não consolidado, alto custo de produção de óleo, pouco conhecimento em tecnologias de extração do óleo, irregularidade na oferta e na demanda e falta de conhecimento sobre boas práticas de manejo e capacidade de coleta. Portanto, é de grande importância a investigação de métodos e alternativas para o aumento da produção desse óleo para que o mesmo possa 
ser utilizado como uma fonte de óleos vegetais e vitaminas. Diversos estudos com o buriti, desde a colheita até a aplicação em alimentos, são relatados na literatura.

Carvalho et al. (2011) testou três métodos de extração para o óleo de buriti. A extração artesanal, a prensagem hidráulica e extração por solvente a fim de verificar qual método de extração apresentava melhor rendimento. Aquino et al. (2012a) desenvolveram biscoitos tipo cookie adicionado de óleo de buriti a fim de analisar sua aceitação sensorial e seu valor nutricional, visando a inclusão desses biscoitos como fontes de vitamina A na merenda de escolas municipais na cidade de Picos no Piauí. Por fim, Sampaio e Carrazza (2012) desenvolveram um manual tecnológico de aproveitamento integral do fruto e da folha do buriti com o objetivo de difundir tecnologias de aproveitamento sustentável dos recursos naturais do Cerrado. Tal manual traz informações sobre a biologia do buriti, boas práticas de coleta de folhas e frutos, manejo dos brejos e dos buritizeiros, processos tecnológicos para a obtenção de diferentes produtos dos frutos e das folhas e as boas práticas de manipulação e fabricação.

Na Tabela 2 pode-se observar a composição do óleo de buriti em termos de seus principais constituintes.

Tabela 2 - Composição do óleo de buriti em termos de seus componentes principais.

\begin{tabular}{llr}
\hline Substância & & Quantidade \\
\hline Carotenoides (mg/kg) & & 1707,00 \\
Tocoferois (mg/kg) & 800,00 \\
Composição de ácidos graxos livres (\%) & & \\
Ácidos graxos saturados & Palmítico & $17,34-19,20$ \\
& Esteárico & 2,00 \\
Ácidos graxos insaturados & Oleico & $73,30-78,73$ \\
& Linoleico & $2,40-3,93$ \\
& Linolênico & 2,20
\end{tabular}

Fonte: ALBUQUERQUE, M.L.S. et al. Characterization of Buriti (Mauritia flexuosa L.) Oil by Absorption and Emission Spectroscopies. Journal of the Brazilian Chemical Society, São Paulo, v. 16, n. 6A, p. 1113-1117, 2005.

Conforme pode-se observar pela Tabela 2, o óleo de buriti é uma fonte riquíssima em carotenoides. Estudos realizados por Rodrigues-Amaya et al. (2008) relataram que dentro da vasta gama de alimentos brasileiros que foram analisados, o 
buriti é o produto alimentício detentor da maior concentração conhecida de $\beta$-caroteno. Além disso, o buriti possui quantidades substanciais de $\gamma$-caroteno, $\alpha$-caroteno e de zeaxantina. A Tabela 3 mostra os principais carotenoides presentes no óleo de buriti e a Tabela 4 os carotenoides totais encontrados em diferentes estudos sobre o óleo de buriti.

Tabela 3 - Diferentes variedades e quantidades de carotenoides presentes no óleo de buriti.

\begin{tabular}{lrlr}
\hline Substância & Quantidade (\%) & Substância & Quantidade $(\%)$ \\
\hline Trans- $\beta$-caroteno & 39,39 & $\zeta$-caroteno & 2,29 \\
13-cis- $\beta$-caroteno & 21,04 & $\beta$-zeacaroteno & 2,23 \\
9-cis- $\beta$-caroteno & 8,79 & Mutacromo & 2,64 \\
$\beta$-10-apo-caroteno & 4,10 & $\alpha$-caroteno & 3,58 \\
Zeaxantina & 5,74 & $\gamma$-caroteno & 0,76 \\
Fitoflueno & 8,79 & $\delta$-caroteno & 0,64
\end{tabular}

Fonte: ALBUQUERQUE, M.L.S. et al. Characterization of Buriti (Mauritia flexuosa L.) Oil by Absorption and Emission Spectroscopies. Journal of the Brazilian Chemical Society, São Paulo, v. 16, n. 6A, p. 1113-1117, 2005.

Tabela 4 - Quantidade de carotenoides totais presentes no óleo de buriti de acordo com diferentes estudos.

\begin{tabular}{llr}
\hline Autor (es) & Método utilizado para quantificação & $\begin{array}{r}\text { Quantidade } \\
(\mathrm{mg} / \mathrm{kg})\end{array}$ \\
\hline FRANÇA et al., 1999 & Espectrofotometria & $1043 \pm 8$ \\
CERIANI et al., 2008 & Espectrofotometria & 1296 \\
SILVA et al., 2009 & Espectrofotometria & $1003 \pm 20$ \\
& HPLC & $900 \pm 10$ \\
\hline
\end{tabular}

Fonte: Própria autoria.

Os carotenoides são pigmentos naturais lipossolúveis encontrados principalmente em verduras e frutas. Além de possuir ação corante no intervalo do amarelo ao vermelho, os carotenoides possuem propriedades de precursores da vitamina A, proteção celular contra oxigênio singlete e radicais livres (ação antioxidante), absorvedores de energia luminosa e transportadores de oxigênio (FRASER; BRAMLEY, 2004).

O fruto do buriti, bem como o seu óleo, é uma das principais fontes de próvitamina A encontradas na biodiversidade brasileira, e tal elevado potencial próvitamínico deve-se aos altos teores de $\beta$-caroteno nele encontrados (MARIATH et al., 
1989). Estudos encontrados na literatura comprovam o potencial pró-vitamínico A do buriti. Foi possível, por exemplo, determinar que um grama de óleo de buriti contém 1.181 microgramas de $\beta$-caroteno, o que faz deste óleo uma das maiores fontes de próvitamina A da natureza (OLIVEIRA, 2011).

A Figura 3 mostra algumas variedades de carotenoides que podem ser convertidos em vitamina A (retinol). Como pode-se observar pela Figura 3, se a molécula de $\beta$-caroteno for quebrada ao meio e uma molécula de água for acrescida no final da cadeia poliênica, duas moléculas de retinol serão formadas. Como consequência o $\beta$-caroteno dará origem a duas moléculas de retinol, por esse motivo ele é considerado o carotenoide de maior potência vitamínica A, e ao qual se atribui $100 \%$ de atividade pró-vitamínica A. Já o $\alpha$-caroteno e a $\beta$-criptoxantina possuem cerca de $50 \%$ da atividade pró-vitamínica $\mathrm{A}$ do $\beta$-caroteno, pois dão origem a somente uma molécula de retinol, e como pode-se observar também pela Figura 3 a luteína não possui nenhuma atividade pró-vitamínica A pois esta não dá origem a nenhuma molécula de retinol (RODRIGUES-AMAYA et al., 2008).

Figura 3 - Estruturas de alguns carotenoides.

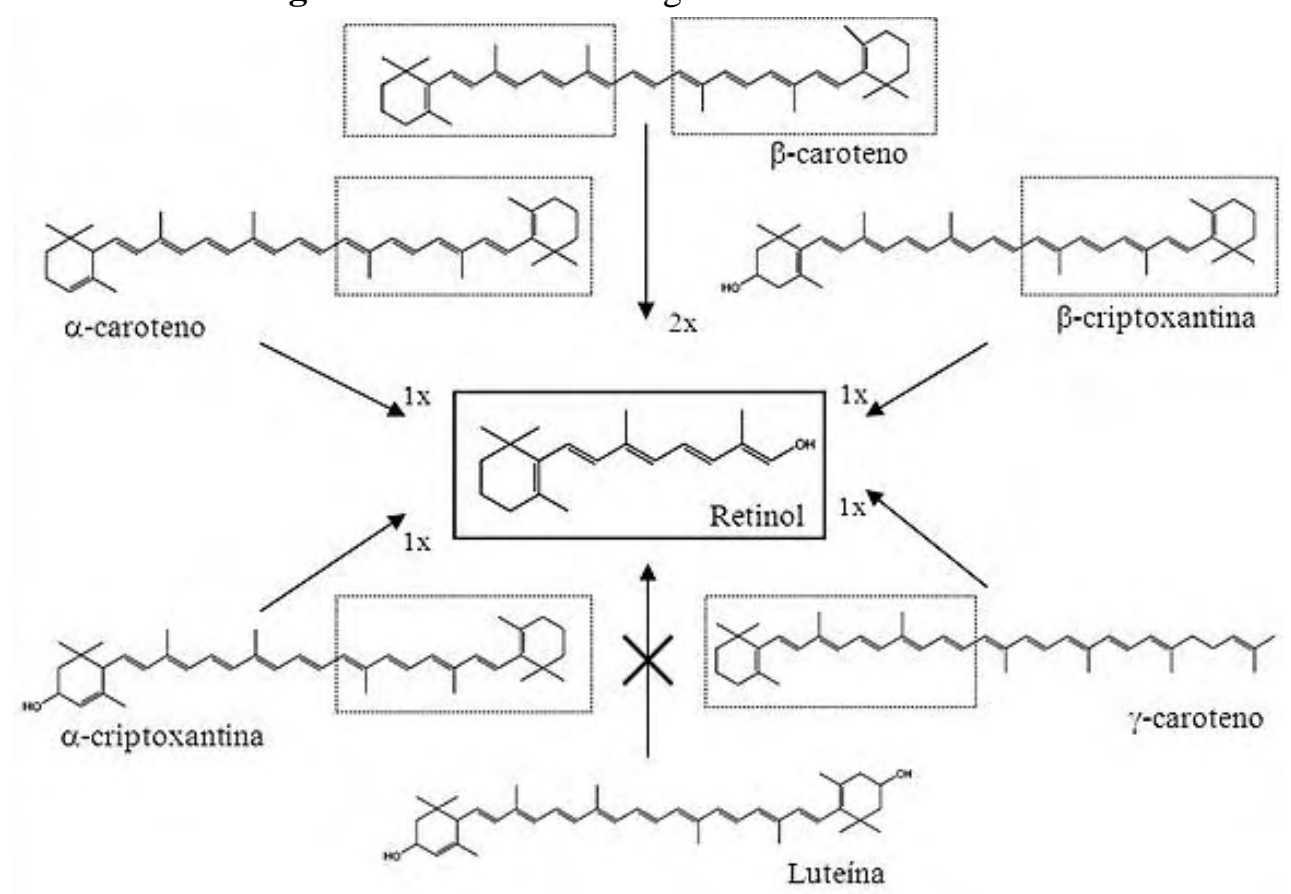

Fonte: PACHECO, S. Cromatografia Líquida: vitamina A. Brasília, 2015. Disponível em <www.cromatografialiquida.com.br/carotenoidesindex.htm>. Acesso em: 29 ago. 2015. 
Conforme pode-se observar, também pela Tabela 2, além de ser rico em carotenoides e ácidos graxos, o óleo de buriti é uma rica fonte em tocoferois. Os tocoferois são compostos cíclicos com um grupamento hidroxila e oxigênio heterocíclico facilmente oxidáveis a quinonas, e por esse motivo, possuem ação antioxidante. Existem quatro tocoferois principais $(\alpha-, \beta-, \gamma-$ e $\delta)$, bem como quatro formas de tocotrienois correspondentes. Os tocotrienois, juntamente com os tocoferois, compõem o grupo de homólogos do cromanol com atividade de vitamina $\mathrm{E}$ (REGITANO-D’ARCE, 2006). A presença de tocoferois na alimentação humana é importante pois estes são antioxidantes naturais, sequestrantes de radicais livres e possuem atividade de pró-vitamina $\mathrm{E}$, propriedades nutricionais estas que contribuem para a promoção da saúde e prevenção de doenças (PIMENTEL et al., 2005). A Tabela 5 mostra os principais tipos de tocoferois presentes no óleo de buriti.

Tabela 5 - Conteúdo de tocoferois no óleo de buriti (valores expressos em mg.kg ${ }^{-1}$ ).

\begin{tabular}{lrrr}
\hline Substância & FRANÇA et al., 1999 & PIMENTEL et al., 2005 & SILVA et al., 2009 \\
\hline$\alpha$ - Tocoferol & - & $885 \pm 53$ & $614 \pm 5$ \\
$\beta$ - Tocoferol & - & $409 \pm 19$ & $687 \pm 8$ \\
$\gamma$ - Tocoferol & - & $167 \pm 9$ & $50 \pm 2$ \\
$\delta$ - Tocoferol & - & $228 \pm 8$ & $136 \pm 0$ \\
$\gamma$ - Tocotrienois & - & - & $12 \pm 1$ \\
$\delta$ - Tocotrienois & - & - & $18 \pm 1$ \\
Tocoferois totais & $1960 \pm 100$ & $1689 \pm 89$ & $1517 \pm 13$ \\
\hline
\end{tabular}

Fonte: Própria autoria.

Além disso, em termos de ácidos graxos, também de acordo com a Tabela 2, o óleo de buriti contém em sua composição elevados teores de ácidos graxos monoinsaturados, destacando-se o ácido oleico com cerca de $73 \%$ a $78 \%$, bem como de ácidos graxos saturados, principalmente o ácido palmítico com cerca de 17\% a 19\%, sendo estes os ácidos graxos majoritários presentes no óleo de buriti (ALBUQUERQUE et al., 2005). Óleos monoinsaturados, também conhecidos como MUFA (Monounsaturated fatty acids), possuem a propriedade de reduzir o nível de colesterol LDL no sangue. Devido à presença de grandes quantidades do ácido oleico, o óleo de buriti se mostra um candidato em potencial para contribuir com a prevenção do colesterol LDL (ALBUQUERQUE et al., 2005; CERIANI et al., 2008; SILVA et al., 
2009; SANTOS et al., 2013a). O outro ácido graxo majoritário presente no óleo de buriti, o ácido palmítico, é o mais comumente encontrado nos óleos vegetais e apresenta grande resistência à oxidação em razão de ser um ácido graxo saturado (REGITANOD’ARCE, 2006; SANTOS et al., 2013a).

Com relação aos ácidos graxos minoritários presentes no óleo de buriti, também de acordo com a Tabela 2, destacam-se o ácido linoleico (C18:2), com 2,4 - 3,9\%, o ácido esteárico (C18:0), com 2\% e o ácido linolênico (C18:3), com 2,2 \%. A presença de ácido linoleico, também conhecido como ômega 6, é benéfico à saúde pois este é um ácido graxo essencial que participa de rotas metabólicas importantes no organismo, principalmente, na formação de eicosanoides. Os eicosanoides são compostos hormonais que executam diversas funções corporais, tais como atividade intracelular e funções vitais do corpo (PIMENTEL et al., 2005; GUINÉ; HENRIQUES, 2011). O ácido esteárico, diferentemente dos outros ácidos graxos saturados é conhecido por possuir efeito neutro sobre o colesterol (SANTOS et al., 2013a). E por fim, o ácido linolênico, também conhecido como ômega 3, é de grande importância para à saúde uma vez que é responsável pelo controle de diversos distúrbios metabólicos, tais como diabetes, tensão pré-menstrual, eczema atópico, entre outros (PIMENTEL et al., 2005). Ainda segundo Guiné e Henriques (2011), o ômega 3 é responsável por formar as paredes das células tornando-as elásticas e flexíveis. Tal fato fornece aos glóbulos vermelhos flexibilidade e funcionalidade e consequente melhora na circulação e captação de oxigênio. Além disso, a baixa concentração dos ácidos graxos poliinsaturados linoleico e linolênico, conhecidos também como PUFA (polyunsaturated fatty acids) conferem ao óleo de buriti uma grande estabilidade oxidativa (SILVA et al., 2009). A Tabela 6 mostra a composição em ácidos graxos do óleo de buriti relatados em diferentes estudos e a Tabela 7, a comparação da composição, em ácidos graxos, entre o óleo de buriti e outros óleos vegetais.

É importante esclarecer que a composição e, consequentemente o valor nutricional do óleo de buriti pode variar de acordo com a safra, período de colheita e o método de extração utilizado. Também o manejo inadequado após colheita do fruto do buritizeiro pode levar a altos índices de acidez, devido a hidrólise dos triacilglicerois, o que leva a uma redução da estabilidade oxidativa, diminui o ponto de fumaça e induz a oxidação de vitaminas (SILVA et al., 2009). 
Tabela 6 - Composição em ácidos graxos do óleo de buriti (valores em porcentagem).

\begin{tabular}{lrrrrr}
\hline $\begin{array}{l}\text { Ácidos Graxos } \\
\text { (cadeia carbônica) }\end{array}$ & $\begin{array}{r}\text { PIMENTEL CERIANI } \\
\text { et al., 2005 et al, 2008 }\end{array}$ & $\begin{array}{r}\text { SILVA } \\
\text { et al., 2009 }\end{array}$ & $\begin{array}{r}\text { RODRIGUES } \\
\text { et al., 2010 }\end{array}$ & $\begin{array}{r}\text { AQUINO } \\
\text { et al., 2012b }\end{array}$ \\
\hline Palmítico (16:0) & 15,59 & 18,00 & 16,78 & 18,75 & 19,40 \\
Palmitoleico (16:1) & 0,50 & 0,45 & 0,32 & 0,25 & - \\
Esteárico (18:0) & 1,30 & 1,18 & 1,77 & 1,35 & 3,90 \\
Oleico (18:1) & 79,40 & 77,34 & 74,06 & 75,50 & 72,20 \\
Linoleico (18:2) & 1,50 & 1,39 & 4,94 & 2,15 & 2,30 \\
Linolênico (18:3) & 0,80 & 1,25 & 1,04 & 0,10 & 1,50 \\
Araquídico (20:0) & 0,10 & 0,08 & 0,12 & 1,65 & - \\
Gadoleico (20:1) & 0,30 & 0,21 & 0,53 & & - \\
\hline
\end{tabular}

Fonte: Própria autoria.

Tabela 7 - Comparação da composição, em ácidos graxos, entre o óleo de buriti e outros óleos vegetais.

\begin{tabular}{lrrr}
\hline Óleos Vegetais & Monoinsaturados (\%) & Poliinsaturados (\%) & Saturados (\%) \\
\hline Azeite de oliva & 72,3 & 11,5 & 16,2 \\
Buriti & $\mathbf{7 6 , 0}$ & $\mathbf{4 , 6}$ & $\mathbf{1 9 , 4}$ \\
Canola & 65,3 & 27,9 & 6,8 \\
Castanha do Pará & 73,6 & 5,1 & 21,3 \\
Girassol & 18,7 & 68,7 & 12,6 \\
Milho & 27,6 & 57,9 & 14,5 \\
Óleo de palma & 38,9 & 9,7 & 51,4 \\
Soja & 23,5 & 61,0 & 15,5
\end{tabular}

Fonte: SILVA, S. M. Desacidificação por via física de óleo de buriti (Mauritia flexuosa). 2009. 120 f. Dissertação (Mestrado em Engenharia de Alimentos) - Universidade Estadual de Campinas, Campinas, 2009. 


\subsection{NANOEMULSÕES: ESTRUTURA E PRODUÇÃO POR MÉTODOS DE BAIXA ENERGIA}

Nos últimos anos houve um crescente interesse pela produção de nanoemulsões. Tal interesse se deu pelas diversas possibilidades e áreas de aplicação das mesmas, como na indústria cosmética, farmacêutica, alimentícia e química (SOLANS; SOLÉ, 2012).

Nanoemulsões consistem de uma mistura de líquidos imiscíveis, no qual um está disperso no outro na forma de glóbulos em escala nanométrica (ANTON et al., 2008). Tais estruturas coloidais são altamente estáveis à separação gravitacional devido ao tamanho médio das gotas ser relativamente pequeno, o que significa que os efeitos de movimento Browniano predominam sobre as forças gravitacionais (McCLEMENTS, 2005). Devido ao fato de as nanoemulsões serem coloides que possuem gotas com tamanho médio na faixa de 50 a $500 \mathrm{~nm}$, estas podem ser sistemas translúcidos a olho nu e apresentar alta estabilidade cinética (MORALES et al., 2003). Estas características, em especial, a translucidez óptica das nanoemulsões as tornam extremamente atraentes como insumos para o uso na produção de alimentos que são translúcidos, como por exemplo alguns tipos de bebida (Limonchelo®, Gatorade $\AA$, Powerade ${ }^{\circledR}$ ).

As nanoemulsões apresentam vantagens em relação as emulsões convencionais devido ao seu tamanho de gota reduzido, o que as confere estabilidade contra sedimentação e cremeação. Entretanto, vale ressaltar que nanoemulsões são termodinamicamente instáveis e podem sofrer floculação, coalescência e amadurecimento de Ostwald (McCLEMENTS, 2008). Tais fenômenos físico-químicos de instabilidade das nanoemulsões são ilustrados na Figura 4. Todavia, com a seleção apropriada dos componentes do sistema, da composição e do método de preparo, nanoemulsões com alta estabilidade cinética podem ser produzidas (SOLANS; SOLÉ, 2012; McCLEMENTS; RAO, 2011).

Os métodos utilizados para produzir nanoemulsões podem ser divididos em duas categorias, com base nos princípios fundamentais envolvidos na formação de gotas: métodos de baixa e alta energia. Vale ressaltar que as características das nanoemulsões que são alcançadas utilizando-se de cada método, seja de baixa ou alta energia, depende do projeto do equipamento, condições operacionais e a formulação do sistema (McCLEMENTS, 2012). 
Figura 4 - Mecanismos de instabilidade das nanoemulsões.

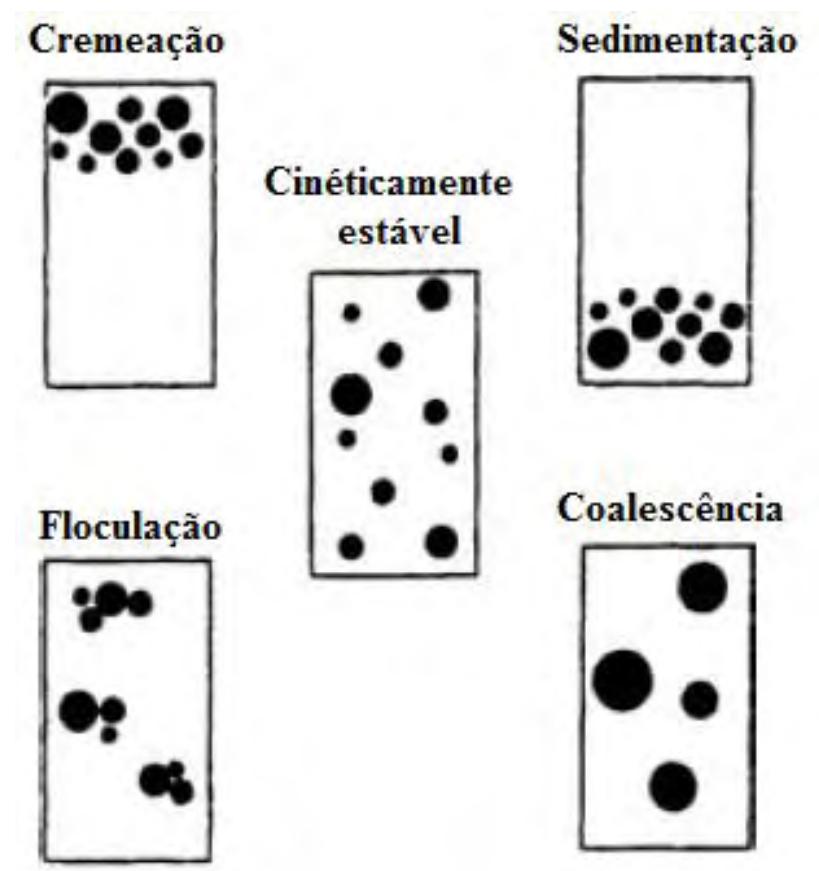

Fonte: Adaptado de McCLEMENTS, D.J. Lipid-based emulsions and emulsifiers. In: AKOH, C.C.; MIN, D.B. Food lipids: chemistry, nutrition, and biotechnology. 3 ed. Boca Raton: CRC Press, 2008. p. 63 - 97.

A primeira categoria envolve a adição de grande quantidade de energia no sistema (processos de alta energia), sendo a energia mecânica inserida nos sistemas por equipamentos como homogeneizadores a alta pressão, microfluidizadores ou pela aplicação de altos níveis de energia ultrassônica (SPERNATH; MAGDASSI, 2007; ANTON et al., 2007; ANTON et al., 2008). Entretanto, tais métodos muitas vezes são extremamente dispendiosos para aplicações industriais, especialmente quando se deseja um tamanho médio de gota muito pequeno (20 - 100nm).

Por sua vez, os métodos de baixa energia requerem baixo consumo de energia para a produção das nanoemulsões e dependem principalmente das propriedades físicoquímicas intrínsecas do tensoativo e da fase oleosa (McCLEMENTS; RAO, 2011). Segundo Anton e Vandamme (2009), os métodos de baixa energia são de particular interesse pois podem minimizar a degradação potencial de moléculas termosensíveis, por exemplo. Os métodos de baixa energia mais conhecidos e amplamente empregados são o método da temperatura de inversão de fase (phase inversion temperature, ou método PIT), o método da emulsificação espontânea e o método do ponto de inversão da emulsão (emulsion inversion point, ou método EIP).

O método PIT foi introduzido por Shinoda e Saito (1968) e Shinoda (1969). Neste método, a fase oleosa (FO), os tensoativos não-iônicos polietoxilados e a fase 
aquosa (FA) são misturados e agitados, e em seguida a mistura é gradualmente aquecida. Como resultado do aquecimento, a solubilidade do tensoativo se altera progressivamente, pois os grupos etoxilados gradualmente se desidratam com o aquecimento, tornando o tensoativo gradualmente mais hidrofóbico. Acima da temperatura de inversão de fase ( $\mathrm{T}_{\mathrm{PIT}}$ ) o tensoativo é inteiramente solubilizado em óleo e, assim, a mistura sofre uma inversão de fase, de uma emulsão óleo em água (O/A) para uma emulsão de água em óleo $(\mathrm{A} / \mathrm{O})$. Durante o resfriamento o tensoativo se reidrata e se torna novamente hidrofílico induzindo uma migração rápida e espontânea para fase aquosa, o que dá origem as nanoemulsões (ANTON; VANDAMME, 2009). A Figura 5 mostra esquematicamente o que acontece durante o processo de inversão de fases devido ao aquecimento no método PIT.

Figura 5 - Etapas do processo PIT. (A) $\mathrm{T}<\mathrm{T}_{\mathrm{PIT}}$ e os tensoativos são principalmente hidrofílicos, (B) $\mathrm{T}$ é aumentada, o tensoativo se torna lipofílico e é solubilizado pela FO, (C) $\mathrm{T}=\mathrm{T}_{\mathrm{PIT}}$, microemulsões bicontinuas se formam e (D) A emulsão é invertida e então a água é dispersa em uma mistura de óleo e tensoativo lipofílico. O sistema é então resfriado, fazendo com que de repente o tensoativo fique hidrofílico e induza uma migração rápida e espontânea para a fase aquosa, gerando as nanoemulsões.
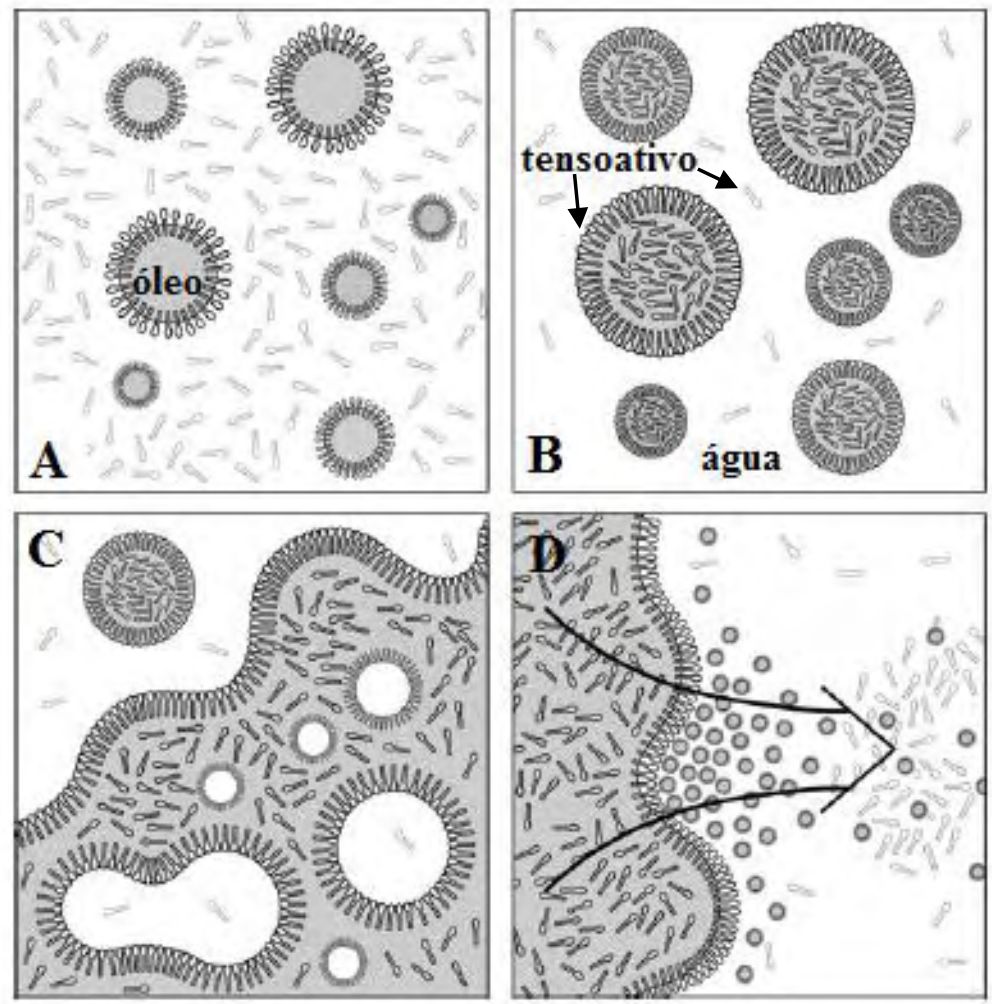

Fonte: ANTON, N.; VANDAMME, T.F. The universality of low-energy nano-emulsification. International Journal of Pharmaceutics, Amsterdam, v. 377, p. 142-147, 2009. 
O método da emulsificação espontânea foi proposto por Ruschak e Miller em 1972. Neste método a emulsão é criada como resultado da mistura de dois líquidos a temperatura ambiente. Um é a fase aquosa pura e o outro é uma mistura de óleo, tensoativo e solvente miscível em água (ANTON; VANDAMME, 2009). Segundo Solans e Solé (2012) o método da emulsificação espontânea faz uso da energia química liberada devido ao processo de diluição com a fase contínua. Durante o processo de diluição ocorre a difusão dos componentes miscíveis a água (solvente, tensoativo e/ou co-tensoativo) da fase orgânica para fase aquosa, essa transferência rápida de componentes hidrofílicos do óleo para água resulta em um aumento da área interfacial dando origem a uma emulsão metaestável óleo em água. Também tem sido reportado na literatura a produção de emulsões pelo método da emulsificação espontânea sem a utilização de tensoativo. Esta emulsificação é denominada de efeito Ouzo e para produção da mesma basta derramar sobre a água uma solução contendo uma pequena concentração de óleo e solvente (s) totalmente miscível (is) em água (SOLANS et al., 2005; ANTON et al., 2008; GANACHAUD; KATZ, 2009; SOLANS; SOLÉ, 2012).

Outro método de baixa energia amplamente empregado é o método do ponto de inversão da emulsão (ou EIP, emulsion inversion point). Este método baseia-se numa inversão de fase catastrófica que ocorre quando a água é titulada em um sistema que contém uma mistura de óleo e um agente tensoativo. Inicialmente uma emulsão água em óleo $(\mathrm{A} / \mathrm{O})$ é formada e depois uma emulsão múltipla de óleo/água/óleo $(\mathrm{O} / \mathrm{A} / \mathrm{O})$ e, em seguida, uma emulsão óleo em água (O/A). A origem das mudanças estruturais que ocorrem durante as transições de fase catastróficas tem sido relacionada com o equilíbrio de separação das gotículas, a coalescência no sistema e o tamanho de gotícula produzida para a formação da emulsão múltipla intermediária. A Figura 6 (parte inferior) mostra esquematicamente o protocolo usado por Ostertag et al. (2012) para produção de nanoemulsões pelo método EIP. Tal protocolo consiste na titulação, pelo uso de uma bureta, de uma fase aquosa em uma fase orgânica (óleo + tensoativo) sobre agitação magnética constante (750 rotações por minuto - rpm).

A Figura 6 (parte superior) mostra também um mapa típico de formulação vs. composição para um sistema contendo óleo/água/tensoativo e uma ilustração de inversão de fase catastrófica e transicional. O método EIP é categorizado baseado na inversão de fase catastrófica enquanto que o método PIT por inversão de fase transicional. De acordo com Ostertag et al. (2012) a inversão de fase catastrófica depende de mudanças no parâmetro composição (por exemplo, proporção água e óleo) e 
a inversão de fase transicional depende de mudanças no parâmetro formulação (por exemplo, características físico-químicas da fase aquosa, oleosa e do tensoativo).

Figura 6 - Protocolo método EIP e mapa típico de formulação vs. composição para um sistema contendo óleo/água/tensoativo.

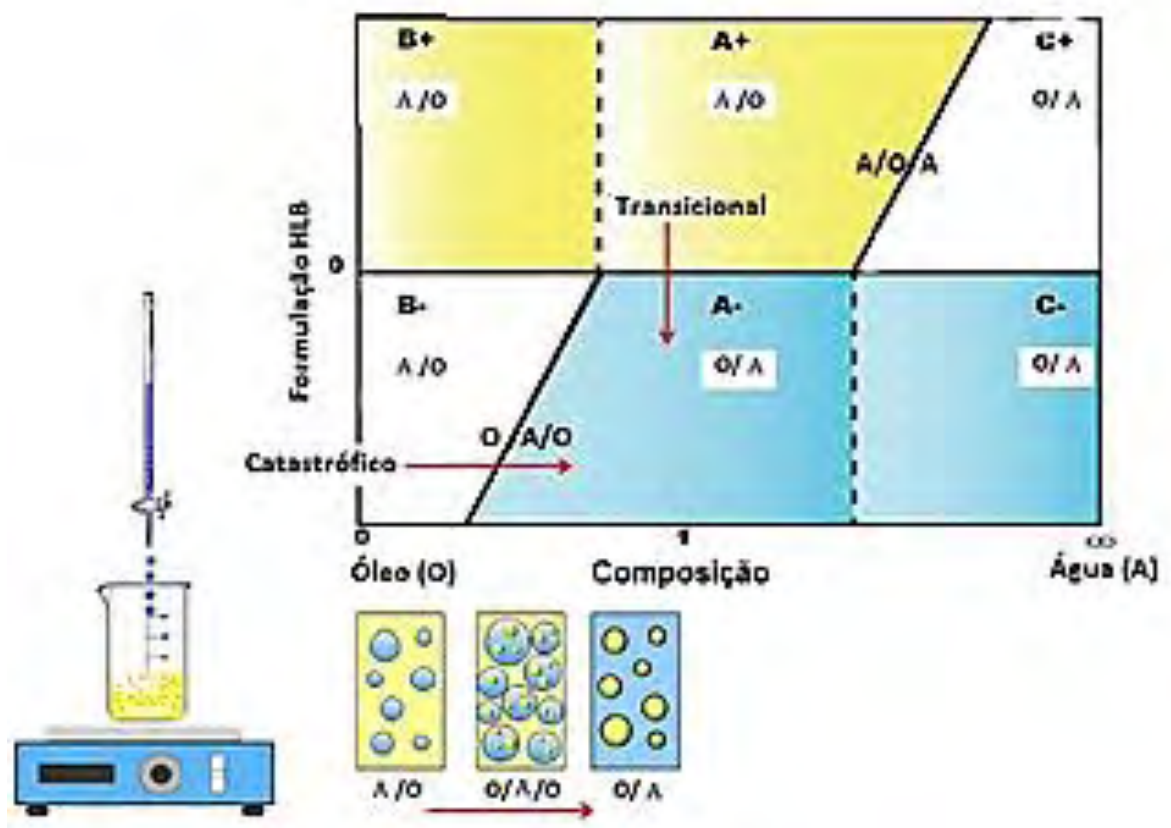

Fonte: Adaptado de OSTERTAG, F.; WEISS, J.; MCCLEMENTS, D.J. Low-energy formation of edible nanoemulsions: Factors influencing droplet size produced by emulsion phase inversion. Journal of Colloid and Interface Science, New York, 388, p. 95-102, 2012.

Independentemente do método empregado para produção de nanoemulsões, o uso das mesmas se mostra vantajoso uma vez que são capazes de aumentar a biodisponibilidade de substâncias bioativas lipofílicas. Em alguns casos a encapsulação permite ainda o aumento da estabilidade dos bioativos encapsulados como por exemplo, à proteção contra volatilização e oxidação (McCLEMENTS, 2012). Conforme pode-se observar pela Tabela 8 , diferentes estudos, tanto pelo método PIT quanto pelos métodos de emulsificação espontânea e EIP vem sendo relatados na literatura. Estes estudos visam aplicação nos mais diferentes campos, como por exemplo na indústria farmacêutica, de cosméticos, química e na alimentícia. Vale ressaltar que para ser aplicada no setor de alimentos, todos os componentes da formulação da nanoemulsão devem ser de grau alimentício. 
Tabela 8 - Estudos de produção de nanoemulsões por método de baixa energia relatados na literatura $(\mathrm{O}=$ óleo; $\mathrm{T}=$ tensoativo; $\mathrm{CS}=$ co-solvente e $\mathrm{CE}=$ composto encapsulado).

\begin{tabular}{|c|c|c|c|c|}
\hline Autor (es) & Método empregado & Matérias primas utilizadas & Indústria & Objetivo do estudo \\
\hline $\begin{array}{c}\text { BOUCHEMAL } \\
\text { et al., } 2004\end{array}$ & $\begin{array}{c}\text { Emulsificação } \\
\text { espontânea }\end{array}$ & $\begin{array}{l}\text { O: Ácidos graxos de cadeia média } \\
\text { T: Span } 80, \text { Span } 85 \text { e Tween } 80 \\
\text { CS: Acetona, etanol e acetato de etila } \\
\text { CE: } \alpha \text {-tocoferol }\end{array}$ & Alimentícia & $\begin{array}{c}\text { Otimização do processo de emulsificação } \\
\text { espontânea. Os parâmetros testados foram os } \\
\text { tipos de óleo, agente tensoativo e } \\
\text { solventes miscíveis em água . }\end{array}$ \\
\hline $\begin{array}{l}\text { OLIVEIRA, } \\
2008\end{array}$ & EIP & $\begin{array}{l}\text { O: Copaíba e andiroba } \\
\text { T: Span 80, Tween } 80 \\
\text { CE: Copaíba e andiroba }\end{array}$ & Cosmética & $\begin{array}{c}\text { Desenvolver formulações tópicas na forma de } \\
\text { nanoemulsões e avaliar a atividade repelente } \\
\text { das mesmas frente ao mosquito Aedes } \\
\text { aegypti. }\end{array}$ \\
\hline $\begin{array}{l}\text { ZANATTA } \\
\text { et al., } 2010\end{array}$ & PIT/EIP & $\begin{array}{c}\text { O: Buriti } \\
\text { T: Ceteareth-5/20, Span 80, Steareth-2 e } \\
\text { Ultramona R40 } \\
\text { CE: } \alpha \text {-tocoferol e óleo de buriti }\end{array}$ & Farmacêutica & $\begin{array}{l}\text { Investigar se loções e cremes tópicos } \\
\text { produzidos com óleo de buriti podem exercer } \\
\text { efeito foto protetor contra radiação UVA e } \\
\text { UVB nos queratinócitos e fibroblastos. }\end{array}$ \\
\hline $\begin{array}{c}\text { TEO } \\
\text { et al., } 2010\end{array}$ & $\begin{array}{c}\text { Emulsificação } \\
\text { espontânea }\end{array}$ & $\begin{array}{c}\text { O: Palma } \\
\text { T: Tween } 80 \text {, Plurionic F-68 } \\
\text { CE: Vitamina E }\end{array}$ & Cosmética & $\begin{array}{l}\text { Desenvolvimento de nanoemulsões de óleo de } \\
\text { palma a partir de ésteres para utilização como } \\
\text { um sistema de entrega para produção de } \\
\text { nanocosméticos. }\end{array}$ \\
\hline $\begin{array}{c}\text { MEI } \\
\text { et al., } 2011\end{array}$ & PIT & $\begin{array}{c}\text { O: Parafina líquida } \\
\text { T: Span 80, Tween 20, Tween } 80 \text { e } \\
\text { cetyltrimethylammonium bromide (CTAB) }\end{array}$ & $\begin{array}{c}\text { Farmacêutica, } \\
\text { cosmética e } \\
\text { alimentícia }\end{array}$ & $\begin{array}{l}\text { Desenvolver nanoemulsões O/A carregadas } \\
\text { positivamente por adição de tensoativos } \\
\text { catiônicos diretamente no sistema. }\end{array}$ \\
\hline
\end{tabular}




\begin{tabular}{|c|c|c|c|c|}
\hline $\begin{array}{l}\text { OSTERTAG } \\
\text { et al., } 2012\end{array}$ & EIP & $\begin{array}{l}\text { O: Canola, oliva, semente de uva, limonese, } \\
\text { triacilgliceróis de cadeia média, mineral, } \\
\text { laranja, amendoim e gergelim } \\
\text { T:Tween } 20,80 \text { e } 85\end{array}$ & Alimentícia & $\begin{array}{l}\text { Produção de diferentes formulações com } \\
\text { matéria prima de grau alimentício. }\end{array}$ \\
\hline $\begin{array}{l}\text { BORRIN } \\
\text { et al., } 2015\end{array}$ & EIP & $\begin{array}{l}\text { O: Soja comercial } \\
\text { T: Tween } 80 \\
\text { CS: Glicerol } \\
\text { CE: Curcumina }\end{array}$ & Alimentícia & $\begin{array}{l}\text { Encapsulação da curcumina e obtenção de } \\
\text { parâmetros de operação que possibilitem } \\
\text { futuro escalonamento do processo }\end{array}$ \\
\hline
\end{tabular}

Fonte: Própria Autoria. 


\subsection{SUPLEMENTOS HIDROELETROLÍTICOS (BEBIDAS ISOTÔNICAS)}

Nos últimos anos o Brasil apresentou um aumento no consumo de bebidas isotônicas, tendo ocorrido um crescimento, em termos de volume, de $19 \%$ ao ano (taxa média de crescimento) entre 2008 e 2013. O consumo per capita deste tipo de bebida no Brasil é de 0,6 litro, enquanto que nos Estados Unidos, maior consumidor mundial, o consumo é de 15,6 litros ao ano por habitante. Em outros países da América Latina, como por exemplo, no Peru, o consumo é de 5,3 litros per capita. Em teoria, essa comparação com outros países mostra que ainda há espaço para explorar o mercado brasileiro (BRASIL ECONÔMICO, 2014).

Os suplementos hidroeletrolíticos, popularmente conhecidos como isotônicos, são bebidas que visam repor a perda de água e eletrólitos durante a prática de atividades físicas. O seu uso previne a desidratação, permite uma recuperação mais rápida do corpo fatigado e um melhor rendimento. De acordo com Monteiro e De Marchi (2010), a osmolalidade de uma bebida isotônica situa-se em torno de $300 \mathrm{mOsm} / \mathrm{L}$, que é próxima à do sangue, o que favorece a absorção de água e de eletrólitos perdidos na transpiração. Além disso, por possuírem de 6 a 8\% de carboidratos em sua composição são absorvidos mais rapidamente na corrente sanguínea do que a água pura.

As matérias-primas que podem compor as bebidas isotônicas são: água, açúcares, eletrólitos, acidulantes, conservadores, corantes naturais, idênticos aos naturais, ou artificiais e aromatizantes. Vitaminas, polpa e/ou suco de frutas também podem ser adicionados ao suplemento hidroeletrolítico (MONTEIRO; DE MARCHI, 2010).

A água é o ingrediente mais importante da bebida, pois além de solubilizar todos os outros ingredientes é o ingrediente responsável por repor os fluidos perdidos durante a prática esportiva. Os açúcares são a fonte de energia. Os eletrólitos ajudam a reabastecer os minerais perdidos através do suor. Os acidulantes além de conferir acidez ajudam a mascarar o gosto doce dos açúcares e também auxiliam na conservação do produto. A adição de vitaminas pode promover diversos benefícios a saúde como, por exemplo, no caso da vitamina C (ácido ascórbico), pode promover aumento da resistência a infecções e servir como antioxidante, além de promover a absorção de ferro. Por sua vez, os corantes e os aromatizantes conferem sabor e aroma agradáveis (BOTTERI; BOTTERI, 2005). 
Segundo a Resolução 18, de 27 de abril de 2010 (BRASIL, 2010), um suplemento hidroeletrolítico,

É um produto destinado a auxiliar a hidratação e deve atender aos
seguintes requisitos para produto pronto para consumo: a
concentração de sódio deve situar-se entre 460 e $1150 \mathrm{mg} / \mathrm{L} ;$ a
osmolalidade deve ser inferior a $330 \mathrm{mOsm} / \mathrm{kg}$ de água; os
carboidratos podem constituir até $8 \%(\mathrm{~m} / \mathrm{v}) ;$ o produto pode ser
adicionado de vitaminas e minerais e de potássio em até $700 \mathrm{mg} / \mathrm{L} ;$ o
produto não pode ser adicionado de outros nutrientes e não nutrientes
e de fibras alimentares. Adicionalmente nos rótulos de suplementos
hidroeletrolíticos para atletas, pode constar a expressão: I-
"isotônico" para os produtos prontos para consumo com
osmolalidade entre 270 e $330 \mathrm{mOsm} / \mathrm{kg}$ água; II- "hipotônico" para
os produtos prontos para consumo com osmolalidade abaixo de 270
mOsm/kg água.

Bebidas isotônicas, também chamadas de bebidas esportivas, destinam-se principalmente a atletas profissionais e por pessoas praticantes de esportes, pois, conforme já foi mencionado, devido ao fato de a osmolalidade ser similar à do sangue, a mesma entra mais rapidamente na corrente sanguínea promovendo uma rápida hidratação. Porém, atualmente diversas bebidas vêm sendo formuladas com o intuito de não só apresentar função repositória de eletrólitos e água, mas também com o objetivo de controlar deficiências vitamínica em comunidades carentes, além de prevenir algumas doenças (CASTRO et al., 2006; CAVALCANTI et al., 2010).

Tradicionalmente, as bebidas isotônicas são produzidas utilizando-se corantes e aromatizantes artificiais, porém no intuito de acompanhar a preferência dos consumidores por produtos mais saudáveis, uma nova perspectiva vem sendo apontada, a qual emprega produtos naturais para na formulação da bebida. Além disso, a fortificação de isotônicos e de bebidas energéticas com vitaminas tem sido uma prática adotada pela maioria das empresas do ramo. As principais vitaminas que vem sendo empregadas são as do complexo B, C e ácido fólico. As vitaminas lipossolúveis, tais como a A e E, também vem sendo estudadas através da microencapsulação (CASTRO et al., 2006).

Porém, para garantir a segurança dos consumidores que consomem essas bebidas, é preciso que a adição desses nutrientes obedeça a Ingestão Diária Recomendada (IDR). Castro et al. (2006) quantificaram vitaminas do complexo B e da vitamina C em 14 bebidas isotônicas disponíveis comercialmente. Os resultados encontrados foram todos superiores aos valores declarados pelos fabricantes. Em alguns casos o valor encontrado foi superior a 10 vezes o valor declarado no rótulo. Portanto, é 
extremamente importante que as substituições e/ou adição de ingredientes seja feita levando-se em conta a IDR.

Diversos estudos e patentes são encontrados na literatura. Na Tabela 9 pode-se observar alguns estudos relatados que apresentam substituição de ingredientes artificiais por naturais e também a adição de diferentes vitaminas em bebidas isotônicas. 
Tabela 9 - Estudos com bebida isotônica relatados na literatura.

\begin{tabular}{|c|c|c|c|}
\hline Autores ou Inventores & Diferencial & Objetivo do estudo ou patente & 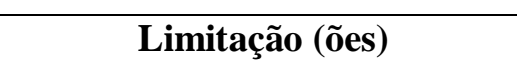 \\
\hline $\begin{array}{l}\text { DE MARCHI } \\
\text { et al., } 2003\end{array}$ & $\begin{array}{l}\text { Substituição de corante e } \\
\text { acidulante por polpa de maracujá. }\end{array}$ & $\begin{array}{c}\text { Estudar a vida-de-prateleira de um isotônico } \\
\text { natural de maracujá. }\end{array}$ & $\begin{array}{l}\text { O tratamento térmico provocou } \\
\text { uma perda de } 70,7 \% \text { do } \\
\text { conteúdo de vitamina } \mathrm{C} \text { presente } \\
\text { na bebida. }\end{array}$ \\
\hline $\begin{array}{l}\text { BOTTERI; BOTTERI, } \\
2005\end{array}$ & $\begin{array}{l}\text { Fortificação da bebida isotônica } \\
\text { com ferro, cálcio e vitaminas } \\
\text { essenciais. }\end{array}$ & $\begin{array}{c}\text { Fornecer à adolescentes e atletas do sexo } \\
\text { feminino que estão em risco de ter anemia, } \\
\text { osteoporose e amenorreia uma bebida } \\
\text { fortificada. }\end{array}$ & --- \\
\hline $\begin{array}{c}\text { ROSSO; MERCADANTE, } \\
2007\end{array}$ & $\begin{array}{l}\text { Substituição de corante por } \\
\text { extrato de acerola e de açaí (ricos } \\
\text { em antocianinas). }\end{array}$ & $\begin{array}{l}\text { Adição de extrato de antocianinas como } \\
\text { colorante e ingrediente funcional. }\end{array}$ & $\begin{array}{c}\text { Baixa estabilidade uma vez que } \\
\text { depende do } \mathrm{pH} \text {, temperatura, } \\
\text { presença de luz e de oxigênio. }\end{array}$ \\
\hline $\begin{array}{l}\text { MARTINS } \\
\text { et al., } 2011\end{array}$ & $\begin{array}{l}\text { Bebida isotônica à base de frutas } \\
\text { (laranja seleta, maracujá e } \\
\text { melancia) e hortaliças (alface, } \\
\text { abobrinha, cenoura, espinafre, } \\
\text { hortelã, inhame, pepino e rúcula). }\end{array}$ & $\begin{array}{c}\text { Analisar a qualidade sensorial, } \\
\text { microbiológica e a estabilidade da fração de } \\
\text { carboidratos de uma polpa isotônica natural } \\
\text { produzida a partir do suco de frutas e } \\
\text { hortaliças. }\end{array}$ & $\begin{array}{l}\text { As amostras foram armazenadas } \\
\text { a }-18{ }^{\circ} \mathrm{C} \text { durante os } 30 \text { dias da } \\
\text { análise. Comercialmente as } \\
\text { bebidas isotônicas são } \\
\text { armazenadas sob refrigeração ou } \\
\text { a temperatura ambiente. }\end{array}$ \\
\hline $\begin{array}{l}\text { SANTOS } \\
\text { et al., } 2013 \mathrm{~b}\end{array}$ & $\begin{array}{l}\text { Bebida isotônica orgânica de } \\
\text { tangerina: com nível reduzido de } \\
\text { aditivos e agrotóxicos. }\end{array}$ & $\begin{array}{c}\text { Elaboração de uma bebida isotônica } \\
\text { orgânica e consequente comparação com } \\
\text { bebida isotônica comercial sabor tangerina. }\end{array}$ & --- \\
\hline
\end{tabular}




\begin{tabular}{|c|c|c|c|}
\hline $\begin{array}{c}\text { GIRONÉS-VILAPLANA } \\
\text { et al.,2013 }\end{array}$ & $\begin{array}{l}\text { Bebida isotônica com propriedade } \\
\text { antioxidante e biológica } \\
\text { produzida com: } \\
\text { *suco de limão: rico em vitamina } \\
\text { C, minerais, ácido cítrico e } \\
\text { flavonoides; } \\
\text { *maqui: capacidade antioxidante } \\
\text { e fonte natural de corante } \\
\text { (antocianinas); } \\
\text { *açaí: atividade antioxidante e } \\
\text { anti-inflamatória; } \\
\text { *abrunho: antioxidante, diurético, } \\
\text { adstringente e purgante. }\end{array}$ & $\begin{array}{l}\text { Avaliar a qualidade e atividade biológica } \\
\text { (capacidade antioxidante e efeitos sobre os } \\
\text { lipídios e glicose no metabolismo) de } \\
\text { bebidas isotônicas produzidas com } \\
\text { diferentes ingredientes, no que diz respeito } \\
\text { ao potencial uso dos ingredientes funcionais } \\
\text { em novos produtos. }\end{array}$ & $\begin{array}{c}\text { Não foi realizado nenhum teste } \\
\text { sensorial para verificar a } \\
\text { aceitabilidade do produto. }\end{array}$ \\
\hline
\end{tabular}

Fonte: Própria autoria. 


\title{
2.4 CORANTES ALIMENTÍCIOS
}

A cor é um atributo muito importante na indústria alimentícia uma vez que influencia diretamente na preferência e escolha dos consumidores. A aparência de um alimento (determinada principalmente por sua cor) seduz os consumidores e é o atributo o qual eles utilizam como ferramenta para aceitar ou rejeitar o produto (PRADO; GODOY, 2003; SCHUMANN et al., 2008; PATHARE et al., 2013). Diversos produtos alimentícios não possuem coloração e em outros a cor original é modificada ou perdida devido ao processamento industrial. Desta forma, se faz necessário a adição de corantes com a finalidade de atribuir ou recompor a coloração perdida a fim de torná-los atrativos para os consumidores (VIDOTTI; ROLLEMBERG, 2006).

Para o uso em alimentos existem cinco categorias de corante permitidos pela legislação brasileira, o orgânico natural, o orgânico sintético, o qual é subdividido em artificial e orgânico sintético idêntico ao natural, o inorgânico, o caramelo e por fím o caramelo (processo amônia). Segundo a resolução nº 44, de 25 de novembro de 1977 (BRASIL, 1977), considera-se como corante orgânico natural,

\begin{abstract}
"Aquele obtido a partir de vegetal ou de animal" como corante orgânico sintético, "aquele obtido por síntese orgânica", como corante inorgânico, "aquele obtido a partir de substâncias minerais", como caramelo "o obtido pelo aquecimento de açúcares à temperatura superior ao ponto de fusão" e por fim como corante caramelo (processo de amônia), "o orgânico sintético idêntico ao natural obtido pelo processo amônia"
\end{abstract}

Os corantes artificiais não possuem valor nutritivo, são utilizados em produtos alimentícios com o objetivo específico de conferir coloração. Internacionalmente há diversas opiniões com relação à inocuidade dos diferentes corantes artificiais e o uso de diferentes corantes e as quantidades permitidas variam de país para país. Nos Estados Unidos, por exemplo, o uso de amaranto, azorrubina, ponceau 4R e azul patente é proibido. Já a União Europeia não permite o uso de verde rápido (DOWNHAM; COLLINS, 2000; PRADO; GODOY, 2003). Pelas Resoluções da ANVISA de n 382 a 388, de 9 de agosto de 1999 são permitidos no Brasil para uso em alimentos e bebidas os seguintes corantes artificiais: amaranto, vermelho de eritrosina, vermelho 40, ponceau $4 \mathrm{R}$, amarelo crepúsculo, amarelo tartrazina, azul de indigotina, azul brilhante, azorrubina, verde rápido e azul patente V (BRASIL, 1999). Na Tabela 10 pode-se observar algumas propriedades dos corantes artificiais permitidos no Brasil. 
Tabela 10 - Propriedades dos corantes utilizados no Brasil (IDA expresso em mg/kg do peso corpóreo, limite máximo expresso em mg/100g e solubilidade expressa em $\mathrm{g} / 100 \mathrm{~mL}$ a $25^{\circ} \mathrm{C}$ ).

\begin{tabular}{|c|c|c|c|c|c|c|c|}
\hline Nome usual & Fórmula & Código ${ }^{1,2}$ & Cor $^{2}$ & IDA $^{1,2}$ & $\begin{array}{c}\text { Limite } \\
\text { máximo }\end{array}$ & Solubilidade $\mathbf{e m}^{1}$ & Sinônimos ${ }^{1}$ \\
\hline Tartrazina & $\mathrm{C}_{16} \mathrm{H}_{9} \mathrm{~N}_{4} \mathrm{Na}_{3} \mathrm{O}_{9} \mathrm{~S}_{2}$ & E-102 & $\begin{array}{l}\text { Amarelo } \\
\text { limão }\end{array}$ & 7,5 & 30,00 & $\begin{array}{c}\text { Água } 20 \\
\text { Glicerina } 18 \\
\text { Propileno } 7 \\
\text { Etanol }<0,1 \\
\end{array}$ & $\begin{array}{c}\text { Tartrazine FD\&C, Yellow No. } 5 \text { e } \\
\text { Food Yellow No.4 }\end{array}$ \\
\hline $\begin{array}{l}\text { Amarelo } \\
\text { Crepúsculo }\end{array}$ & $\mathrm{C}_{16} \mathrm{H}_{10} \mathrm{~N}_{2} \mathrm{Na}_{2} \mathrm{O}_{7} \mathrm{~S}_{2}$ & E-110 & Laranja & 2,5 & 10,0 & $\begin{array}{c}\text { Água } 19 \\
\text { Glicerina } 20 \\
\text { Propileno 2,2 } \\
\text { Etanol <0,1 } \\
\end{array}$ & $\begin{array}{l}\text { Sunset yellow, FCF, Food Yellow } \\
\text { No.5, FD\&C e Yellow No.6 }\end{array}$ \\
\hline Azorrubina & $\mathrm{C}_{20} \mathrm{H}_{12} \mathrm{~N}_{2} \mathrm{Na}_{2} \mathrm{O}_{7} \mathrm{~S}_{2}$ & E-122 & Vermelho & 4,0 & 5,00 & $\begin{array}{c}\text { Água } 5-10 \\
\left(\mathrm{~g} / 100 \mathrm{~mL} \text { a } 19{ }^{\circ} \mathrm{C}\right)\end{array}$ & $\begin{array}{c}\text { Carmoisine, Food Red } 3 \text { e } \\
\text { Acid red } 14 \\
\end{array}$ \\
\hline Amaranto & $\mathrm{C}_{20} \mathrm{H}_{11} \mathrm{~N}_{2} \mathrm{Na}_{3} \mathrm{O}_{10} \mathrm{~S}_{3}$ & E-123 & Magenta & 0,5 & 10,0 & $\begin{array}{c}\text { Água } 8 \\
\text { Glicerina } 1,5 \\
\text { Propileno } 0,4 \\
\text { Etanol }<0,1\end{array}$ & $\begin{array}{c}\text { Amaranth, } \\
\text { Food Red No.2 e } \\
\text { Bordeaus S }\end{array}$ \\
\hline Ponceau 4R & $\mathrm{C}_{20} \mathrm{H}_{11} \mathrm{~N}_{2} \mathrm{Na}_{3} \mathrm{O}_{10} \mathrm{~S}_{3}$ & E-124 & Cereja & 4,0 & 10,00 & $\begin{array}{c}\text { Água 25 } \\
\text { Glicerina } 1,4 \\
\text { Propileno } 1,4 \\
\text { Etanol } 0,02 \\
\end{array}$ & $\begin{array}{c}\text { New coccine, } \\
\text { Food Red } 7 \text { e } \\
\text { Food Red No.102 }\end{array}$ \\
\hline Eritrosina & $\mathrm{C}_{20} \mathrm{H}_{6} \mathrm{I}_{4} \mathrm{Na}_{2} \mathrm{O}_{5}$ & E-127 & Pink & 0,1 & 5,00 & $\begin{array}{c}\text { Água } 9 \\
\text { Glicerina } 20 \\
\text { Propileno } 20 \\
\text { Etanol } 1 \\
\end{array}$ & $\begin{array}{l}\text { Erythrosine B, } \\
\text { Food Red } 14 \text { e } \\
\text { Acid Red 18, }\end{array}$ \\
\hline Verde Rápido & $\mathrm{C}_{37} \mathrm{H}_{34} \mathrm{~N}_{2} \mathrm{Na}_{2} \mathrm{O}_{10} \mathrm{~S}_{3}$ & E-143 & Verde mar & 10,0 & 30,00 & Água $<10$ & $\begin{array}{c}\text { Fast green, FCF, Food Green } 3 \text { e } \\
\text { FD\&C Green No 3, }\end{array}$ \\
\hline Vermelho 40 & $\mathrm{C}_{18} \mathrm{H}_{14} \mathrm{~N}_{2} \mathrm{Na}_{2} \mathrm{O}_{8} \mathrm{~S}_{2}$ & E-129 & $\begin{array}{l}\text { Vermelho } \\
\text { alaranjado }\end{array}$ & 7,0 & 30,00 & $\begin{array}{c}\text { Água } 22 \\
\text { Glicerina } 3 \\
\text { Propileno } 1,5 \\
\text { Etanol } 0,001 \\
\end{array}$ & $\begin{array}{l}\text { Allura Red, AC e } \\
\text { Food Red } 17\end{array}$ \\
\hline
\end{tabular}




\begin{tabular}{|c|c|c|c|c|c|c|c|}
\hline $\begin{array}{l}\text { Azul Patente } \\
\qquad \text { V }\end{array}$ & $\mathrm{C}_{27} \mathrm{H}_{31} \mathrm{~N}_{2} \mathrm{Na}_{2} \mathrm{O}_{6} \mathrm{~S}_{2}$ & E-131 & Azul & 15,0 & 30,00 & Água $<10$ & $\begin{array}{c}\text { Acid blue } 3, \\
\text { Patent Blue V e } \\
\text { Food Blue } 5\end{array}$ \\
\hline $\begin{array}{c}\text { Azul } \\
\text { Indigotina }\end{array}$ & $\mathrm{C}_{16} \mathrm{H}_{8} \mathrm{~N}_{2} \mathrm{Na}_{2} \mathrm{O}_{8} \mathrm{~S}_{2}$ & E-132 & Azul royal & 5,0 & 30,00 & $\begin{array}{c}\text { Água } 1,6 \\
\text { Glicerina } 1 \\
\text { Propileno 0,1 } \\
\text { Etanol }<0,1 \\
\end{array}$ & $\begin{array}{l}\text { Indigo carmine, } \\
\text { FD\&C Blue, No. } 2 \text { e Food Blue No. } 2\end{array}$ \\
\hline $\begin{array}{c}\text { Azul } \\
\text { Brilhante }\end{array}$ & $\mathrm{C}_{37} \mathrm{H}_{34} \mathrm{~N}_{2} \mathrm{Na}_{2} \mathrm{O}_{9} \mathrm{~S}_{3}$ & E-133 & Azul turquesa & 10,0 & 30,00 & $\begin{array}{c}\text { Água } 20 \\
\text { Glicerina } 20 \\
\text { Propileno } 20 \\
\text { Etanol } 0,15\end{array}$ & $\begin{array}{c}\text { FD\&C Blue No.1, Food Blue } 2 \text { e } \\
\text { Brilliant blue FCF }\end{array}$ \\
\hline
\end{tabular}

Fonte: ${ }^{1}$ PRADO, M.A.; GODOY, H. T. Corantes artificiais em alimentos. Alimentos e Nutrição, Araraquara, v. 14, n. 2, p. 237-250, 2003. ${ }^{2}$ OLIVEIRA, A. P. et al. Consumo de corantes artificiais em balas e chicletes por crianças de seis a nove anos. Analytica, São Paulo, v. 8, n. 44, p. 79-85, 2010. 
Dentre estes corantes o amarelo crepúsculo e o amarelo tartrazina se destacam uma vez que são os corantes sintéticos mais amplamente empregados em produtos alimentícios (VIDOTTI; ROLLEMBERG, 2006). Segundo Prado e Godoy (2003), tanto o amarelo crepúsculo quanto o amarelo tartrazina apresentam boa estabilidade na presença de luz, calor e ácido e apresenta descoloração na presença de ácido ascórbico e $\mathrm{SO}_{2}$. Porém, o corante tartrazina tem despertado uma maior atenção dos toxicologistas e alergistas uma vez que este vem sendo apontado como a responsável por várias reações adversas tais como urticária e asma (MOUTINHO et al., 2007). Entretanto, tal corante é um dos mais utilizados em alimentos e é permitido em muitos países tais como Brasil, Canadá, Estados Unidos e União Europeia. A ANVISA inclusive publicou um Informe Técnico ( ${ }^{\circ} 30$ de 20 de julho de 2007) com algumas considerações sobre o corante amarelo tartrazina. $\mathrm{O}$ informe técnico ressaltou que não é possível concluir a relação entre o corante amarelo tartrazina com reações adversas. Porém, foi identificada uma necessidade de informar nos rótulos de produtos alimentícios a presença de tal corante.

Os corantes naturais são pigmentos extraídos de fontes naturais com a finalidade de conferir coloração a produtos alimentícios. Os corantes naturais urucum, carmim de cochonilha, curcumina, antocianinas e as betalaína são os tipos de corantes naturais mais utilizados pelas indústrias alimentícias (HENRY, 1996). Na Tabela 11 pode-se observar tais corantes naturais juntamente com uma breve descrição.

Os corantes artificiais possuem diversas vantagens quando comparados aos corantes naturais, como por exemplo alta estabilidade a luz, oxigênio, calor, alto poder tintorial e custo de produção relativamente baixo. Apesar de apresentar diversas vantagens a substituição de corantes artificias por naturais vem acontecendo de forma gradativa uma vez que há uma tendência mundial para o consumo de produtos mais naturais. Entretanto a substituição desses corantes ainda é um desafio devido às questões relacionadas com a estabilidade dos corantes naturais (CONSTANT et al., 2002).

Dentro do contexto exposto na presente revisão bibliográfica, nota-se a importância da substituição de corantes artificiais por naturais. Como já foi dito, o óleo de buriti é o óleo vegetal detentor da maior concentração de $\beta$-caroteno encontrado na biodiversidade brasileira e possui ação corante, além de tocoferol e ácido oleico. A encapsulação do óleo de buriti permite que o mesmo seja utilizado como corante natural em produtos alimentícios de base aquosa. A emulsificação por métodos de baixa energia, como o método PIT, permite a produção de emulsões em escala nanométrica 
que podem se apresentar translúcidas a olho nu. Tal transparência óptica se mostra extremamente vantajosa quando se deseja aplicar em produtos translúcidos, como é o caso de bebidas isotônicas. Dentro deste contexto insere-se a importância deste trabalho de Mestrado, o qual pretende apresentar uma alternativa para utilização do óleo de buriti como corante natural em alimentos hidrofílicos. 
Tabela 11 - Corantes naturais mais utilizados pelas indústrias alimentícias.

\begin{tabular}{|c|c|c|}
\hline Nome usual $^{1,2}$ & Código $^{1,2}$ & Descrição $^{1,2}$ \\
\hline Antocianinas & E-163 & $\begin{array}{l}\text { Pigmentos que variam do vermelho ao azul. São comumente encontrados em frutas maduras (ex } \\
\text { morango, mirtilo, cerejas e uvas), vegetais (ex: cebola e repolho), sementes (ex: girassol roxo) e } \\
\text { flores. }\end{array}$ \\
\hline Betalaínas & E-162 & Pigmento majoritário encontrado na beterraba. \\
\hline Caramelo & E-150 & $\begin{array}{l}\text { Equivalente ao açúcar caramelizado. É obtido através do aquecimento de alimentos ricos em } \\
\text { carboidratos na presença de catálise. }\end{array}$ \\
\hline Ácido carminico ou carmim & E-120 & É um extrato obtido do inseto, do sexo feminino, cochonilha. \\
\hline Carotenoides & E-160 & Possuem ação corante no intervalo do amarelo ao vermelho. \\
\hline B-caroteno & E-160a & Extraído majoritariamente da cenoura. \\
\hline Bixina, norbixina ou annatto & E-160b & Extraído da semente da Bixa orellana $L$. \\
\hline Licopeno & E-160d & Pigmento encontrado em uma grande variedade de frutas (ex: melancia e tomate). \\
\hline Luteína & E-161b & Pigmento encontrado em uma grande variedade de vegetais (ex: alfafa e milho). \\
\hline Cantaxantina & E-161g & Pigmento naturalmente encontrado em salmão, camarão e nas penas dos flamingos. \\
\hline Clorofila & E-140 & Pigmento verde natural que participa do processo fotossintético. \\
\hline Clorofilina & E-141 & Pigmento verde natural que participa do processo fotossintético. \\
\hline Curcumina & E-100 & Pigmento extraído do rizoma de uma planta (Curcuma longa). \\
\hline
\end{tabular}

Fonte: ${ }^{1}$ BLANC, P.J. Natural Food Colorants. Biotechnology, Faisalabad, v. 2, 2002. ${ }^{2}$ WISSGOTT, U.; BORTLIK, K. Prospects for new natural food colorants. Trends in Food Science \& Technology, Cambridge, v. 7, n. 9, p. 298-302, 1996. 


\section{OBJETIVOS}

Esse projeto de Mestrado teve como objetivo geral a produção, caracterização e verificação da estabilidade de óleo de buriti nanoemulsionado por método de baixa energia (temperatura de transição de fases - $\mathrm{T}_{\mathrm{PIT}}$ ), para incorporação em bebida isotônica (suplemento hidroeletrolítico), como corante natural.

Para alcançar tal objetivo geral, os objetivos específicos determinados foram:

- Produção de óleo de buriti nanoemulsionado pelo método temperatura de inversão de fases (método PIT);

- Avaliação da estabilidade das nanoemulsões produzidas, buscando formulações ótimas em termos de preservação dos compostos de óleo de buriti encapsulado, bem como em termos de manutenção do diâmetro médio hidrodinâmico ao longo do tempo de estocagem;

- Incorporação das nanoemulsões mais estáveis em bebida isotônica;

- Avaliação físico-química e microbiológica da bebida isotônica incorporada com nanoemulsões;

- Avaliação sensorial da bebida isotônica adicionada de nanoemulsões. 


\section{MATERIAIS E MÉTODOS}

\subsection{MATERIAIS}

\subsubsection{Produção e caracterização de óleo de buriti nanoemulsionado}

Para a produção de óleo de buriti nanoemulsionado foi selecionado como fase lipídica o óleo de buriti (Beraca Sabará Químicos e Ingredientes S.A., Santa Barbara D’Oeste, SP, Brasil). O tensoativo utilizado foi o polisorbato 80 (Tween 80, Labsynth, Diadema, SP, Brasil) e o sal foi o cloreto de sódio (Labsynth, Diadema, SP, Brasil) em diferentes concentrações. O $\alpha$-tocoferol (Sigma-Aldrich, Saint Louis, MO, EUA, pureza 97\%) foi adicionado em algumas formulações.

Para a quantificação dos carotenoides totais encapsulados nas nanoemulsões empregou-se n-hexano, metanol, etanol (Dinâmica, Diadema, SP, Brasil), hidróxido de potássio, sulfato de sódio anidro, di-terc-butil metil fenol (BHT) (Labsynth, Diadema, SP, Brasil).

Por sua vez, na quantificação da oxidação lipídica pelo método das substâncias reativas ao ácido tiobarbitúrico (TBARS) empregou-se ácido tricloroacético (TCA), BHT (Labsynth, Diadema, São Paulo, Brasil), ácido tiobarbitúrico (TBA) (Fluka, St. Gallen, Suíça), ácido clorídrico (HCl) (Dinâmica, Diadema, SP, Brasil).

Ao longo do trabalho foi utilizada água deionizada ultrapurificada produzida pelo equipamento Direct Q3 (Millipore, Bedford, MA, EUA).

\subsubsection{Produção e caracterização da bebida isotônica}

Para produção da bebida isotônica foi utilizada água deionizada ultrapurificada (Direct Q3, Millipore, Bedford, MA, EUA), sacarose $\left(\mathrm{C}_{12} \mathrm{H}_{22} \mathrm{O}_{11}\right)$ (Caravelas, Usina Colombo, Ariranha, SP, Brasil), glicose anidra $\left(\mathrm{C}_{6} \mathrm{H}_{12} \mathrm{O}_{6}\right)$, fosfato de potássio $\left(\mathrm{KH}_{2 \mathrm{P}} \mathrm{O}_{4}\right)$, cloreto de sódio $(\mathrm{NaCl})$, citrato de sódio $\left(\mathrm{Na}_{3} \mathrm{C}_{6} \mathrm{H}_{5} \mathrm{O}_{7} \cdot 2 \mathrm{H}_{2} \mathrm{O}\right)$, ácido cítrico $\left(\mathrm{C}_{6} \mathrm{H}_{8} \mathrm{O}_{7}\right)$, ácido ascórbico $\left(\mathrm{C}_{6} \mathrm{H}_{8} \mathrm{O}_{6}\right)$ (Labsynth, Diadema, SP, Brasil), sorbato de potássio $\left(\mathrm{C}_{6} \mathrm{H}_{7} \mathrm{KO}_{2}\right)$ (Dinâmica Química Contemporânea Ltda., Diadema, SP, Brasil), aroma natural de tangerina doado pela Sun Foods (Sun Foods Indústria Produtos Alimentícios, Barueri, SP, Brasil), corante amarelo crepúsculo (Duas Rodas, Jaraguá do Sul, SC, Brasil) e óleo de buriti nanoemulsionado. Para a descontaminação das embalagens foi 
utilizada uma solução de ácido peracético 0,05\% (v/v) (Tech Apa San, Jaguariúna, SP, Brasil). As embalagens, de $300 \mathrm{~mL}$ e de polietileno de alta densidade (PEAD) (Usicomp, Santa Bárbara D'Oeste, SP, Brasil), foram adquiridas na Casa das Embalagens, situada na cidade de Pirassununga/SP.

Para acidez titulável foi diluída em água destilada e foi utilizado $\mathrm{NaOH} \mathrm{0,1} \mathrm{M}$ (Dinâmica, Diadema, SP, Brasil) padronizado (molaridade real 0,1015) para titulação e fenolftaleína como indicador.

\subsection{MÉTODOS}

\subsubsection{Determinação da temperatura de inversão de fases}

A princípio, a inversão de fase foi observada visivelmente, através da mudança na viscosidade e transparência do sistema. Em seguida, analisaram-se tais mudanças através da utilização de um condutivímetro (DM-32, Digimed, Campo Grande, MS, Brasil) de acordo com Morales et al. (2003). Foram construídas curvas de condutividade vs. temperatura em diferentes concentrações de $\mathrm{NaCl}(2,5 \mathrm{M}, 3 \mathrm{M}, 3,5 \mathrm{M}$ e $4 \mathrm{M})$, sendo a temperatura de inversão de fases ( $\left.\mathrm{T}_{\mathrm{PIT}}\right)$ determinada pela média entre a temperatura de início do decaimento da condutividade e a temperatura mínima atingida pelo sistema após a inversão de fases.

\subsubsection{Produção de óleo de buriti nanoemulsionado pelo método da} temperatura de inversão de fase

Para produção das nanoemulsões, os componentes da formulação (água, tensoativos, sal e óleo de buriti) foram aquecidos, em banho-maria (MA-127, Marconi, Piracicaba, SP, Brasil) até $80{ }^{\circ} \mathrm{C}$. Durante o processo de aquecimento as amostras foram misturadas sob agitação mecânica (MA-259, Marconi, Piracicaba, SP, Brasil) a 300 rotações por minuto com impelidor tipo disco de Cowles de diâmetro de 4,4 centímetros. A seguir, a amostra sofreu um rápido resfriamento sob agitação magnética, utilizando-se uma camisa de resfriamento alimentada com água a $0{ }^{\circ} \mathrm{C}$ (resfriada em banho ultratermostatizado (MA-184, Marconi Piracicaba, SP, Brasil)) até que a temperatura de $20{ }^{\circ} \mathrm{C}$ fosse atingida. A Figura 7 mostra uma representação esquemática 
de algumas etapas do protocolo utilizado para a produção do óleo de buriti nanoemulsionado. A etapa de aquecimento-resfriamento foi repetida 2 vezes para que as nanoemulsões obtivessem diâmetro médio de gota reduzido.

Figura 7 - Algumas etapas do protocolo utilizado para produção do óleo de buriti nanoemulsionado: (A) processo de aquecimento da nanoemulsão sobre agitação mecânica, (B) aparência da nanoemulsão após retirada do aquecimento e (C) processo de resfriamento da nanoemulsão sobre aquecimento magnético.

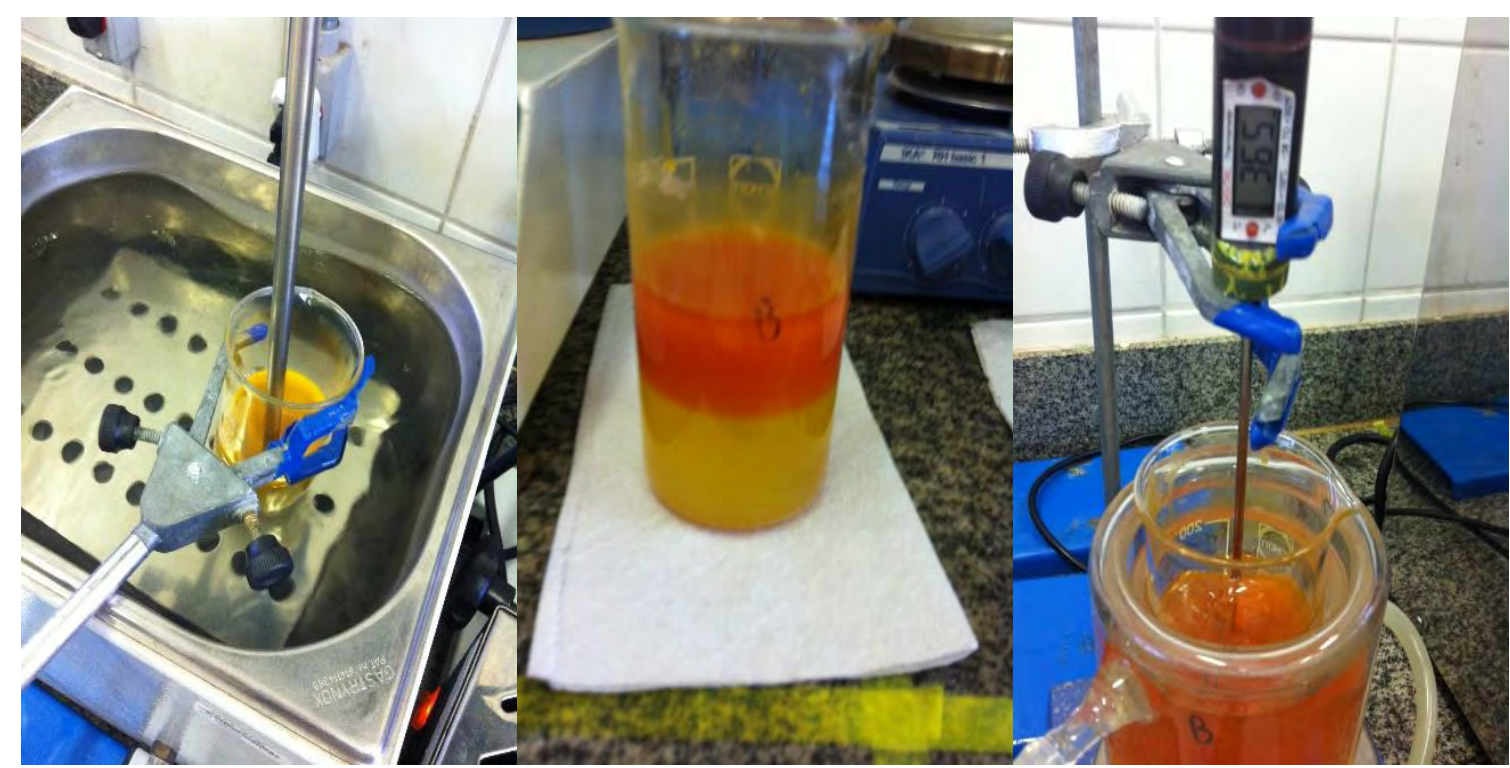

Fonte: Própria autoria.

A Tabela 12 contém as oito formulações de nanoemulsões escolhidas. As oito formulações foram feitas em triplicata totalizando 24 amostras. $\mathrm{O}$ armazenamento das nanoemulsões foi feito sob refrigeração em vidro âmbar até o momento das análises de quantificação de carotenoides totais, avaliação da oxidação lipídica e diâmetro médio hidrodinâmico e distribuição de tamanho de gota. 
Tabela 12 - As proporções utilizadas na nomenclatura se referem a proporção entre carotenoides totais (CT) presentes no óleo de buriti e $\alpha$-tocoferol (AT) (CT:AT). Massa total de amostra: $200 \mathrm{~g}$.

Ingredientes

\begin{tabular}{|c|c|c|c|c|c|}
\hline Nomenclatura & Tween $80(\mathrm{~g})$ & Óleo de buriti (g) & $\mathrm{NaCl}(\mathrm{g})$ & Água deionizada (g) & $\alpha$-tocoferol (mg) \\
\hline 2,5 $\mathrm{M}$ de $\mathrm{NaCl}$ (1: sem $\alpha$-tocoferol) & 40 & 20 & 29,22 & 110,78 & - \\
\hline 2,5 M de $\mathrm{NaCl}(1: 0,5)$ & 40 & 20 & 29,22 & 110,78 & 0,15 \\
\hline 2,5 $\mathrm{M}$ de $\mathrm{NaCl}(1: 1)$ & 40 & 20 & 29,22 & 110,78 & 0,30 \\
\hline $2,5 \mathrm{M}$ de $\mathrm{NaCl}(1: 1,5)$ & 40 & 20 & 29,22 & 110,78 & 0,45 \\
\hline 3,0 M de $\mathrm{NaCl}$ (1: sem $\alpha$-tocoferol) & 40 & 20 & 35,06 & 104,94 & - \\
\hline $3,0 \mathrm{M}$ de $\mathrm{NaCl}(1: 0,5)$ & 40 & 20 & 35,06 & 104,94 & 0,15 \\
\hline $3,0 \mathrm{M}$ de $\mathrm{NaCl}(1: 1)$ & 40 & 20 & 35,06 & 104,94 & 0,30 \\
\hline $3,0 \mathrm{M}$ de $\mathrm{NaCl}(1: 1,5)$ & 40 & 20 & 35,06 & 104,94 & 0,45 \\
\hline
\end{tabular}

Fonte: Própria autoria. 


\subsubsection{Avaliação da estabilidade físico-química das nanoemulsões}

Para a avaliação da estabilidade físico-química das nanoemulsões foram feitas as análises de determinação do diâmetro médio hidrodinâmico e distribuição de tamanho de gota, quantificação de carotenoides totais e avaliação da oxidação lipídica, por um período de armazenamento de 60 dias.

\subsubsection{Distribuição e diâmetro médio de tamanho de gota $\mathrm{e}$ polidispersidade}

O diâmetro médio hidrodinâmico das nanoemulsões foi determinado por espectroscopia de correlação de fótons (PCS, photon corrrelation spectroscopy), utilizando-se o equipamento Zeta Plus (Brookhaven Instruments Company, Holtsville, NY, EUA), com um laser de He-Ne de $627 \mathrm{~nm}$ com um ângulo de incidência de $90^{\circ}$, na temperatura de $25{ }^{\circ} \mathrm{C}$. Antes da análise as amostras foram diluídas com água deionizada ultrapurificada (Millipore, Bedford, MA, EUA) para evitar interferências devido ao espalhamento múltiplo de luz. As análises dos dados foram realizadas pelo software incluído no sistema (90Plus).

\subsubsection{Quantificação dos carotenoides totais}

A quantificação de carotenoides encapsulados foi feita por espectrofotometria, e para tanto foi necessário extraí-los das nanoemulsões. A amostra de nanoemulsão foi diluída (1:50), e a $2 \mathrm{~mL}$ da amostra diluída adicionou-se 1,5 $\mathrm{mL}$ de etanol, com a finalidade de desestabilizar a emulsão, e $1 \mathrm{~mL}$ de metanol contendo hidróxido de potássio foi adicionado para promover a saponificação. Após agitação em vórtex por 10 segundos, o sistema foi deixado sob aquecimento $\left(45^{\circ} \mathrm{C}\right)$ por 30 minutos, com o intuito de aumentar a taxa de reação. Decorrido este tempo, a porção apolar do sistema bifásico, que continha o $\beta$-caroteno foi extraída, e a ela adicionou-se $2 \mathrm{~mL}$ de hexano (contendo $0,01 \%$ de BHT), o sistema resultante foi agitado por 30 segundos no vórtex. Este procedimento de extração e agitação foi repetido 3 vezes. A obtenção da fase orgânica se deu após 10 minutos, e o passo subsequente foi a sua leitura a $450 \mathrm{~nm}$, que é 
o comprimento de onda de absorção máxima do $\beta$-caroteno em hexano. Para a leitura em espectrofotômetro a camada superior foi removida e adicionou-se sulfato de sódio anidro para absorção de possíveis resíduos de água. Este protocolo foi uma adaptação do protocolo apresentado por Cornacchia e Roos (2011).

\subsubsection{Avaliação da oxidação lipídica}

As substâncias reativas do ácido tiobarbitúrico (TBARS) foram usadas para mensurar os produtos resultantes da reação secundária da oxidação lipídica. Primeiramente, foi produzido $100 \mathrm{~mL}$ da solução de TBA - TCA - HCl. Uma solução de TCA com TBA e $\mathrm{HCl}$ foi preparada na seguinte proporção: $15 \mathrm{~g}$ de TCA, 0,33 g de TBA, $1,8 \mathrm{~mL}$ de $12 \mathrm{M} \mathrm{HCl}$ e $83 \mathrm{~mL}$ de água. Adicionou-se a esta solução $3 \mathrm{~mL}$ de etanol contendo $2 \%$ (mássico) de BHT. Misturou-se $2 \mathrm{~mL}$ da solução final obtida com 2 $\mathrm{mL}$ da amostra de nanoemulsão diluída (1:10). Esta mistura foi então aquecida em água fervente $\left(100{ }^{\circ} \mathrm{C}\right)$ por 15 min e resfriada por 10 minutos até temperatura ambiente, e então centrifugada a 1000 rpm por 20 min. Decorrido os 20 minutos, a absorbância do sobrenadante foi medida no comprimento de onda igual a 532 em espectrofotômetro (Biochrom Libra 22S, Holliston, MA, EUA). A concentração de TBARS foi determinada pela curva padrão usando 1,1,3,3 - tetraetoxipropano (TEP). Este protocolo é uma adaptação do procedimento utilizado por Lee et al. (2011).

\subsubsection{Análises estatísticas}

Os dados foram submetidos à análise de variância (ANOVA), e em caso de resultados significativos, foram realizados testes de Tukey para comparação das médias dos tratamentos. O nível de significância utilizado para todos os testes foi de $5 \%$, utilizando-se o software SAS versão 9.3. 


\subsubsection{Incorporação do óleo de buriti nanoemulsionado em bebida} isotônica

\subsubsection{Produção da bebida isotônica sabor tangerina adicionada de}

\section{óleo de buriti nanoemulsionado}

Para a incorporação do óleo de buriti nanoemulsionado em bebida isotônica sabor tangerina foi utilizada a Planta Piloto da Faculdade de Zootecnia e Engenharia de Alimentos (FZEA), Figura 8, instalada no Departamento de Engenharia de Alimentos, no campus da Universidade de São Paulo (USP) de Pirassununga/SP.

Figura 8 - Planta Piloto de Processamento de Alimentos Fluidos da FZEA/USP: (A) recepção (alimentação), (B) trocador de calor a placas isotérmico, (C) tanque para produto pasteurizado, (D) cabina de fluxo de ar unidirecional ISO classe 5 e (E) dosadora gravimétrica semiautomática.

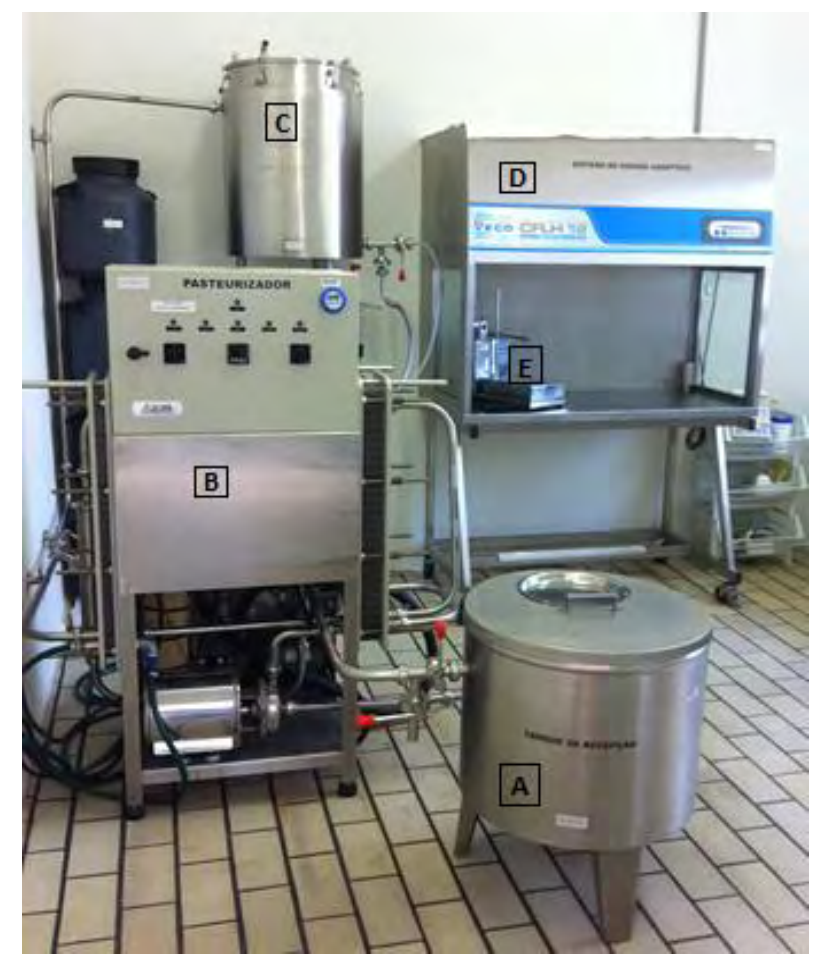

Fonte: Própria autoria.

Foram processadas na Planta Piloto três diferentes formulações de bebida isotônica sabor tangerina (controle, I2 e I3). A controle com 100\% de corante, a I2 com substituição de $25 \%$ do corante por nanoemulsão de óleo de buriti 2,5 $\mathrm{M}$ de $\mathrm{NaCl}$ e a I3 com $30 \%$ de substituição do corante por óleo de buriti nanoemulsionado $3 \mathrm{M}$ de $\mathrm{NaCl}$. 
As formulações foram adaptadas de Petrus e Faria (2005) e encontram-se descritas na Tabela 13.

Tabela 13 - Ingredientes utilizados nas formulações das bebidas isotônicas sabor tangerina.

\begin{tabular}{lrrrr} 
& & \multicolumn{3}{c}{ Formulação } \\
\cline { 4 - 6 } \multicolumn{1}{c}{ Ingredientes } & Unidade & Controle & $\mathrm{I} 2$ & $\mathrm{I} 3$ \\
\hline Sacarose $\left(\mathrm{C}_{12} \mathrm{H}_{22} \mathrm{O}_{11}\right)$ & $(\mathrm{g} / \mathrm{L})$ & 40,000 & 40,000 & 40,000 \\
Glicose anidra $\left(\mathrm{C}_{6} \mathrm{H}_{12} \mathrm{O}_{6}\right)$ & $(\mathrm{g} / \mathrm{L})$ & 10,000 & 10,000 & 10,000 \\
Fosfato de potássio $\left(\mathrm{KH}_{2} \mathrm{PO}_{4}\right)$ & $(\mathrm{g} / \mathrm{L})$ & 0,300 & 0,300 & 0,300 \\
Cloreto de sódio $(\mathrm{NaCl})$ & $(\mathrm{g} / \mathrm{L})$ & 1,050 & - & - \\
Sorbato de potássio $\left(\mathrm{C}_{6} \mathrm{H}_{7} \mathrm{KO}_{2}\right)$ & $(\mathrm{g} / \mathrm{L})$ & 0,050 & 0,050 & 0,050 \\
Citrato de sódio $\left(\mathrm{Na}_{3} \mathrm{C}_{6} \mathrm{H}_{5} \mathrm{O}_{7} * 2 \mathrm{H}_{2} \mathrm{O}\right)$ & $(\mathrm{g} / \mathrm{L})$ & 0,208 & 0,208 & 0,208 \\
Ácido cítrico $\left(\mathrm{C}_{6} \mathrm{H}_{8} \mathrm{O}_{7}\right)$ & $(\mathrm{g} / \mathrm{L})$ & 1,550 & 1,550 & 1,550 \\
Ácido ascórbico $\left(\mathrm{C}_{6} \mathrm{H}_{8} \mathrm{O}_{6}\right)$ & $(\mathrm{g} / \mathrm{L})$ & 0,120 & 0,120 & 0,120 \\
Corante & $(\mathrm{g} / \mathrm{L})$ & 0,013 & 0,010 & 0,090 \\
Aroma de tangerina & $(\mathrm{mL} / \mathrm{L})$ & 2,880 & 2,880 & 2,880 \\
Água deionizada & $(\mathrm{L})$ & 1,000 & 1,000 & 1,000 \\
Nanoemulsões $2,5 \mathrm{M} \mathrm{NaCl}_{\text {Nanoemulsões 3,0 } \mathrm{M} \mathrm{NaCl}}$ & $(\mathrm{mL} / \mathrm{L})$ & - & 10,000 & - \\
Nanoonyyy & $(\mathrm{mL} / \mathrm{L})$ & - & - & 12,000 \\
\hline
\end{tabular}

Fonte: Própria autoria.

Os ingredientes foram misturados no tanque de recepção e em seguida iniciou-se o tratamento térmico da bebida isotônica no trocador de calor a placas elétrico (Sumá Indústria e Comércio Ltda, Campinas, SP, Brasil) com vazão nominal de $300 \mathrm{~L} / \mathrm{h}$. O binômio tempo x temperatura de $80{ }^{\circ} \mathrm{C} / 15 \mathrm{~s}$ utilizado foi adaptado de Petrus e Faria (2005). A bebida pasteurizada e resfriada $\left(10{ }^{\circ} \mathrm{C}\right)$ foi bombeada para o tanque isotérmico hermeticamente fechado. O envase foi realizado utilizando-se uma dosadora gravimétrica semiautomática (Polienva-Movitron, São Paulo, SP, Brasil) instalada no interior de uma cabina de fluxo de ar unidirecional (ISO classe 5) horizontal (Veco do Brasil, Campinas, SP, Brasil). Após o envase, o lote foi armazenado a $7{ }^{\circ} \mathrm{C}$ na ausência de luz.

Na Figura 9 pode-se visualizar o fluxograma de processo utilizado para a produção das três formulações da bebida isotônica. 
Figura 9 - Fluxograma do processamento da bebida isotônica sabor tangerina.

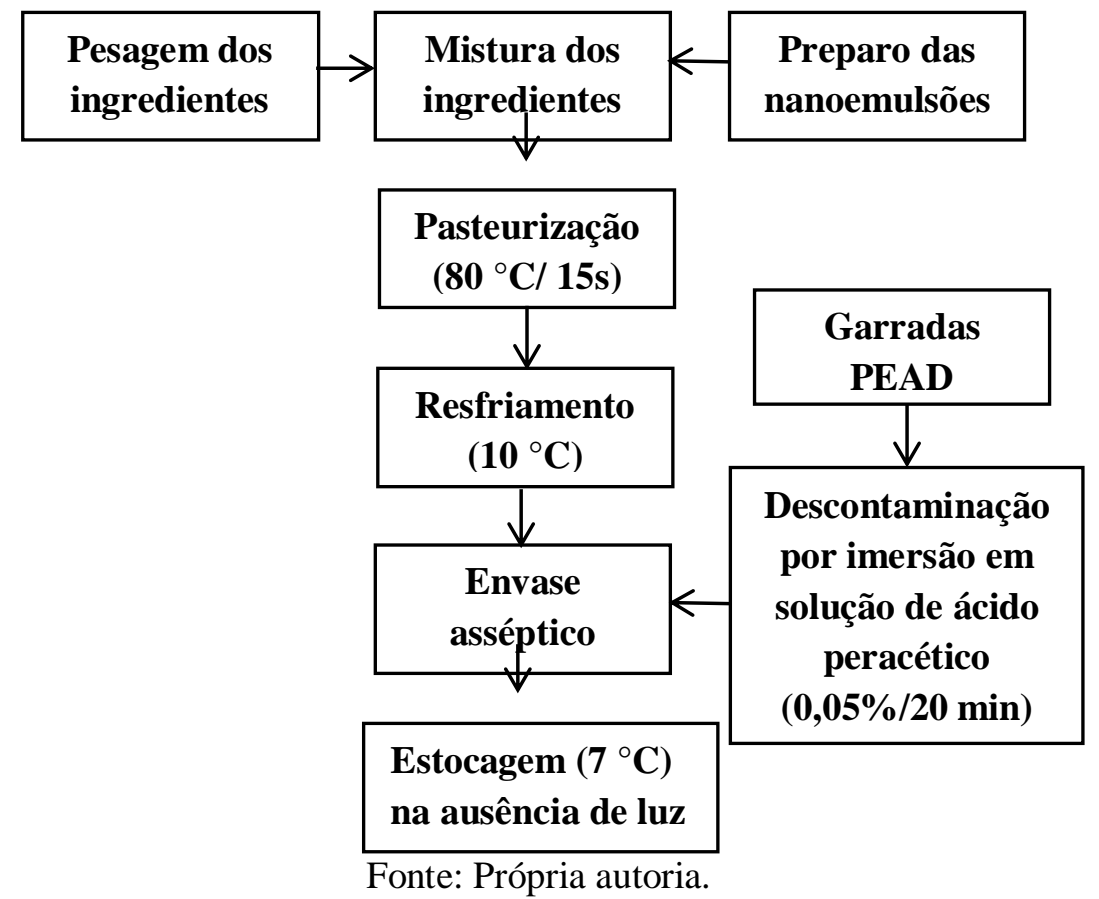

\subsubsection{Caracterização da bebida isotônica sabor tangerina} adicionada de nanoemulsões de óleo de buriti

Os lotes processados foram caracterizados por meio de determinações físico químicas de $\mathrm{pH}$, acidez total titulável, teor de sólidos solúveis, quantificação dos teores de sódio e potássio, osmolalidade e cor instrumental.

\subsection{Medidas de $\mathrm{pH}$}

As medidas de $\mathrm{pH}$ foram feitas em pHmetro (UB-10, Denver Instruments, Bohemia, NY, EUA).

\subsection{Acidez total titulável}

A metodologia utilizada foi adaptada do Manual de Métodos de Análises de Bebidas e Vinagres do Ministério da Agricultura, Pecuária e Abastecimento (MAPA) 
(BRASIL, 1986). O ponto de viragem foi o momento em que a solução apresentou coloração rosácea, conforme mostrado na Figura 10.

Figura 10 - Ponto de viragem acidez titulável: (A) representação do ponto de viragem e (B) aspectos visual da solução antes da análise.

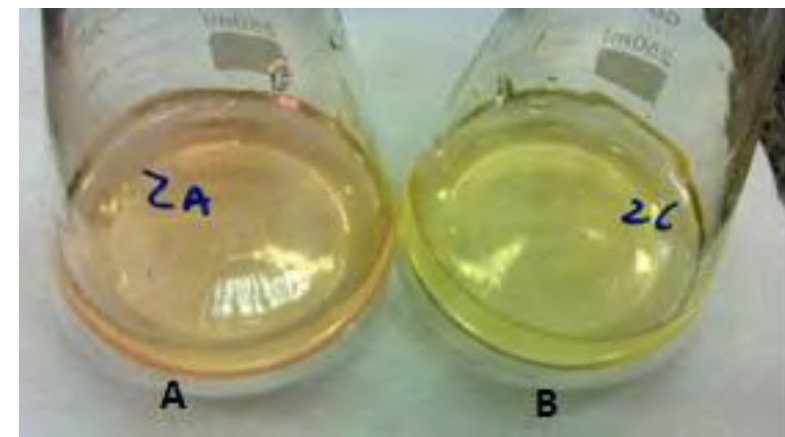

Fonte: Própria autoria.

\subsection{Teor de sólidos solúveis}

O teor de sólidos solúveis (expresso em ${ }^{\circ}$ Brix) foi medido em refratômetro manual com escala Modelo 103 da Biobrix (Equipar - Equipamentos Laboratoriais e Hospitalares, Curitiba, PR, Brasil) a $20^{\circ} \mathrm{C}$. Tal metodologia foi adaptada do Manual de Métodos de Análises de Bebidas e Vinagres do MAPA (BRASIL, 1986).

\subsection{Quantificação dos teores de sódio e potássio}

A quantidade de sódio e potássio foi determinada a partir de cálculos estequiométricos.

\subsection{Osmolalidade}

A osmolalidade da bebida isotônica foi medida em osmômetro de ponto crioscópico (Advanced® Micro-Osmometer Model 3300, Norwood, MA, EUA). 


\subsection{Cor instrumental}

A colorimetria instrumental da bebida isotônica foi realizada em colorímetro (Miniscan MSEZ 1049, Hunterlab, Reston, VA, EUA). Foram determinados os parâmetros $\left(\mathrm{L}^{*}, \mathrm{a}^{*}, \mathrm{~b}^{*}\right)$ e calculados os valores de croma $\left(\mathrm{C}^{*} \mathrm{ab}\right)$. Esta análise foi realizada no Laboratório de Tecnologia de Alimentos, FZEA/USP.

A determinação do parâmetro $C^{*}{ }_{a b}$ foi determinada pela Equação (1):

$$
C *_{a b}=\sqrt{\left(a^{*}\right)^{2}+\left(b^{*}\right)^{2}}
$$

Onde:

C*ab: croma (saturação da cor)

$\mathrm{b}^{*}$ : cromaticidade no eixo variando do amarelo/azul

$\mathrm{a}^{*}$ : cromaticidade no eixo variando do vermelho/verde

A tonalidade do sistema, definida como o ângulo de Hue, foi obtida pela Equação (2):

$$
h_{a b}=\tan ^{-1}\left(\frac{b *}{a *}\right)
$$

onde:

$h_{a b}$ ângulo de Hue (tonalidade definida em graus)

$\mathrm{b}^{*}$ : cromaticidade no eixo variando do amarelo/azul

$\mathrm{a}^{*}$ : cromaticidade no eixo variando do vermelho/verde

Por sua vez, a diferença total de cor (TCD) foi obtida pela Equação (3):

$$
T C D=\sqrt{\left(L^{*}-L_{0} *\right)^{2}+\left(a^{*}-a_{0} *\right)^{2}+\left(b^{*}-b_{0}\right)^{2}}
$$

onde,

$\mathrm{L}_{0} *, \mathrm{a}_{0} *$ e $\mathrm{b}_{0}$ * são parâmetros obtidos no dia zero de estocagem.

$L^{*}, a^{*}$ e b* são parâmetros obtidos nos dias de amostragem. 


\subsubsection{Análises microbiológicas}

Análises de mesófilos aeróbios totais da bebida isotônica recém-processada foram realizadas para quantificar a população microbiana remanescente no produto pasteurizado, utilizando-se a metodologia descrita por Silva et al. (2010).

A contagem de micro-organismos mesófilos foi feita, em triplicata, diluindo-se $25 \mathrm{~mL}$ de bebida isotônica pasteurizada em $225 \mathrm{~mL}$ água peptonada $0,1 \%$ esterilizada $\left(121{ }^{\circ} \mathrm{C} / 15 \mathrm{~min}\right) . \mathrm{O}$ plaqueamento foi feito em duplicata espalhando $0,1 \mathrm{~mL}$ de cada uma das diluições em meio de cultura PCA (plate count agar) esterilizado $\left(121^{\circ} \mathrm{C} / 15\right.$ min) sob condições assépticas.

Após esta etapa as placas foram incubadas a $35 \pm 1{ }^{\circ} \mathrm{C}$ em estufa BOD por 48 horas. Após este período, foi feita a contagem do número de unidades formadoras de colônia nas placas.

A contagem de micro-organismos psicrotróficos obedeceu a mesma metodologia citada acima. O plaqueamento da diluição foi feito espalhando $0,1 \mathrm{~mL}$ do diluído sobre a superfície do meio de cultura em condições assépticas. As análises de bactérias psicrotróficas foram feitas em meio de cultura ágar dicloran rosa de bengala cloranfenicol (DRBC). Os meios de cultura foram esterilizados a $121^{\circ} \mathrm{C} / 15 \mathrm{~min}$.

Após esta etapa as placas foram incubadas a $17 \pm 1^{\circ} \mathrm{C}$ por 16 horas e a $7 \pm 1{ }^{\circ} \mathrm{C}$ por 48 horas em estufa BOD. Após este período, foi feita a contagem do número de unidades formadoras de colônia nas placas.

Os testes microbiológicos foram conduzidos no Laboratório de Bioprocessos do Departamento de Engenharia de Alimentos da Faculdade de Zootecnia e Engenharia de Alimentos - FZEA/ USP.

\subsubsection{Análise sensorial}

\subsubsection{Teste de diferença de controle}

Inicialmente foi feito um teste de diferença de controle a fim de verificar se havia diferença significativa entre as formulações. Para tal utilizou-se a metodologia descrita por Meilgaard et al. (1999). Uma equipe de 100 provadores julgou o produto. Foi oferecido a cada provador uma amostra padrão (controle) e mais duas amostras. Os provadores avaliaram o grau de diferença dos atributos cor, aroma e sabor com relação 
ao padrão (controle) utilizando-se escala estruturada de 5 pontos, na qual: 1- nenhuma diferença com o padrão, 2- ligeiramente diferente do padrão, 3- moderadamente diferente do padrão, 4- muito diferente do padrão e 5- extremamente diferente do padrão. Cada amostra foi codificada com números aleatórios de três dígitos. Antes da análise foi fornecido aos provadores o termo de consentimento livre e esclarecido (Apêndice A), o qual foi lido e assinado pelos mesmos antes da realização das análises. Juntamente com as amostras foi fornecido uma ficha de avaliação (Apêndice B).

\subsubsection{Teste de escala hedônica}

Um teste de aceitação também foi feito por meio de uma escala hedônica de 9 pontos a fim de verificar a aceitação da bebida. Uma equipe de 100 provadores julgou o produto quanto aos atributos cor, aroma e sabor.

Antes da análise foi fornecido aos provadores o termo de consentimento livre e esclarecido (mostrado no Apêndice C), o qual foi lido e assinado pelos mesmos antes da realização das análises. Um teste de intenção de compra complementou a análise. Juntamente com as amostras foi fornecido uma ficha de avaliação (Apêndice D).

Ambas as análises sensoriais da bebida isotônica contendo óleo de buriti nanoemulsionado foram realizadas no Laboratório de Análise Sensorial da FZEA, no Departamento de Engenharia de Alimentos da FZEA/USP, em cabines individuais com luz fluorescente branca. A bebida isotônica foi servida em copos plásticos descartáveis de $80 \mathrm{~mL}$ devidamente codificados. Entre as amostras foram servidos aos provadores água e biscoito cream cracker, para evitar qualquer tipo de interferência entre uma amostra e outra. O presente projeto obteve parecer favorável (995.450) do Comitê de Ética em Pesquisa da Escola de Enfermagem da Universidade de São Paulo (EEUSP) para realização da análise sensorial.

\subsubsection{Análises estatísticas}

Os dados foram submetidos à análise de variância (ANOVA), e, em caso de resultados significativos, foram realizados testes de Tukey para comparação das médias dos tratamentos. O nível de significância utilizado para todos os testes foi de 5\%, utilizando-se o software SAS versão 9.3. 


\section{RESULTADOS E DISCUSSÃO}

\subsection{DETERMINAÇÃO DAS CONDIÇÕES DE PROCESSO PARA PRODUÇÃO DE ÓLEO DE BURITI NANOEMULSIONADO PELO MÉTODO PIT}

Para determinação das condições de processo para produção de óleo de buriti nanoemulsionado diversos parâmetros tais como razão entre tensoativo e óleo (SOR surfactant oil ratio), diferentes porcentagens mássicas de tensoativo e óleo, número de ciclos, taxa de resfriamento e aquecimento, velocidade de agitação e tipo de banho (areia e água) foram testados nos experimentos. Os resultados qualitativos obtidos variando-se o parâmetro SOR são mostrados na Tabela 14 e a Figura 11 mostra a diferença entre a execução do processo com 1 ou 2 ciclos. Como se pode observar, ao se realizar dois ciclos a nanoemulsão resultante se mostra mais translúcida, uma vez que o diâmetro médio hidrodinâmico de gota é menor.

Tabela 14 - Resultados qualitativos dos testes para as nanoemulsões produzidas com o tensoativo polisorbato $80, \mathrm{NaCl}$, água deionizada e óleo de buriti $(\mathrm{T}=$ tensoativo, $\mathrm{O}=$ óleo e $\mathrm{SOR}=$ razão entre $\mathrm{T}$ e $\mathrm{O})$.

\begin{tabular}{cccc}
\hline SOR & $\%$ mássica (T:O) & {$[\mathrm{NaCl}]$} & Aspecto visual \\
\hline 1,5 & $15: 10$ & - & Separação de fases \\
1,5 & $15: 10$ & $2,5 \mathrm{M}$ & Separação de fases \\
2,0 & $20: 10$ & - & Separação de fases \\
2,0 & $20: 10$ & $2,5 \mathrm{M}$ & Estáveis \\
\hline
\end{tabular}

Fonte: Própria autoria.

Como a nanoemulsão contendo 2,5 $\mathrm{M}$ de $\mathrm{NaCl}$ e $\mathrm{SOR}=2,0$ se mostrou estável testes posteriores, mantendo este SOR e variando-se as porcentagens mássicas de tensoativo e óleo e a concentração de $\mathrm{NaCl}$, foram feitos. Tais resultados são mostrados na Tabela 15. 
Figura 11 - Aspectos das dispersões : (A) nanoemulsão após o primeiro ciclo de aquecimento e resfriamento e (B) nanoemulsão após o segundo ciclo de aquecimento e resfriamento.

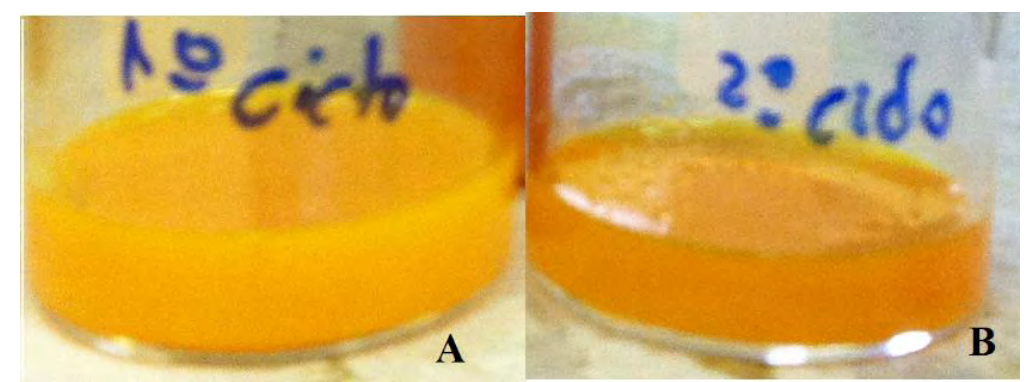

Fonte: Própria autoria.

Tabela 15 - Resultados qualitativos dos testes para as nanoemulsões produzidas com o tensoativo Tween 80, NaCl, água deionizada e óleo de buriti para $\mathrm{SOR}=2,0(\mathrm{~T}=$ tensoativo e $\mathrm{O}$ = óleo).

\begin{tabular}{ccc}
\hline \% mássica (T:O) & {$[\mathrm{NaCl}]$} & Aspecto visual \\
\hline $10: 5$ & $2,5 \mathrm{M}$ & Separação de fases \\
$16: 8$ & $2,5 \mathrm{M}$ & Separação de fases \\
$18: 9$ & $2,5 \mathrm{M}$ & Estáveis \\
$20: 10$ & $2,5 \mathrm{M}$ & Estáveis \\
$22: 11$ & $2,5 \mathrm{M}$ & Estáveis \\
$20: 10$ & - & Separação de fases \\
$20: 10$ & $1,0 \mathrm{M}$ & Separação de fases \\
$20: 10$ & $2,0 \mathrm{M}$ & Separação de fases \\
$20: 10$ & $3,0 \mathrm{M}$ & Estáveis \\
$20: 10$ & $4,0 \mathrm{M}$ & Estáveis \\
$20: 10$ & $5,0 \mathrm{M}$ & Estáveis \\
\hline $30: 15$ & - & Dificuldade na produção: devido à alta \\
$30: 15$ & $2,5 \mathrm{M}$ & concentração de tensoativo a mistura \\
$30: 15$ & $3,0 \mathrm{M}$ & é muito viscosa, o que impossibilitou \\
$30: 15$ & $5,0 \mathrm{M}$ & uma agitação magnética adequada \\
$40: 20$ & $2,5 \mathrm{M}$ & \\
\hline
\end{tabular}

Fonte: Própria autoria.

Pode-se observar que foi necessário a adição de altas concentrações de $\mathrm{NaCl}$ para que as nanoemulsões se mantivessem estáveis, e tal fato se deve provavelmente à capacidade do sal de auxiliar no processo de desidratação do Tween 80 . Conforme já foi mencionado para produção de nanoemulsões pelo método PIT ocorre uma etapa de 
aquecimento, na qual como resultado a solubilidade do tensoativo se altera progressivamente uma vez que os grupos etoxilados gradualmente se desidratam tornando o tensoativo gradualmente mais hidrofóbico (ANTON; VANDAMME, 2009). Acredita-se que a adição de sal atue justamente nesta etapa da produção das nanoemulsões.

Com base nos resultados qualitativos obtidos optou-se pela utilização de nanoemulsões com SOR = 2 na porcentagem mássica de 20 de tensoativo para 10 de óleo.

\subsection{DETERMINAÇÃO DA TEMPERATURA DE INVERSÃO DE FASES}

Para determinação da temperatura de inversão de fases $\left(T_{P I T}\right)$, curvas de condutividade foram feitas medindo-se os parâmetros condutividade e tempo simultaneamente à produção das nanoemulsões. Para a obtenção dessas curvas o sistema foi aquecido até aproximadamente $60{ }^{\circ} \mathrm{C}$ e resfriado até $20{ }^{\circ} \mathrm{C}$, numa taxa de aquecimento e resfriamento de respectivamente $4{ }^{\circ} \mathrm{C} / \mathrm{min}$ e $11{ }^{\circ} \mathrm{C} / \mathrm{min}$. Tais curvas podem ser visualizadas na Figura 12. As curvas foram feitas com formulações de diferentes concentrações de sal: 2,5 M; $3 \mathrm{M} ; 3,5 \mathrm{M}$ e $4 \mathrm{M}$ de $\mathrm{NaCl}$ para um $\mathrm{SOR}=2,0$ na porcentagem mássica de 20 de tensoativo para 10 de óleo.

Segundo Izquierdo et al. (2002), Spernath e Magdassi (2007) a temperatura de inversão de fase é obtida através da média da temperatura entre a maior e a menor condutividade. Analisando a Figura 12, pode-se perceber um declínio da condutividade a partir de certa temperatura, portanto, com base nesses gráficos pôde-se determinar a temperatura de inversão de fase para as nanoemulsões, conforme mostrado na Tabela 16. 
Figura 12 - Curva de condutividade da nanoemulsão durante o aquecimento (A) 2,5 M de $\mathrm{NaCl}$, (B) $3 \mathrm{M}$ de $\mathrm{NaCl}$, (C) 3,5 $\mathrm{M}$ de $\mathrm{NaCl}$ e (D) $4 \mathrm{M}$ de $\mathrm{NaCl}$.
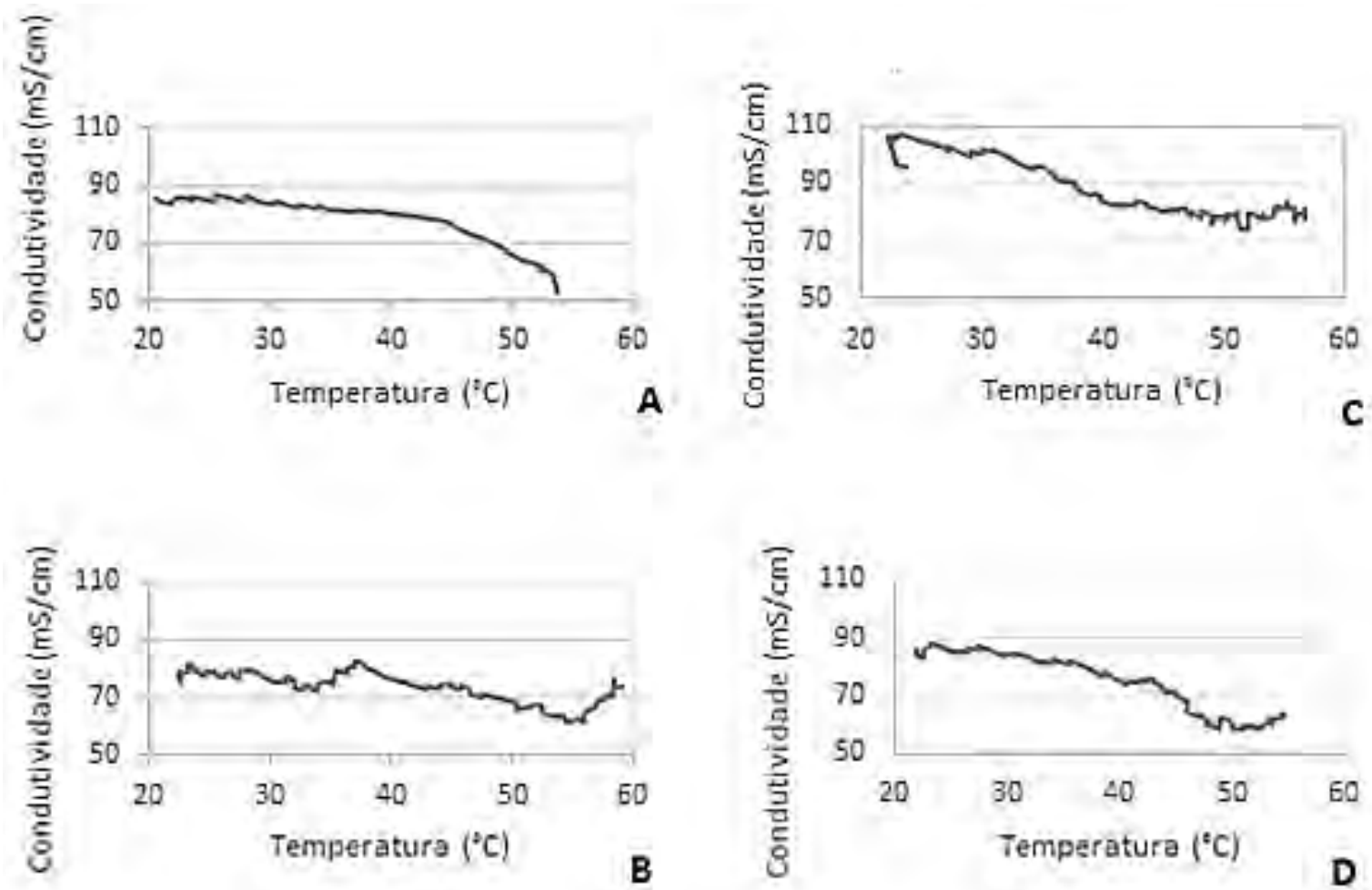

Fonte: Própria autoria.

Tabela 16 - Determinação da temperatura de inversão de fases.

\begin{tabular}{lccc}
\cline { 2 - 4 } & \multicolumn{3}{c}{ Temperaturas $\left({ }^{\circ} \mathrm{C}\right)$} \\
\hline Nanoemulsão & T $_{\text {Maior Condutividade }}$ & $\mathrm{T}_{\text {Menor Condutividade }}$ & $\mathrm{T}_{\text {PIT }}$ \\
\hline $2,5 \mathrm{M} \mathrm{de} \mathrm{NaCl}$ & 27,9 & 58,7 & 43,3 \\
$3,0 \mathrm{M} \mathrm{de} \mathrm{NaCl}$ & 28,2 & 55,9 & 42,1 \\
$3,5 \mathrm{M} \mathrm{de} \mathrm{NaCl}$ & 29,9 & 51,9 & 40,9 \\
$4,0 \mathrm{M} \mathrm{de} \mathrm{NaCl}$ & 30,6 & 50,1 & 40,4 \\
\hline
\end{tabular}

Fonte: Própria autoria.

Diversos estudos na literatura comprovam que a adição de sal no sistema provoca o abaixamento da TPIT. Por exemplo, Heurtaut et al. (2002) e Mei et al. (2011) fizeram experimentos alterando a salinidade do sistema e reportaram o abaixamento na $\mathrm{T}_{\mathrm{PIT}}$.

Heurtaut et al. (2002) produziram nanoemulsões pelo método PIT, utilizando os tensoativos Lipoid (lecitina de soja) e Solutol (tensoativo não-iônico). Os autores observaram o comportamento das curvas de condutividade em diferentes concentrações de $\mathrm{NaCl}, 1 \%, 2 \%, 3 \%$ e $5 \%$ (w/w). Os resultados mostraram que a salinidade do meio 
alterou claramente zona de inversão de fases (phase inversion zone, ou PIZ). A PIZ, também conhecida como zona de inversão de fase compreende a área na qual a condutividade tem um declínio até o momento que a mesma volta a subir. Os autores reportaram que quanto maior a concentração de sal no sistema mais a PIZ é deslocada de temperaturas maiores para menores.

Ao produzir nanoemulsões pelo método PIT com uma mistura de tensoativos (Tween 80 e Span 80) e solução aquosa 0,2 M de $\mathrm{NaBr}$ (em substituição a água pura), Mei et al. (2011) relataram que a $\mathrm{T}_{\text {PIT }}$ de todas as amostras diminuíram com o aumento de sal. Os autores afirmam que tal fato acontece devido ao efeito salting-out do $\mathrm{Na}^{+} \mathrm{e}$ do $\mathrm{Br}^{+}$, o que leva a uma mudança na curvatura espontânea do tensoativo na interface óleo/água para valores mais negativos.

Com base nos dados obtidos no presente estudo pode-se afirmar que a salinidade do sistema contribuiu efetivamente para o abaixamento da temperatura de transição de fases no método PIT e também que tais resultados estão em conformidade com o que já foi reportado em diferentes estudos.

$\mathrm{Na}$ presença de sal, juntamente com o abaixamento da temperatura de transição de fase ocorre a diminuição do cloud point do tensoativo. O cloud point, também conhecido como ponto de nuvem, é o ponto no qual o tensoativo se torna turvo. Esse ponto acontece quando o tensoativo é aquecido acima de uma determinada temperatura. Com o aumento da temperatura, o grupo hidrofílico do tensoativo se desidrata gradualmente o que causa uma agregação das moléculas do tensoativo. Esses agregados se tornam tão grandes que dispersam a luz, motivo pelo qual a solução tem aparência turva (McCLEMENTS, 2008). O ponto de nuvem do tensoativo Tween 80 é de $65^{\circ} \mathrm{C}$ (SIGMA-ALDRICH, 2015), porém como pode-se observar, as temperaturas de transição de fase mostradas na Tabela 16 são inferiores a $65^{\circ} \mathrm{C}$, o que indica que a presença de sal provocou uma diminuição considerável do ponto de nuvem do tensoativo. 


\subsection{PRODUÇÃO DE ÓlEO DE BURITI NANOEMULSIONADO PELO MÉTODO DA TEMPERATURA DE INVERSÃO DE FASE}

Para o estudo da estabilidade físico-química as formulações das nanoemulsões com $2 \mathrm{M}, 3,5 \mathrm{M}$ e $4 \mathrm{M}$ de $\mathrm{NaCl}$ foram descartadas. A formulação produzida com $2 \mathrm{M}$ de $\mathrm{NaCl}$, conforme já foi dito, apresentou separação de fase, e as formulações com 3,5 $\mathrm{M}$ e $4 \mathrm{M}$ de $\mathrm{NaCl}$ apresentaram após algumas horas intensa separação do sal, conforme ilustrado na Figura 13. A separação do sal indica que possivelmente grande parte do sal adicionado foi utilizado apenas para auxiliar na desidratação do tensoativo, não sendo necessariamente utilizado para a manutenção das nanoemulsões em sua forma estável ao longo do armazenamento.

Figura 13 - Aspecto visual do sal decantado na nanoemulsão produzida com 3,5 M NaCl.

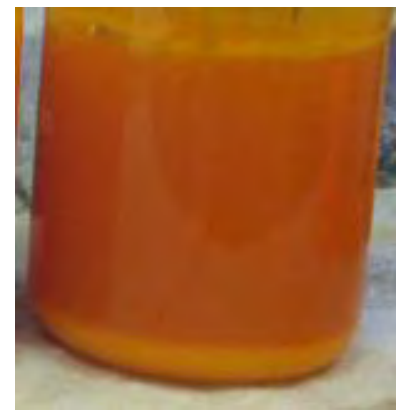

Fonte: Própria autoria.

Portanto, para o presente estudo foram desenvolvidas formulações somente com 2,5 $\mathrm{M}$ e $3 \mathrm{M}$ de $\mathrm{NaCl}$. No total foram produzidas oito formulações de nanoemulsões, sendo quatro formulações com 2,5 $\mathrm{M}$ de $\mathrm{NaCl}$ (variando-se a proporção carotenoides totais (CT): $\alpha$-tocoferol (AT) em 1: sem $\alpha$-tocoferol, 1:05, 1:1 e 1:1,5) e quatro com $3 \mathrm{M}$ de $\mathrm{NaCl}$, também variando-se as quantidades de CT:AT nas mesmas proporções. Para avaliação da estabilidade das nanoemulsões somente 6 formulações foram estudadas pois as que continham a proporção de $(1: 1,5)$ de CT:AT apresentaram separação de fase nas primeiras 24 horas após serem produzidas, como pode-se observar na Figura 14. 
Figura 14 - Aspecto visual das dispersões de nanoemulsões contendo 2,5 e 3,0 M de $\mathrm{NaCl}$ na proporção $(1: 1,5)$ durante o primeiro dia após a produção.

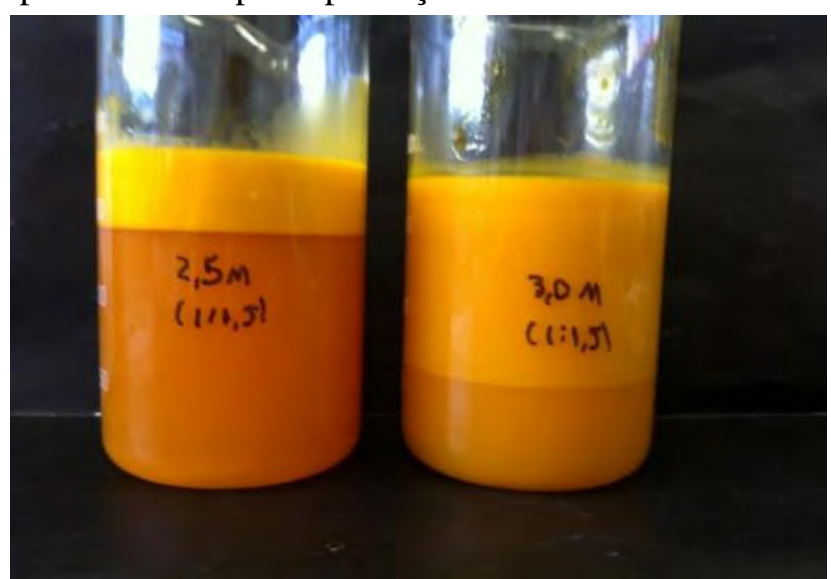

Fonte: Própria autoria.

A quantidade de $\alpha$-tocoferol foi calculada com base na concentração de $1,5 \mathrm{~g} / \mathrm{L}$ de carotenoides totais, quantificados como beta-caroteno, pois esta foi a quantidade de carotenoide total encontrada em estudos preliminares no óleo de buriti nanoemulsionado produzido no presente estudo.

\subsection{AVALIAÇÃ̃O DA ESTABILIDADE FÍSICO-QUíMICA DAS NANOEMULSÕES}

Todas as nanoemulsões produzidas foram monitoradas ao longo do tempo de estocagem, por 60 dias, sob refrigeração, em relação ao diâmetro médio hidrodinâmico e à distribuição de tamanho de gota, polidispersidade, quantificação dos carotenoides totais e avaliação da oxidação lipídica.

\subsubsection{Distribuição e diâmetro médio de tamanho de gota e polidispersidade}

As Figura 15 e 16 mostram as curvas de distribuição de tamanho de gota das nanoemulsões produzidas com óleo de buriti, em função do período de estocagem, sob refrigeração para as nanoemulsões contendo 2,5 e $3 \mathrm{M}$ de $\mathrm{NaCl}$ respectivamente. As curvas foram analisadas segundo o parâmetro intensidade e expresso em porcentagem de gotas.

Conforme pode ser observar, as nanoemulsões produzidas, tanto com 2,5 $\mathrm{M}$ de $\mathrm{NaCl}$ quanto com $3 \mathrm{M}$ de $\mathrm{NaCl}$, apresentaram distribuições bimodais, ou seja, duas 
populações distintas de gotas. Para as nanoemulsões contendo $2,5 \mathrm{M}$ de $\mathrm{NaCl}$ a primeira população concentrou-se por volta de 30 a $40 \mathrm{~nm}$ e a segunda, em torno de $160 \mathrm{~nm}$, para as três diferentes formulações. Já para as nanoemulsões contendo $3 \mathrm{M}$ de $\mathrm{NaCl}$ a primeira população oscilou entre 20 a $50 \mathrm{~nm}$ e a segunda, em torno de $80 \mathrm{~nm}$, também para as diferentes três diferentes formulações.

Figura 15 - Curvas de distribuição de tamanho de gota das nanoemulsões produzidas com 2,5 M de NaCl: (A) proporção CT:AT de (1: sem $\alpha$-tocoferol) e (B) proporção CT:AT de $(1: 0,5)$ e (C) proporção CT:AT de (1:1).

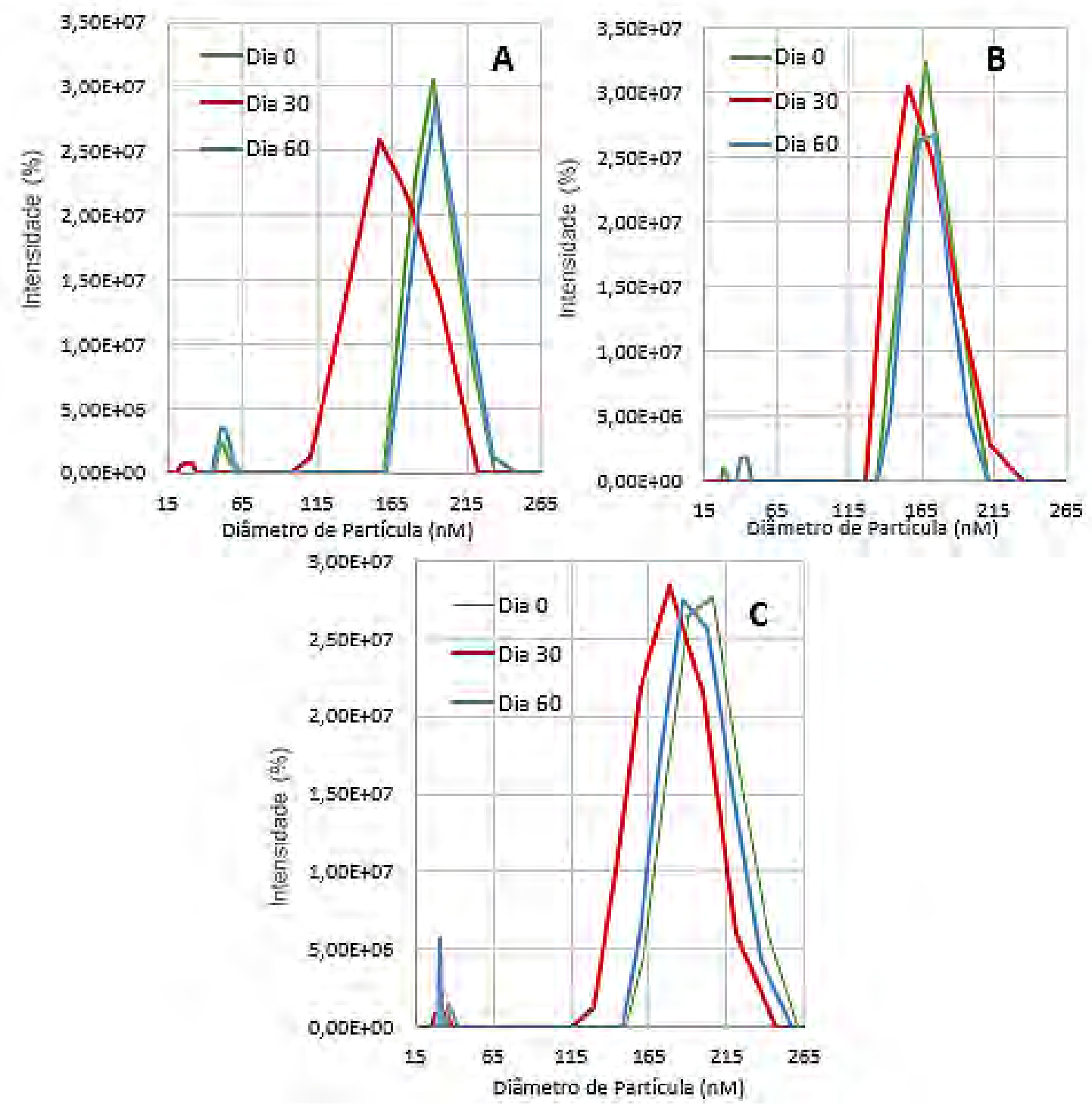

Fonte: Própria autoria. 
Figura 16 - Curvas de distribuição de tamanho de gota das nanoemulsões produzidas com $3 \mathrm{M}$ de NaCl. (A) Proporção CT:AT de (1: sem $\alpha$-tocoferol) e (B) proporção CT:AT de (1:0,5) e (C) Proporção CT:AT de (1:1).

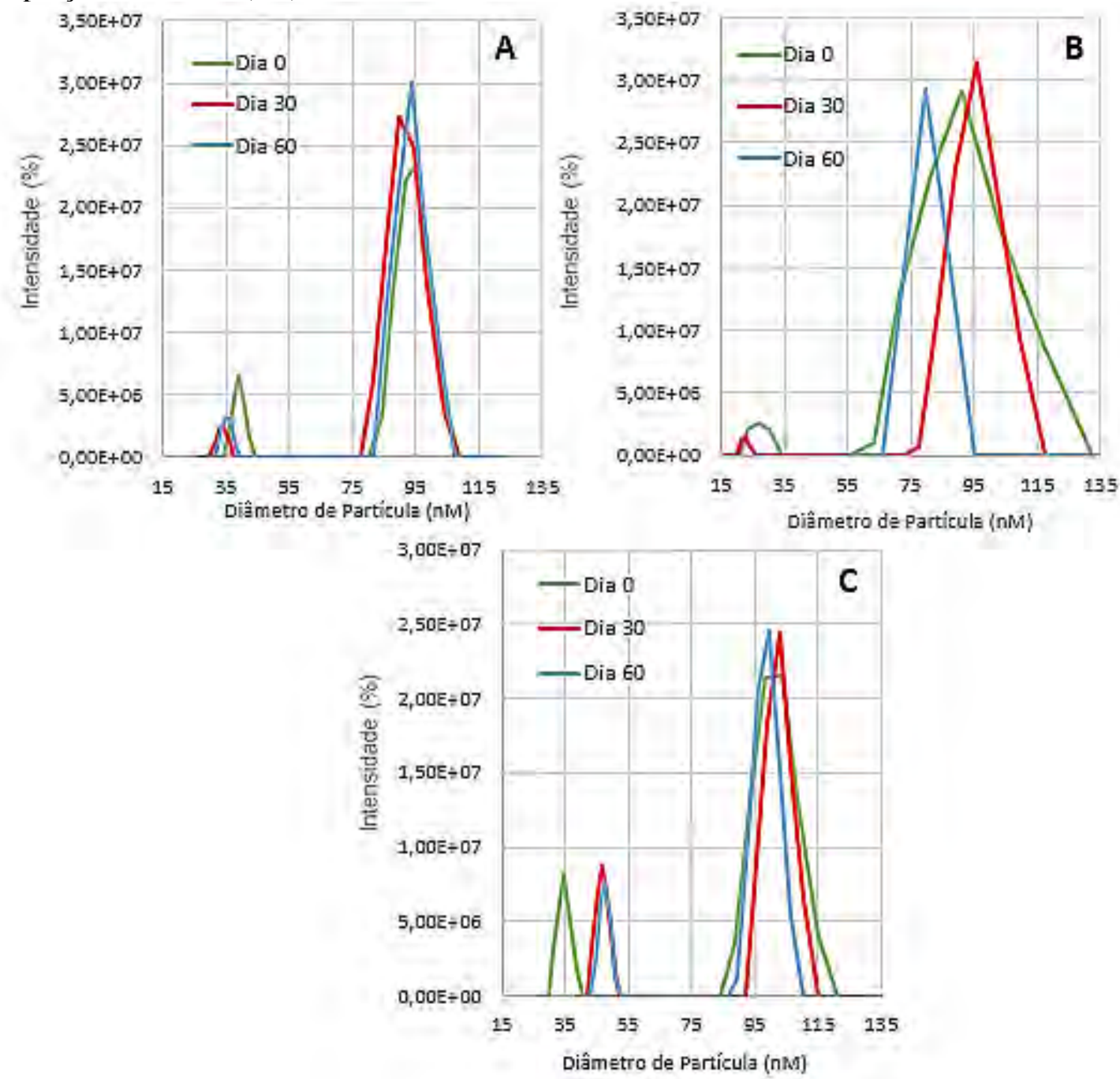

Fonte: Própria autoria.

A partir destes resultados é possível afirmar que todas as amostras, independentemente da concentração de $\mathrm{NaCl}$ ou da presença de alfa-tocoferol, se mostraram extremamente estáveis durante o tempo de estocagem, em relação a distribuição do tamanho de partícula. Nas Tabela 17 e 18 é possível visualizar o diâmetro médio hidrodinâmico das formulações de nanoemulsões produzidas com 2,5 $\mathrm{M}$ e de $3 \mathrm{M}$ de $\mathrm{NaCl}$, respectivamente, bem como o tratamento estatístico dos resultados. 
Tabela 17 - Diâmetros hidrodinâmicos médios de gota das nanoemulsões produzidas com 2,5 $\mathrm{M}$ de $\mathrm{NaCl}$.

Diâmetro hidrodinâmico médio (nm)

Tempo de estocagem (dias) $\quad(1:$ sem $\alpha$-tocoferol $) \quad(1: 0,5)$

\begin{tabular}{rrrr}
\hline 0 & $169^{\mathrm{A}, \mathrm{a}} \pm 11,2$ & $166^{\mathrm{A}, \mathrm{a}} \pm 16,0$ & $178^{\mathrm{A}, \mathrm{B}, \mathrm{a}} \pm 3,2$ \\
3 & $170^{\mathrm{A}, \mathrm{a}} \pm 8,3$ & $178^{\mathrm{A}, \mathrm{a}} \pm 10,5$ & $174^{\mathrm{A}, \mathrm{B}, \mathrm{a}} \pm 5,9$ \\
7 & $169^{\mathrm{A}, \mathrm{a}} \pm 7,0$ & $163^{\mathrm{A}, \mathrm{a}} \pm 12,6$ & $174^{\mathrm{A}, \mathrm{B}, \mathrm{a}} \pm 7,5$ \\
15 & $168^{\mathrm{A}, \mathrm{a}} \pm 13,1$ & $161^{\mathrm{A}, \mathrm{a}} \pm 10,4$ & $179^{\mathrm{A}, \mathrm{a}} \pm 2,9$ \\
30 & $165^{\mathrm{A}, \mathrm{a}} \pm 7,3$ & $163^{\mathrm{A}, \mathrm{a}} \pm 19,2$ & $175^{\mathrm{A}, \mathrm{B}, \mathrm{a}} \pm 4,3$ \\
45 & $171^{\mathrm{A}, \mathrm{a}} \pm 9,9$ & $164^{\mathrm{A}, \mathrm{a}} \pm 16,7$ & $167^{\mathrm{B}, \mathrm{a}} \pm 5,5$ \\
60 & $165^{\mathrm{A}, \mathrm{a}} \pm 11,1$ & $158^{\mathrm{A}, \mathrm{a}} \pm 8,9$ & $174^{\mathrm{A}, \mathrm{B}, \mathrm{a}} \pm 1,7$
\end{tabular}

Médias de resultados seguidas por letras maiúsculas distintas na mesma coluna apresentam diferença estatística significativa a $\mathrm{p}<0,05$ pelo teste de Tukey. Médias de resultados seguidas por letras minúsculas distintas na mesma linha não apresentam diferença estatística significativa a $p>0,05$ pelo teste de Tukey.

Fonte: Própria autoria.

Tabela 18 - Diâmetros hidrodinâmicos médios de gota das nanoemulsões produzidas com $3 \mathrm{M}$ de $\mathrm{NaCl}$.

Diâmetro hidrodinâmico médio (nm)

\begin{tabular}{crcc} 
Tempo de estocagem (dias) & (1: sem $\alpha$-tocoferol) \\
\hline 0 & $75^{\mathrm{C}, \mathrm{a}} \pm 3,4$ & $75^{\mathrm{B}, \mathrm{a}} \pm 2,2$ & $73^{\mathrm{B}, \mathrm{a}} \pm 1,6$ \\
3 & $80^{\mathrm{B}, \mathrm{a}} \pm 3,0$ & $82^{\mathrm{A}, \mathrm{a}} \pm 2,0$ & $80^{\mathrm{A}, \mathrm{a}} \pm 2,0$ \\
7 & $82^{\mathrm{A}, \mathrm{B}, \mathrm{a}} \pm 1,9$ & $83^{\mathrm{A}, \mathrm{a}} \pm 5,1$ & $83^{\mathrm{A}, \mathrm{a}} \pm 2,2$ \\
15 & $82^{\mathrm{A}, \mathrm{B}, \mathrm{a}} \pm 2,5$ & $84^{\mathrm{A}, \mathrm{a}} \pm 2,1$ & $81^{\mathrm{A}, \mathrm{a}} \pm 1,2$ \\
30 & $82^{\mathrm{A}, \mathrm{B}, \mathrm{a}} \pm 1,6$ & $86^{\mathrm{A}, \mathrm{a}} \pm 2,1$ & $82^{\mathrm{A}, \mathrm{a}} \pm 3,0$ \\
45 & $83^{\mathrm{A}, \mathrm{a}} \pm 1,1$ & $85^{\mathrm{A}, \mathrm{a}} \pm 2,4$ & $82^{\mathrm{A}, \mathrm{a}} \pm 2,8$ \\
60 & $82^{\mathrm{A}, \mathrm{B}, \mathrm{a}} \pm 1,8$ & $84^{\mathrm{A}, \mathrm{a}} \pm 2,0$ & $83^{\mathrm{A}, \mathrm{a}} \pm 2,3$
\end{tabular}

Médias de resultados seguidas por letras maiúsculas distintas na mesma coluna apresentam diferença estatística significativa a $\mathrm{p}<0,05$ pelo teste de Tukey. Médias de resultados seguidas por letras minúsculas distintas na mesma linha não apresentam diferença estatística significativa a $p>0,05$ pelo teste de Tukey.

Fonte: Própria autoria.

A análise estatística mostrou que para a nanoemulsão contendo $2,5 \mathrm{M}$ de $\mathrm{NaCl}$, nas proporções de (1: sem $\alpha$-tocoferol) e (1:0,5) não houve diferença significativa $(p>0,05)$ entre os 60 dias de estocagem pelo teste de Tukey. Os resultados mostraram 
ainda que, para um mesmo dia de amostragem, não houve diferença significativa entre as três formulações produzidas, a ( $p>0,05)$ pelo teste de Tukey.

Para as nanoemulsões produzidas com $3 \mathrm{M}$ de $\mathrm{NaCl}$ a análise estatística mostrou que para todas as nanoemulsões houve diferença significativa $(\mathrm{p}<0,05)$ pelo teste de Tukey entre os 60 dias de estocagem. Entretanto, para as nanoemulsões (1:0,5) e (1:1) a diferença foi somente no primeiro dia de estocagem. Os resultados mostraram ainda que para um mesmo dia não houve diferença significativa entre as três formulações produzidas $(\mathrm{p}>0,05)$ pelo teste de Tukey.

Apesar de alguns resultados terem apresentado diferença significativa $(p<0,05)$ pelo teste de Tukey o aumento no diâmetro médio de partícula entre o dia zero e o dia 60 para as seis formulações estudadas não foi maior do que $10 \mathrm{~nm}$. No entanto, observou-se que o desvio padrão para as formulações produzidas com 2,5 M de $\mathrm{NaCl}$ na proporção (1: sem $\alpha$-tocoferol) e (1:0,5) foram relativamente altos comparados com as demais formulações. Esse desvio está relacionado com as diferentes médias de leituras para cada triplicada avaliada, que variaram de 158 a $183 \mathrm{~nm}$ para a formulação (1: sem $\alpha$-tocoferol) e de 145 a $187 \mathrm{~nm}$ para a formulação $(1: 0,5)$.

Como se pode observar, as nanoemulsões produzidas com $3 \mathrm{M}$ de $\mathrm{NaCl}$ apresentaram diâmetro hidrodinâmico médio de gota bem inferiores aos diâmetros das nanoemulsões produzidas com 2,5 M de $\mathrm{NaCl}$. É sabido que quanto menor o diâmetro de partícula, mais translúcida será a nanoemulsão. Segundo Mason et al. (2006) as nanoemulsões são muito menores que os comprimentos de onda visíveis, e por esse motivo as mesmas são opticamente translúcidas. Já as emulsões na escala micrométrica exibem forte espalhamento múltiplo de luz visível, e, como resultado apresentam um aspecto turvo. Para o estudo em questão, a translucidez das nanoemulsões é um parâmetro primordial, uma vez que serão aplicadas em bebidas isotônicas, as quais são translúcidas. A partir desses resultados pode-se afirmar que a utilização das nanoemulsões contendo $3 \mathrm{M}$ de $\mathrm{NaCl}$ se mostram mais adequadas para aplicação na bebida isotônica.

Complementando os dados mostrados nas Tabela 17 e 18, pode-se observar na Figura 17 o comportamento do diâmetro médio hidrodinâmico de gota ao longo de um período de 60 dias para as seis formulações testadas. 
Figura 17 - Diâmetro médio hidrodinâmico ao longo de um período de 60 dias das seis formulações testadas.

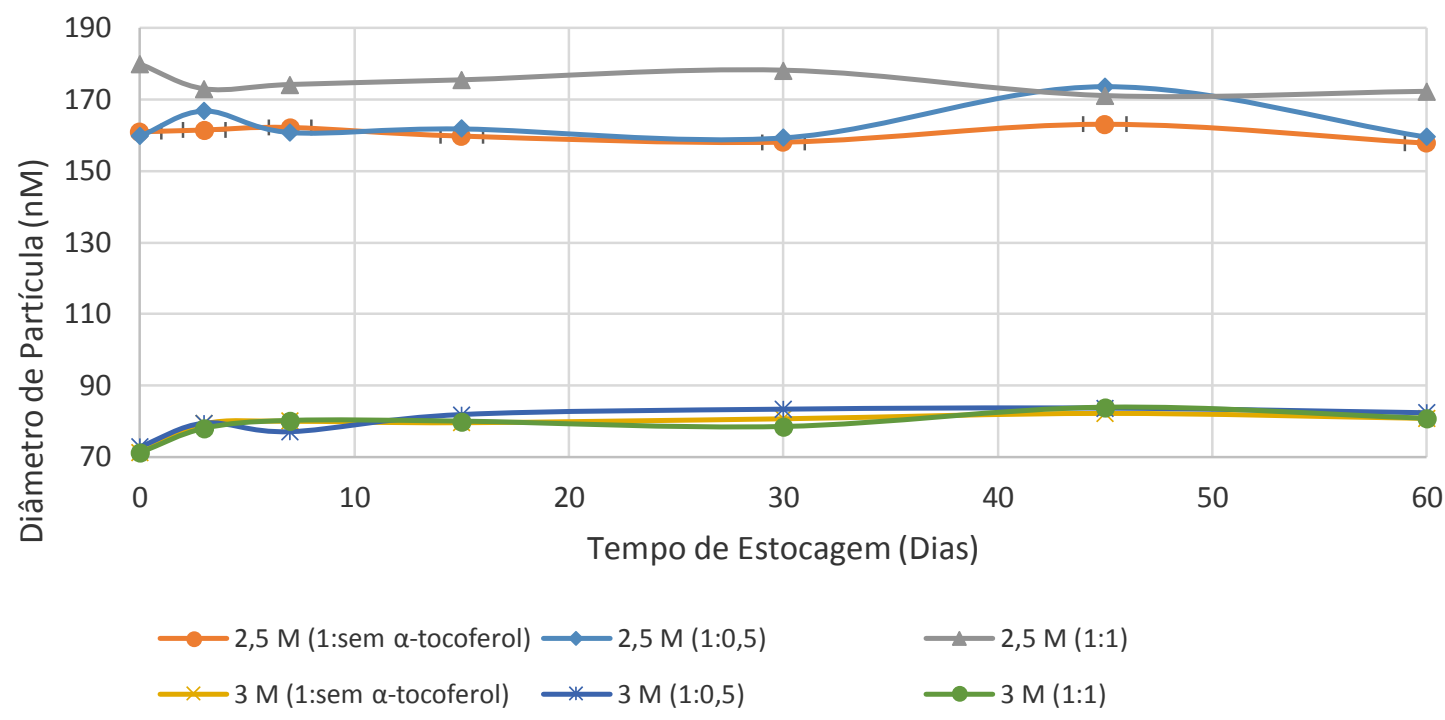

Fonte: Própria autoria.

Nas Tabela 19 e 20 podemos observar os valores de polidispersidade apresentados pelas nanoemulsões de 2,5 $\mathrm{M}$ e $3 \mathrm{M}$ de $\mathrm{NaCl}$, respectivamente, durante os 60 dias de estocagem. Segundo Ruozi et al., (2005) a polidispersidade de um sistema é um indicador da homogeneidade da distribuição do diâmetro médio das partículas e quanto menor for seu valor maior será a uniformidade do diâmetro médio de gota. De acordo com as tabelas nota-se que os valores alternaram entre 0,13 e 0,17 para a nanoemulsão 2,5M de $\mathrm{NaCl}$ e entre 0,08 e 0,15 para a nanoemulsão $3 \mathrm{M}$ de $\mathrm{NaCl}$. Esses resultados indicam uma ótima homogeneidade e estabilidade das dispersões no decorrer dos 60 dias de armazenamento.

Os resultados estatísticos indicam ainda que não houve diferença significativa a ( $p>0,05)$ pelo teste Tukey entre os 60 dias de estocagem para todas as formulações contendo 2,5M de $\mathrm{NaCl}$ e que somente no dia 15 de estocagem as nanoemulsões apresentaram diferença significativa a nível de $(\mathrm{p}<0,05)$ também pelo teste Tukey entre as 3 formulações. Para as nanoemulsões produzidas com $3 \mathrm{M}$ de $\mathrm{NaCl}$ somente a formulação $(1: 0,5)$ não apresentou diferença significativa a $(p>0,05)$ entre os 60 dias de estocagem e não houve diferença significativa entre nenhuma das três formulações a nível de $(\mathrm{p}<0,05)$ pelo teste Tukey. 
Tabela 19 - Polidispersidade das nanoemulsões produzidas com 2,5 M de $\mathrm{NaCl}$.

Polidispersidade

Tempo de estocagem (dias) (1: sem $\alpha$-tocoferol) $\quad(1: 0,5)$

\begin{tabular}{crrr}
\hline 0 & $0,14^{\mathrm{A}, \mathrm{a}} \pm 0,02$ & $0,15^{\mathrm{A}, \mathrm{a}} \pm 0,03$ & $0,15^{\mathrm{A}, \mathrm{a}} \pm 0,00$ \\
3 & $0,16^{\mathrm{A}, \mathrm{a}} \pm 0,02$ & $0,13^{\mathrm{A}, \mathrm{a}} \pm 0,01$ & $0,16^{\mathrm{A}, \mathrm{a}} \pm 0,01$ \\
7 & $0,15^{\mathrm{A}, \mathrm{a}} \pm 0,01$ & $0,14^{\mathrm{A}, \mathrm{a}} \pm 0,02$ & $0,16^{\mathrm{A}, \mathrm{a}} \pm 0,01$ \\
15 & $0,14^{\mathrm{A}, \mathrm{b}} \pm 0,01$ & $0,16^{\mathrm{A}, \mathrm{a}} \pm 0,01$ & $0,16^{\mathrm{A}, \mathrm{a}, \mathrm{b}} \pm 0,00$ \\
30 & $0,16^{\mathrm{A}, \mathrm{a}} \pm 0,02$ & $0,15^{\mathrm{A}, \mathrm{a}} \pm 0,02$ & $0,17^{\mathrm{A}, \mathrm{a}} \pm 0,02$ \\
45 & $0,15^{\mathrm{A}, \mathrm{a}} \pm 0,02$ & $0,16^{\mathrm{A}, \mathrm{a}} \pm 0,03$ & $0,17^{\mathrm{A}, \mathrm{a}} \pm 0,01$ \\
60 & $0,16^{\mathrm{A}, \mathrm{a}} \pm 0,01$ & $0,15^{\mathrm{A}, \mathrm{a}} \pm 0,03$ & $0,16^{\mathrm{A}, \mathrm{a}} \pm 0,02$
\end{tabular}

Médias de resultados seguidas por letras maiúsculas distintas na mesma coluna não apresentam diferença estatística significativa a $\mathrm{p}>0,05$ pelo teste de Tukey. Médias de resultados seguidas por letras minúsculas distintas na mesma linha apresentam diferença estatística significativa a $\mathrm{p}<0,05$ pelo teste de Tukey.

Fonte: Própria autoria.

Tabela 20 - Polidispersidade das nanoemulsões produzidas com $3 \mathrm{M}$ de $\mathrm{NaCl}$.

Polidispersidade

Tempo de estocagem (dias)

(1: sem $\alpha$-tocoferol)

$(1: 0,5)$

$(1: 1)$

$\begin{array}{rrrr}0 & 0,12^{\mathrm{A}, \mathrm{a}} \pm 0,03 & 0,15^{\mathrm{A}, \mathrm{a}} \pm 0,03 & 0,15^{\mathrm{A}, \mathrm{a}} \pm 0,03 \\ 3 & 0,08^{\mathrm{A}, \mathrm{B}, \mathrm{a}} \pm 0,02 & 0,10^{\mathrm{A}, \mathrm{a}} \pm 0,02 & 0,10^{\mathrm{B}, \mathrm{a}} \pm 0,02 \\ 7 & 0,08^{\mathrm{B}, \mathrm{a}} \pm 0,01 & 0,10^{\mathrm{A}, \mathrm{a}} \pm 0,03 & 0,10^{\mathrm{B}, \mathrm{a}} \pm 0,03 \\ 15 & 0,09^{\mathrm{B}, \mathrm{a}} \pm 0,01 & 0,10^{\mathrm{A}, \mathrm{a}} \pm 0,01 & 0,10^{\mathrm{B}, \mathrm{a}} \pm 0,01 \\ 30 & 0,09^{\mathrm{B}, \mathrm{a}} \pm 0,01 & 0,10^{\mathrm{A}, \mathrm{a}} \pm 0,01 & 0,10^{\mathrm{B}, \mathrm{a}} \pm 0,01 \\ 45 & 0,08^{\mathrm{A}, \mathrm{B}, \mathrm{a}} \pm 0,00 & 0,10^{\mathrm{A}, \mathrm{a}} \pm 0,02 & 0,10^{\mathrm{B}, \mathrm{a}} \pm 0,02 \\ 60 & 0,09^{\mathrm{A}, \mathrm{a}} \pm 0,00 & 0,09^{\mathrm{A}, \mathrm{a}} \pm 0,01 & 0,09^{\mathrm{B}, \mathrm{a}} \pm 0,01\end{array}$

Médias de resultados seguidas por letras maiúsculas distintas na mesma coluna apresentam diferença estatística significativa a $\mathrm{p}<0,05$ pelo teste de Tukey. Médias de resultados seguidas por letras minúsculas distintas na mesma linha não apresentam diferença estatística significativa a $p>0,05$ pelo teste de Tukey.

Fonte: Própria autoria. 


\subsubsection{Quantificação dos carotenoides totais}

A quantificação de carotenoides é um ponto muito importante do presente estudo, pois esta análise foi decisiva para escolha de qual nanoemulsão iria ser aplicada na bebida isotônica. Os carotenos totais presentes no óleo de buriti são os responsáveis por dar a coloração alaranjada às nanoemulsões. Tal coloração é extremamente desejável neste estudo uma vez que se deseja substituir o máximo possível do corante amarelo crepúsculo, comumente empregado na produção de bebida isotônica sabor tangerina, por óleo de buriti nanoemulsionado.

A Tabela 21 e a Tabela 22 mostram a quantificação total de carotenoides para as nanoemulsões contendo 2,5 $\mathrm{M}$ e $3 \mathrm{M}$ de $\mathrm{NaCl}$ respectivamente. Pode-se notar que houve diferença significativa $(\mathrm{p}<0,05)$ pelo teste de Tukey para as seis formulações testadas durante os 60 dias de estocagem e também entre as diferentes formulações.

Tabela 21 - Carotenoides totais encapsulados na nanoemulsão produzidas com 2,5 M de NaCl.

\begin{tabular}{crrr} 
& \multicolumn{3}{c}{ Quantificação carotenoides totais (mg/L) } \\
\cline { 2 - 4 } Tempo de estocagem (dias) & $(1$ : sem $\alpha$-tocoferol) & $(1: 0,5)$ & $(1: 1)$ \\
\hline 0 & $1,57^{\mathrm{A}, \mathrm{b}} \pm 0,10$ & $1,54^{\mathrm{A}, \mathrm{b}} \pm 0,05$ & $1,77^{\mathrm{A}, \mathrm{a}} \pm 0,12$ \\
3 & $1,36^{\mathrm{A}, \mathrm{B}, \mathrm{a}} \pm 0,24$ & $1,43^{\mathrm{A}, \mathrm{B}, \mathrm{a}} \pm 0,17$ & $1,64^{\mathrm{A}, \mathrm{a}} \pm 0,10$ \\
7 & $1,16^{\mathrm{B}, \mathrm{C}, \mathrm{a}} \pm 0,11$ & $1,21^{\mathrm{B}, \mathrm{C}, \mathrm{a}} \pm 0,26$ & $1,58^{\mathrm{A}, \mathrm{a}} \pm 0,11$ \\
15 & $1,09^{\mathrm{C}, \mathrm{a}} \pm 0,13$ & $1,07^{\mathrm{C}, \mathrm{D}, \mathrm{a}} \pm 0,16$ & $1,28^{\mathrm{B}, \mathrm{a}} \pm 0,15$ \\
30 & $0,83^{\mathrm{D}, \mathrm{a}} \pm 0,17$ & $0,87^{\mathrm{D}, \mathrm{E}, \mathrm{a}} \pm 0,20$ & $1,14^{\mathrm{B}, \mathrm{C}, \mathrm{a}} \pm 0,08$ \\
45 & $0,75^{\mathrm{D}, \mathrm{E}, \mathrm{a}} \pm 0,20$ & $0,79^{\mathrm{E}, \mathrm{F}, \mathrm{a}} \pm 0,19$ & $0,90^{\mathrm{C}, \mathrm{D}, \mathrm{a}} \pm 0,02$ \\
60 & $0,53^{\mathrm{E}, \mathrm{a}} \pm 0,16$ & $0,52^{\mathrm{F}, \mathrm{a}} \pm 0,21$ & $0,69^{\mathrm{D}, \mathrm{a}} \pm 0,03$
\end{tabular}

Médias de resultados seguidas por letras maiúsculas distintas na mesma coluna apresentam diferença estatística significativa a $\mathrm{p}<0,05$ pelo teste de Tukey. Médias de resultados seguidas por letras minúsculas distintas na mesma linha apresentam diferença estatística significativa a $\mathrm{p}<0,05$ pelo teste de Tukey.

Fonte: Própria autoria. 
Tabela 22 - Carotenoides totais encapsulados na nanoemulsão produzida com $3 \mathrm{M}$ de $\mathrm{NaCl}$.

Quantificação carotenoides totais $(\mathrm{mg} / \mathrm{L})$

\begin{tabular}{crrr}
\hline Tempo de estocagem (dias) & (1: sem $\alpha$-tocoferol $)$ & $(1: 0,5)$ \\
\hline 0 & $1,34^{\mathrm{A}, \mathrm{c}} \pm 0,03$ & $1,66^{\mathrm{A}, \mathrm{a}} \pm 0,05$ & $1,56^{\mathrm{A}, \mathrm{b}} \pm 0,03$ \\
3 & $1,05^{\mathrm{B}, \mathrm{a}} \pm 0,06$ & $1,21^{\mathrm{B}, \mathrm{a}} \pm 0,08$ & $1,26^{\mathrm{B}, \mathrm{a}} \pm 0,05$ \\
7 & $0,95^{\mathrm{B}, \mathrm{b}} \pm 0,10$ & $1,09^{\mathrm{B}, \mathrm{C}, \mathrm{a}, \mathrm{b}} \pm 0,06$ & $1,21^{\mathrm{B}, \mathrm{C}, \mathrm{a}} \pm 0,03$ \\
15 & $0,81^{\mathrm{C}, \mathrm{b}} \pm 0,03$ & $0,96^{\mathrm{C}, \mathrm{D}, \mathrm{a}, \mathrm{b}} \pm 0,10$ & $1,08^{\mathrm{C}, \mathrm{D}, \mathrm{a}} \pm 0,05$ \\
30 & $0,58^{\mathrm{D}, \mathrm{b}} \pm 0,02$ & $0,85^{\mathrm{D}, \mathrm{a}} \pm 0,05$ & $0,98^{\mathrm{D}, \mathrm{a}} \pm 0,06$ \\
45 & $0,37^{\mathrm{E}, \mathrm{b}} \pm 0,03$ & $0,50^{\mathrm{E}, \mathrm{a}, \mathrm{b}} \pm 0,03$ & $0,58^{\mathrm{E}, \mathrm{a}} \pm 0,09$ \\
60 & $0,28^{\mathrm{E}, \mathrm{b}} \pm 0,01$ & $0,44^{\mathrm{E}, \mathrm{a}} \pm 0,06$ & $0,41^{\mathrm{F}, \mathrm{a}} \pm 0,02$
\end{tabular}

Médias de resultados seguidas por letras maiúsculas distintas na mesma coluna apresentam diferença estatística significativa a $\mathrm{p}<0,05$ pelo teste de Tukey. Médias de resultados seguidas por letras minúsculas distintas na mesma linha apresentam diferença estatística significativa a $\mathrm{p}<0,05$ pelo teste de Tukey.

Fonte: Própria autoria.

De forma complementar às Tabelas já apresentadas, pode-se observar na Figura 18 o perfil temporal de decréscimo dos carotenoides totais durante os 60 dias de estocagem para todas as formulações de nanoemulsões. Para as nanoemulsões contendo 2,5 $\mathrm{M}$ de $\mathrm{NaCl}$ o decréscimo da massa de carotenoides totais (quantificados como betacaroteno) foi de $66,3 \%, 66,1 \%$ e $60,7 \%$ e para as nanoemulsões contendo $3 \mathrm{M}$ de $\mathrm{NaCl}$ de 79,1\%,73,4\% e 73,8\% para as formulações (1: sem $\alpha$-tocoferol), (1:0,5) e (1:1), respectivamente. Observa-se também que as nanoemulsões contendo $3 \mathrm{M}$ de $\mathrm{NaCl}$ tiveram uma maior redução nos teores de carotenoides totais sugerindo que a presença de sal afetou a queda mais acentuado dos carotenoides encapsulados. Lima et al. (2004) avaliaram o efeito do estresse salino sobre a concentração de pigmentos em folhas de arroz. Neste estudo foi relatado uma acentuada queda no teor de carotenoides em função do incremento na concentração de $\mathrm{NaCl}$.

Resultados semelhantes foram encontrados por Gomes (2015). Neste estudo foram produzidas nanopartículas lipídicas sólidas pelo método PIT utilizando como fase oleosa manteiga de cupuaçu e manteiga de murumuru para encapsulação do $\beta$-caroteno. Os tensoativos utilizados foram o Cremophor RH 40 e o Span 80 e os sistemas foram produzidos na presença e na ausência de $\alpha$-tocoferol. Os resultados mostraram que as partículas com $\alpha$-tocoferol preservaram melhor o $\beta$-caroteno encapsulado. Depois de 120 dias de estocagem, houve uma redução de somente $10 \%$ da quantidade inicial de $\beta$ caroteno das nanoparticulas produzidas com manteiga de cupuaçu e de $30 \%$ com a 
produzida com manteiga de murumuru. No entanto, após o mesmo período, para as dispersões sem $\alpha$-tocoferol, mais de $30 \%$ da quantidade inicial de $\beta$-caroteno já havia sido degradada nas nanopartículas produzidas com manteiga de cupuaçu, e por volta de $60 \%$ para as nanopartículas produzidas com manteiga de murumuru.

Figura 18 - Quantificação de carotenoides totais em 60 dias de estocagem. (A) 2,5 M de $\mathrm{NaCl}$ e (B) $3 \mathrm{M}$ de $\mathrm{NaCl}$.

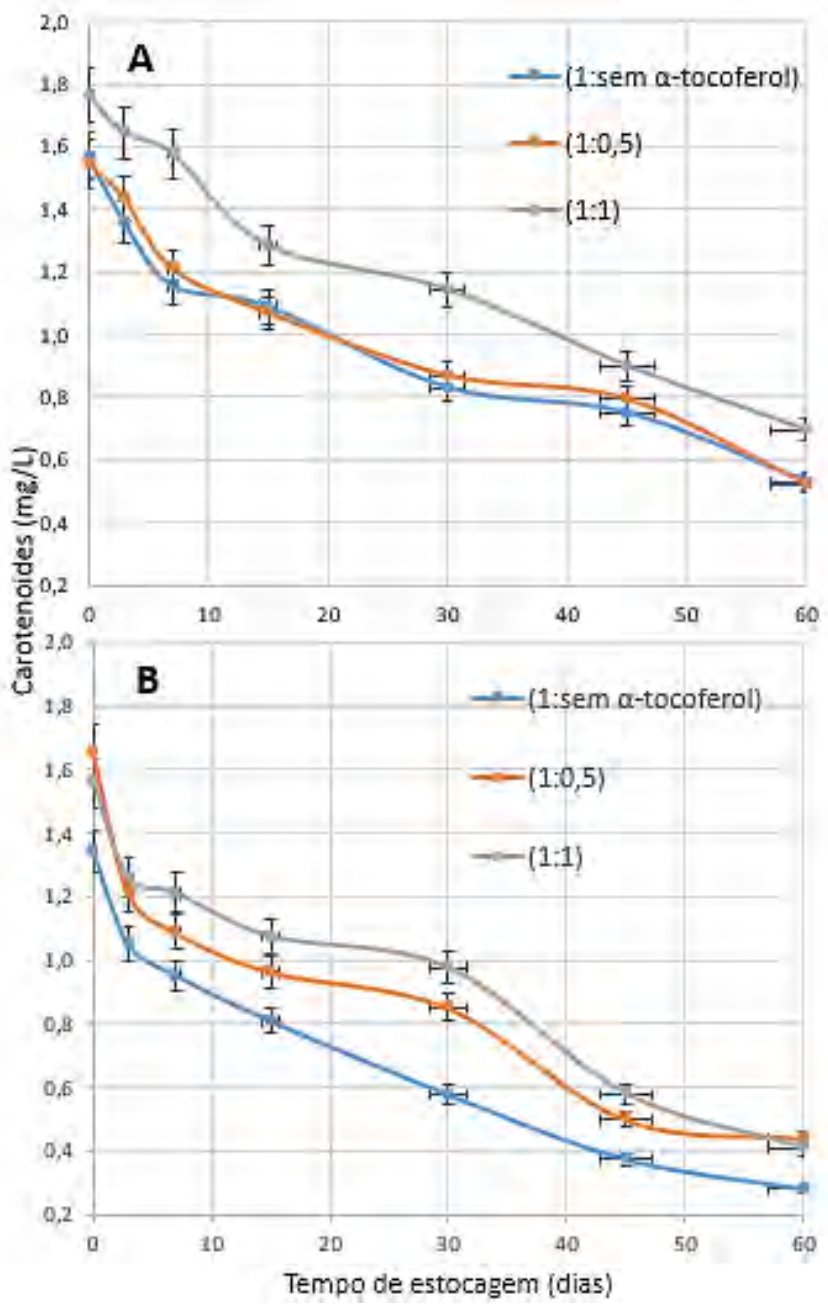

Fonte: Própria autoria.

Observa-se pelos perfis temporais de decaimento da concentração de $\beta$-caroteno que a adição de $\alpha$-tocoferol influenciou decisivamente na estabilidade dos carotenoides presente no óleo de buriti. Porém, pode-se considerar altas as perdas do bioativo encapsulado apresentadas ao final da estocagem. Segundo Rodrigues-Amaya et al. (2008) existem diversos fatores que fazem a análise de quantificação de carotenoides complexa, uma delas é a sensibilidade dos carotenos a oxidação e isomerização durante a análise ou durante a estocagem anterior a análise (incidência de luz e temperaturas 
elevadas). Para tentar minimizar ao máximo estes erros as amostras foram armazenadas sob refrigeração $\left(\sim 7^{\circ} \mathrm{C}\right)$ e conservadas em frascos âmbar na ausência de luz. Portanto, o único fator que pode ter contribuído para o desencadeamento do processo de oxidação dos carotenoides totais foi a etapa da produção das nanoemulsões. Nesta etapa, utilizase temperatura de $60-65{ }^{\circ} \mathrm{C}$, o que pode ter causado a formação de agentes próoxidantes no meio. Podemos considerar que a auto oxidação foi a fonte principal para iniciar o processo de oxidação no óleo de buriti nanoemulsionado.

A degradação do $\beta$-caroteno também pode ser deduzida a partir da perda da coloração das nanoemulsões no decorrer dos 60 dias de estocagem, conforme mostrado na Figura 19.

Figura 19 - Óleo de buriti nanoemulsionado em diferentes dias de estocagem.

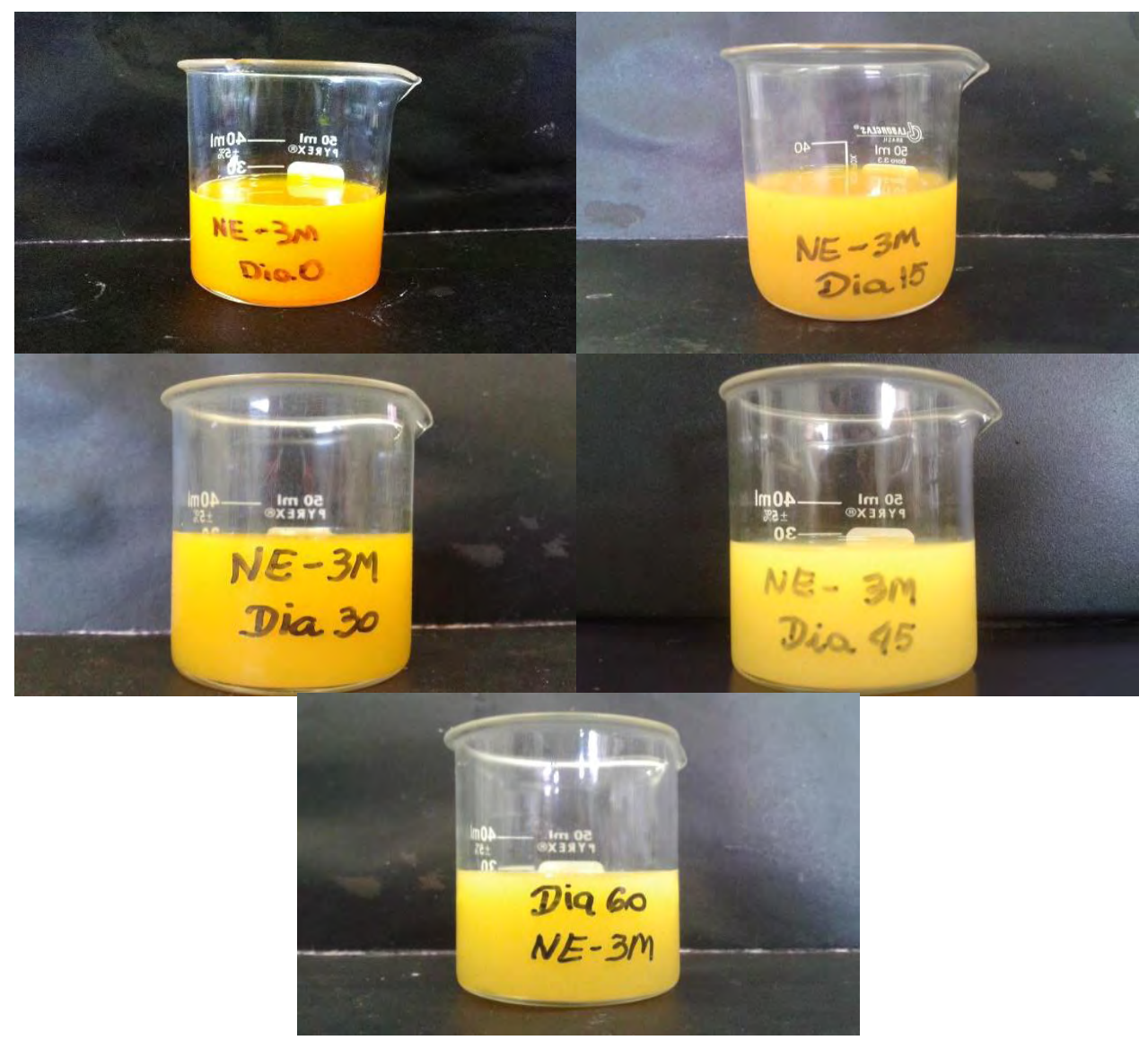

Fonte: Própria autoria. 


\subsubsection{Avaliação da oxidação lipídica}

A determinação da oxidação lipídica foi feita empregando-se o método conhecido como TBARS. Segundo Regitano-d’Arce (2006) o aldeído malônico é considerado um produto final de oxidação e pode ser medido pela reação como o TBA. A Tabela 23 e a Tabela 24 mostram, respectivamente, a oxidação lipídica das nanoemulsões produzidas com 2,5 $\mathrm{M}$ e $3 \mathrm{M}$ de $\mathrm{NaCl}$.

Tabela 23 - Oxidação lipídica quantificada por TBARS para as nanoemulsões produzidas com $2,5 \mathrm{M}$ de $\mathrm{NaCl}$.

$$
\text { Oxidação Lipídica (mmol MDA/kg) }
$$

Tempo de estocagem (dias) (1: sem $\alpha$-tocoferol) $\quad(1: 0,5)$

\begin{tabular}{rrrr}
\hline 0 & $0,05^{\mathrm{A}, \mathrm{a}} \pm 0,02$ & $0,05^{\mathrm{A}, \mathrm{a}} \pm 0,01$ & $0,06^{\mathrm{A}, \mathrm{a}} \pm 0,02$ \\
3 & $0,05^{\mathrm{A}, \mathrm{a}} \pm 0,01$ & $0,08^{\mathrm{A}, \mathrm{a}} \pm 0,03$ & $0,08^{\mathrm{A}, \mathrm{a}} \pm 0,01$ \\
7 & $0,08^{\mathrm{A}, \mathrm{a}} \pm 0,02$ & $0,07^{\mathrm{A}, \mathrm{a}} \pm 0,02$ & $0,07^{\mathrm{A}, \mathrm{a}} \pm 0,00$ \\
15 & $0,08^{\mathrm{A}, \mathrm{a}} \pm 0,01$ & $0,07^{\mathrm{A}, \mathrm{a}} \pm 0,02$ & $0,06^{\mathrm{A}, \mathrm{a}} \pm 0,02$ \\
30 & $0,05^{\mathrm{A}, \mathrm{a}} \pm 0,01$ & $0,04^{\mathrm{A}, \mathrm{a}} \pm 0,01$ & $0,04^{\mathrm{A}, \mathrm{a}} \pm 0,00$ \\
45 & $0,07^{\mathrm{A}, \mathrm{b}} \pm 0,01$ & $0,09^{\mathrm{A}, \mathrm{a}} \pm 0,01$ & $0,08^{\mathrm{A}, \mathrm{a}, \mathrm{b}} \pm 0,00$ \\
60 & $0,06^{\mathrm{A}, \mathrm{a}} \pm 0,02$ & $0,08^{\mathrm{A}, \mathrm{a}} \pm 0,03$ & $0,07^{\mathrm{A}, \mathrm{a}} \pm 0,00$
\end{tabular}

Médias de resultados seguidas por letras maiúsculas distintas na mesma coluna não apresentam diferença estatística significativa a p >0,05 pelo teste de Tukey. Médias de resultados seguidas por letras minúsculas distintas na mesma linha apresentam diferença estatística significativa a $\mathrm{p}<0,05$ pelo teste de Tukey.

Fonte: Própria autoria.

Pode-se notar que não houve diferença significativa $(\mathrm{p}<0,05)$ pelo teste de Tukey para as três nanoemulsões produzidas com $2,5 \mathrm{M}$ de $\mathrm{NaCl}$ e para as nanoemulsões contendo $3 \mathrm{M}$ de $\mathrm{NaCl}$ na proporção (1:0,5) durante os 60 dias de estocagem. Nota-se também que não houve diferença significativa $(p<0,05)$ pelo teste Tukey entre todas as formulações testadas, com exceção da nanoemulsão contendo 2,5 $\mathrm{M}$ de $\mathrm{NaCl}$ na proporção (1: sem $\alpha$-tocoferol). Tanto para as nanoemulsão contendo 2,5 $\mathrm{M}$ de $\mathrm{NaCl}$ quanto para as nanoemulsão contendo $3 \mathrm{M}$ de $\mathrm{NaCl}$ os resultados variaram de 0,04 a $0,1 \mathrm{mmol} / \mathrm{kg}$ para os 60 dias de estocagem. Tais valores são menores do que os apresentados em outros estudos. Lee et al. (2011) por exemplo apresentou resultados variando de $0,2 \mathrm{mmol} / \mathrm{kg}$ (dia 0 ) a $0,9 \mathrm{mmol} / \mathrm{kg}$ (dia 22 ). 
Tabela 24 - Oxidação lipídica quantificada por TBARS para as nanoemulsões produzidas com $3 \mathrm{M}$ de $\mathrm{NaCl}$.

Oxidação Lipídica (mmol MDA/kg)

\begin{tabular}{crrr}
\hline Tempo de estocagem (dias) & (1: sem $\alpha$-tocoferol) & $(1: 0,5)$ & $(1: 1)$ \\
\hline 0 & $0,07^{\mathrm{A}, \mathrm{B}, \mathrm{a}} \pm 0,00$ & $0,10^{\mathrm{A}, \mathrm{a}} \pm 0,02$ & $0,09^{\mathrm{A}, \mathrm{a}} \pm 0,01$ \\
3 & $0,07^{\mathrm{AB}, \mathrm{a}} \pm 0,02$ & $0,06^{\mathrm{A}, \mathrm{a}} \pm 0,04$ & $0,05^{\mathrm{B}, \mathrm{a}} \pm 0,02$ \\
7 & $0,05^{\mathrm{B}, \mathrm{a}} \pm 0,01$ & $0,07^{\mathrm{A}, \mathrm{a}} \pm 0,02$ & $0,07^{\mathrm{A}, \mathrm{B}, \mathrm{a}} \pm 0,01$ \\
15 & $0,07^{\mathrm{A}, \mathrm{B}, \mathrm{a}} \pm 0,00$ & $0,08^{\mathrm{A}, \mathrm{a}} \pm 0,00$ & $0,07^{\mathrm{A}, \mathrm{B}, \mathrm{a}} \pm 0,00$ \\
30 & $0,07^{\mathrm{A}, \mathrm{B}, \mathrm{a}} \pm 0,01$ & $0,08^{\mathrm{A}, \mathrm{a}} \pm 0,01$ & $0,07^{\mathrm{A}, \mathrm{B}, \mathrm{a}} \pm 0,00$ \\
45 & $0,09^{\mathrm{A}, \mathrm{a}} \pm 0,00$ & $0,08^{\mathrm{A}, \mathrm{a}} \pm 0,01$ & $0,07^{\mathrm{A}, \mathrm{a}} \pm 0,01$ \\
60 & $0,08^{\mathrm{A}, \mathrm{a}} \pm 0,01$ & $0,08^{\mathrm{A}, \mathrm{a}} \pm 0,01$ & $0,08^{\mathrm{A}, \mathrm{a}} \pm 0,00$
\end{tabular}

Médias de resultados seguidas por letras maiúsculas distintas na mesma coluna apresentam diferença estatística significativa a p $<0,05$ pelo teste de Tukey. Médias de resultados seguidas por letras minúsculas distintas na mesma linha não apresentam diferença estatística significativa a $p>0,05$ pelo teste de Tukey.

Fonte: Própria autoria.

Os resultados comprovam baixo grau de oxidação lipídica uma vez que houve mínimas quantidades de malonaldeído (MDA) reagindo com o TBA. A presença de tocoferol presente naturalmente no óleo de buriti tanto como a adição de $\alpha$-tocoferol em algumas formulações de nanoemulsões produzidas pode ter auxiliado na baixa oxidação lipídica observada, já que o tocoferol é um antioxidante natural. Segundo Regitanod'Arce (2006) os tocoferois possuem a capacidade de quebrar reações em cadeia reagindo com radicais peroxi e ácidos graxos, sendo que o $\alpha$-tocoferol é o antioxidante mais ativo dentro os antioxidantes fenólicos conhecidos.

Desta forma, para a produção da bebida isotônica duas formulações de nanoemulsões foram escolhidas: a nanoemulsão produzida com $2,5 \mathrm{M}$ de $\mathrm{NaCl}$ na proporção (1:1), e a nanoemulsão produzida com $3 \mathrm{M}$ de $\mathrm{NaCl}$ também na mesma proporção CT:AT. Estas formulações foram escolhidas pois apresentaram bons resultados com relação à capacidade de proteção dos carotenoides totais, diâmetro e distribuição de tamanho de gota, bem como baixa taxa de oxidação lipídica, durante o período de estocagem estudado. 


\subsection{INCORPORAÇÃO DAS NANOEMULSÕES DE ÓLEO DE BURITI EM BEBIDA ISOTÔNICA}

\subsubsection{Produção da bebida isotônica adicionada de nanoemulsões de óleo de} buriti

A bebida isotônica foi o sistema alimentício utilizado para incorporação do óleo de buriti nanoemulsionado. Diferentes formulações de isotônico foram testadas a fim de se determinar aquela (s) que seria (m) utilizada (s) no presente trabalho. O objetivo dos testes foi ajustar a formulação de acordo com os parâmetros exigidos pela Resolução 18, de 27 de abril de 2010 (BRASIL, 2010). Com o objetivo de avaliar se a bebida proposta apresentava características similares às marcas comerciais, realizou-se uma comparação com as bebidas Gatorade ${ }^{\circledR}$ (PepsiCo) e Powerade ${ }^{\circledR}$ (The Coca-Cola Company) em termos de cor, aroma e sabor, conforme mostrado na Figura 20.

Figura 20 - Comparação entre o aspecto visual da bebida isotônica formulada e as bebidas disponíveis comercialmente.

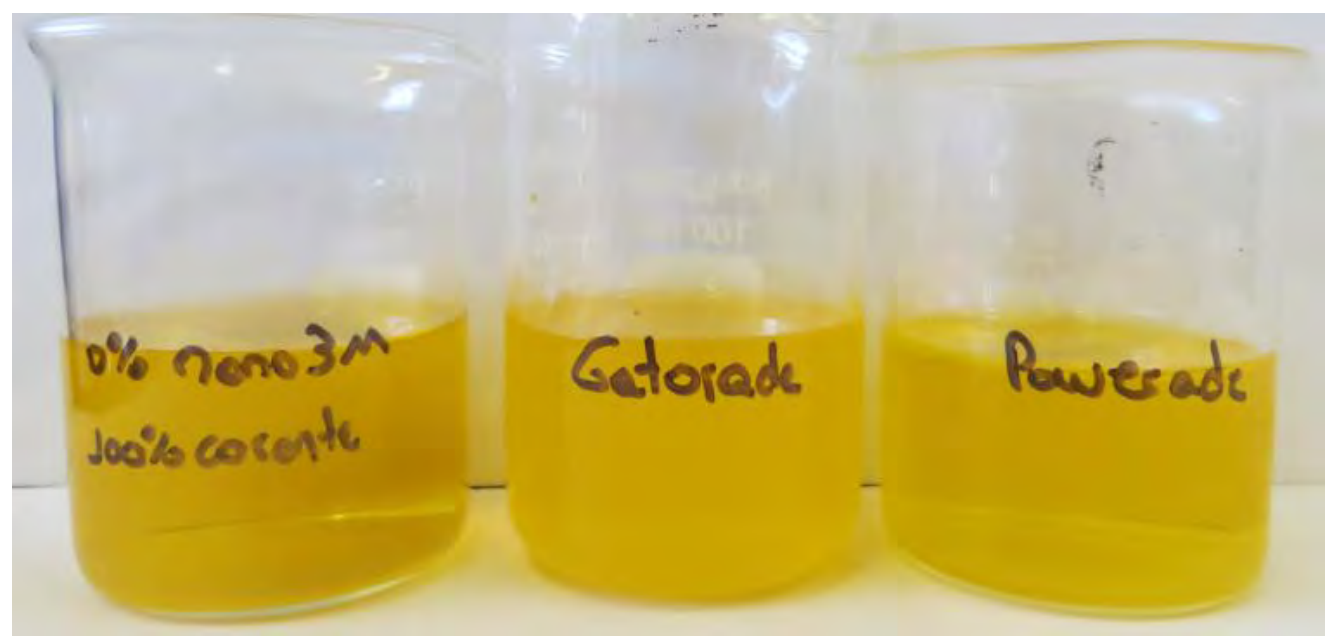

Fonte: Própria autoria.

Já para a definição da quantidade limite de óleo de buriti nanoemulsionado utilizada foi feito uma análise visual, levando-se em conta o parâmetro transparência. Com base na Figura 21 definiu-se que a substituição de corante por nanoemulsão de óleo de buriti deveria ser entre $25 \%$ e $50 \%$, pois neste intervalo a bebida ainda apresentavase translúcida. 
Figura 21 - Aspecto visual das diferentes porcentagens de substituição de corante por nanoemulsão de óleo de buriti.

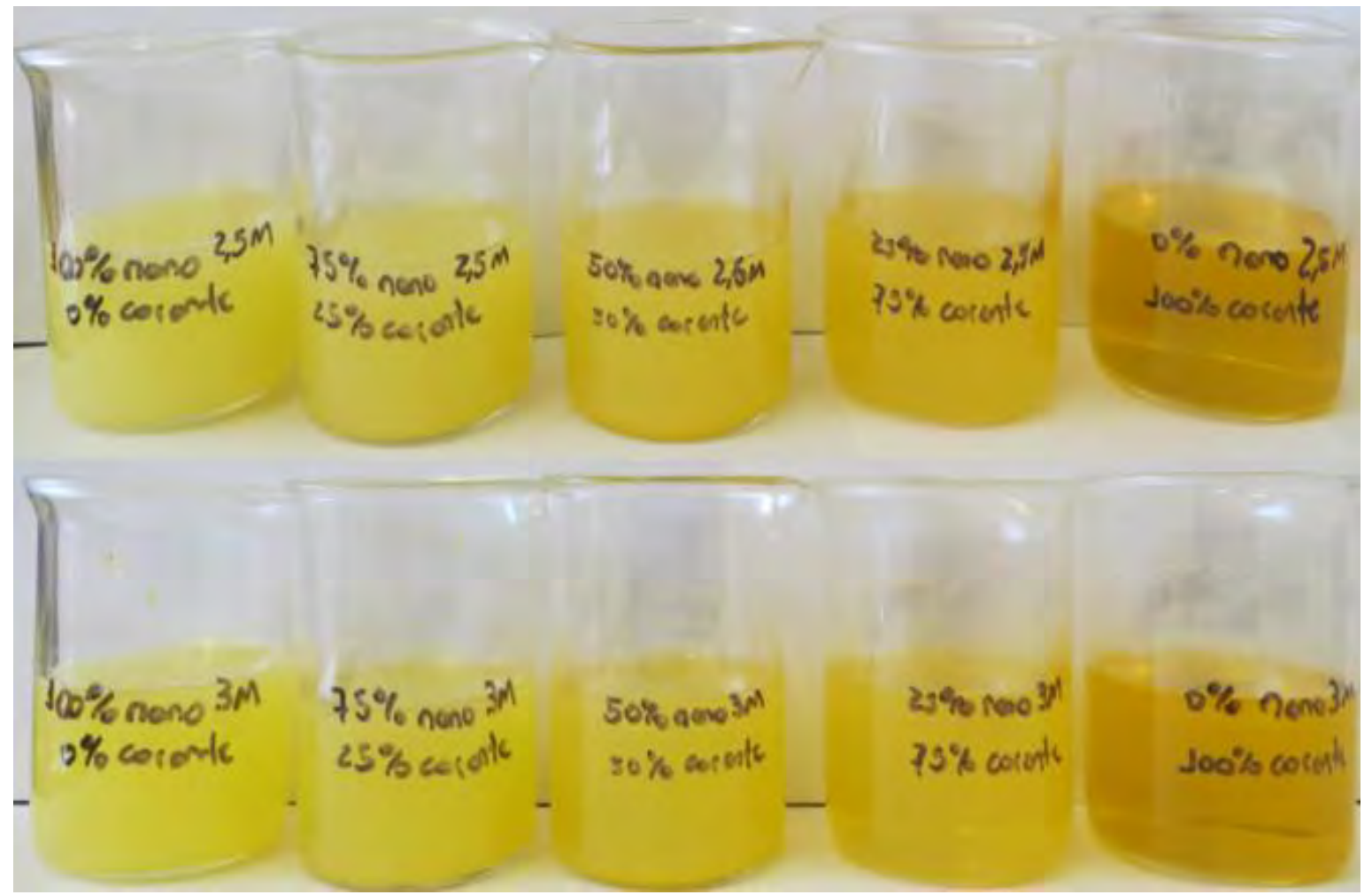

Fonte: Própria autoria.

Por sua vez, na Figura 22 são ilustradas algumas etapas de processo da produção da bebida isotônica sabor tangerina na Planta Piloto da Faculdade de Zootecnia e Engenharia de Alimentos, instalada no Departamento de Engenharia de Alimentos da Faculdade de Zootecnia e Engenharia de Alimentos, no campus da Universidade de São Paulo (USP) de Pirassununga/SP.

Conforme pode-se observar pela Figura $22(\mathrm{C})$, durante a produção da bebida isotônica sabor tangerina houve formação de espuma na formulação I2 (a formulação I3 também apresentou formação de espuma). À formação de espuma se deu devido à presença de tensoativo nestas formulações de isotônico. Como pode-se observar pela Figura 22 (G) após o envase ainda havia espuma na bebida isotônica, que foi reincorporada à fase líquida após algumas horas em repouso. 
Figura 22 - Etapas do processo da produção da bebida isotônica: (A) assepsia das embalagens, (B) formulação I1 no tanque de recepção, (C) formulação I2 no tanque de recepção, (D) pasteurizador, (E) cabina de fluxo de ar unidirecional, (F)envase asséptico, (G) produto após envase e (H) estocagem a $7{ }^{\circ} \mathrm{C}$ na ausência de luz.

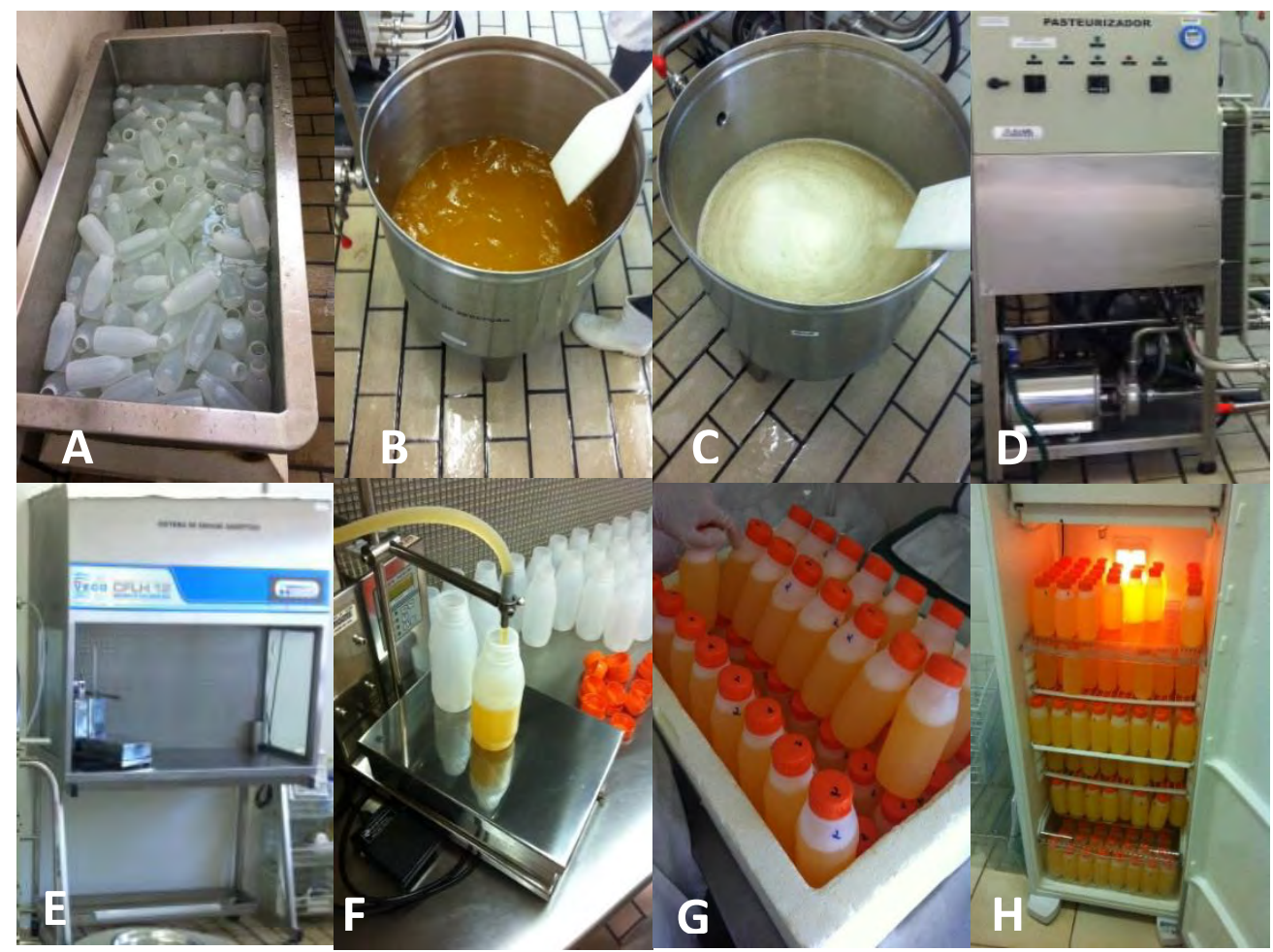

Fonte: Própria autoria.

\subsubsection{Caracterização da bebida isotônica adicionada de nanoemulsões de} óleo de buriti

As formulações de bebida isotônica foram caracterizadas em três dias diferentes. A primeira caracterização ocorreu no dia do processamento (dia 0). A segunda caracterização ocorreu no dia da realização dos testes sensoriais, os quais aconteceram 8 dias após o processamento (dia 8). Por fim, a terceira caracterização ocorreu 30 dias após a realização dos testes sensoriais (dia 38). Vale ressaltar que a formulação 3 apresentou uma leve separação de fase no dia 38, conforme mostrado na Figura 23. Mesmo com a separação de fases, análises físico-químicas foram feitas no dia 38.

A caracterização físico-química da bebida isotônica no dia 0 é mostrada na Tabela 25 e está expressa como média das três amostras. 
Figura 23 - Formulação 3 com uma leve separação de fase no dia 38.

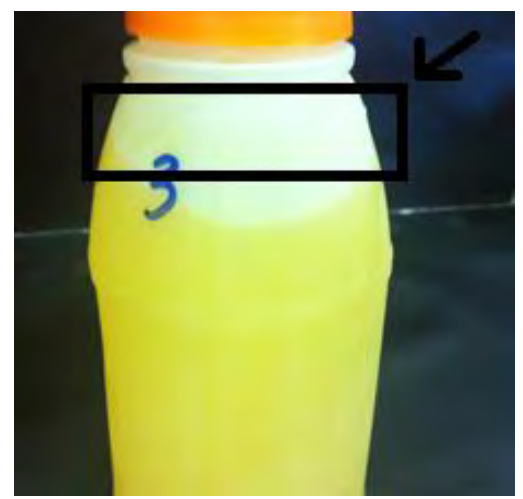

Fonte: Própria autoria.

Tabela 25 - Características físico-químicas do isotônico sabor tangerina recém-pasteurizado (dia 0) (I2 = 25\% nanoemulsão $3 \mathrm{M}$ de $\mathrm{NaCl}$ e I3 = 30\% nanoemulsão $2,5 \mathrm{M} \mathrm{de} \mathrm{NaCl}$ ).

\begin{tabular}{|c|c|c|c|c|}
\hline \multirow[b]{2}{*}{ Parâmetros } & \multirow[b]{2}{*}{ Unidades } & \multicolumn{3}{|c|}{ Formulações } \\
\hline & & Controle & $\mathrm{I} 2$ & $\mathrm{I} 3$ \\
\hline $\mathrm{pH}$ & - & $3,000 \pm 0,010$ & $2,920 \pm 0,010$ & $2,910 \pm 0,000$ \\
\hline Sólidos solúveis & ( ${ }^{\circ}$ Brix) & $4,230 \pm 0,060$ & $4,970 \pm 0,060$ & $5,000 \pm 0,000$ \\
\hline Acidez titulável & $(\mathrm{g} / 100 \mathrm{~mL})$ & $0,171 \pm 0,007$ & $0,173 \pm 0,000$ & $0,171 \pm 0,004$ \\
\hline $\mathrm{L}^{*}$ & - & $57,17 \pm 0,170$ & $60,21 \pm 0,080$ & $55,62 \pm 0,090$ \\
\hline$a^{*}$ & - & $16,22 \pm 0,150$ & $12,86 \pm 0,050$ & $11,46 \pm 0,360$ \\
\hline $\mathrm{b}^{*}$ & - & $45,08 \pm 0,050$ & $45,95 \pm 0,060$ & $45,10 \pm 0,050$ \\
\hline Chroma $\left(\mathrm{C}^{*}{ }_{\mathrm{ab}}\right)$ & - & $47,92 \pm 0,100$ & $47,71 \pm 0,070$ & $46,53 \pm 0,060$ \\
\hline Ângulo de Hue & $\left({ }^{\circ}\right)$ & $70,21 \pm 0,15$ & $74,37 \pm 0,04$ & $75,74 \pm 0,45$ \\
\hline Osmolalidade & $(\mathrm{mosmol} / \mathrm{kg})$ & $275,0 \pm 1,000$ & $303,0 \pm 1,000$ & $304,0 \pm 2,000$ \\
\hline $\mathrm{K}^{+}$ & $(\mathrm{mg} / \mathrm{L})$ & 98,95 & 98,95 & 98,95 \\
\hline $\mathrm{Na}^{+}$ & $(\mathrm{mg} / \mathrm{L})$ & 462,0 & 738,8 & 876,8 \\
\hline
\end{tabular}

Fonte: Própria autoria.

Observa-se que a osmolalidade e o teor de sódio e potássio estão de acordo com os exigidos no Regulamento Técnico sobre Alimentos para Atletas (Resolução 18, de 27 de abril de 2010). Verifica-se também um aumento na concentração de sódio e da 
osmolalidade devido a incorporação da nanoemulsão uma vez que está possui altas concentrações de $\mathrm{NaCl}$ em sua formulação.

A fim de verificar se havia diferença estatisticamente significativa entre as amostras nos três períodos de estocagem as médias dos resultados para cada parâmetro foram comparadas separadamente. Na Tabela 26 pode-se observar os resultados das determinações de $\mathrm{pH}$ para as três formulações de bebida isotônica.

Com relação ao $\mathrm{pH}$ pode-se observar que houve diferença significativa $(\mathrm{p}<0,05)$ pelo teste Tukey entre as três formulações para o dia 0 e dia 8 . Para o dia 38 não houve diferença significativa $(\mathrm{p}>0,05)$ pelo teste de Tukey entre as três formulações testadas. Observa-se também que não houve diferença significativa $(\mathrm{p}>0,05)$ pelo teste de Tukey para os dias 0 e 8 da amostra controle e para os dias 8 e 38 da formulação I2, já para a formulação I3 houve diferença significativa $(\mathrm{p}<0,05)$ pelo teste de Tukey para os três dias analisados.

Tabela 26 - Resultados das determinações de pH para as três formulações de bebida isotônica (I2 = 25\% nanoemulsão $3 \mathrm{M}$ de $\mathrm{NaCl}$ e I3 = 30\% nanoemulsão 2,5 M de $\mathrm{NaCl}$ ).

\begin{tabular}{crrr} 
& \multicolumn{4}{c}{$\mathrm{pH}$} \\
\cline { 2 - 4 } Período de estocagem (dias) & Controle & $\mathrm{I} 2$ & $\mathrm{I} 3$ \\
\hline 0 & $3,00^{\mathrm{A}, \mathrm{a}} \pm 0,01$ & $2,92^{\mathrm{A}, \mathrm{b}} \pm 0,01$ & $2,91^{\mathrm{A}, \mathrm{c}} \pm 0,00$ \\
8 & $3,05^{\mathrm{A}, \mathrm{a}} \pm 0,01$ & $2,81^{\mathrm{B}, \mathrm{b}} \pm 0,06$ & $2,85^{\mathrm{B}, \mathrm{b}} \pm 0,02$ \\
38 & $2,73^{\mathrm{B}, \mathrm{a}} \pm 0,02$ & $2,72^{\mathrm{B}, \mathrm{a}} \pm 0,05$ & $2,70^{\mathrm{C}, \mathrm{a}} \pm 0,02$
\end{tabular}

Médias de resultados seguidas por letras maiúsculas distintas na mesma coluna apresentam diferença estatística significativa a $\mathrm{p}<0,05$ pelo teste de Tukey. Médias de resultados seguidas por letras minúsculas distintas na mesma linha apresentam diferença estatística significativa a $\mathrm{p}<0,05$ pelo teste de Tukey.

Fonte: Própria autoria.

Na Tabela 27 pode-se observar os resultados das determinações de sólidos solúveis ( ${ }^{\circ}$ Brix) para as três formulações de bebida isotônica.

Com relação as determinações de sólidos solúveis pode-se observar que houve diferença significativa $(\mathrm{p}<0,05)$ pelo teste de Tukey entre a formulação controle e as formulações I2 e I3. Observa-se também que não houve diferença significativa $(p>0,05)$ pelo teste de Tukey para os dias 0 e 8 da amostra controle e para todos os dias analisados da formulação I2 e I3. 
Tabela 27 - Resultados das determinações de sólidos solúveis ( ${ }^{\circ}$ Brix) para as três formulações de bebida isotônica (I2 $=25 \%$ nanoemulsão $3 \mathrm{M}$ de $\mathrm{NaCl}$ e $\mathrm{I} 3=30 \%$ nanoemulsão $2,5 \mathrm{M}$ de $\mathrm{NaCl})$.

\begin{tabular}{crrr}
\cline { 2 - 4 } & \multicolumn{4}{c}{${ }^{\circ}$ Brix } \\
\hline Período de estocagem (dias) & Controle & I2 & $\mathrm{I} 3$ \\
\hline 0 & $4,23^{\mathrm{B}, \mathrm{b}} \pm 0,06$ & $4,97^{\mathrm{A}, \mathrm{a}} \pm 0,06$ & $5,00^{\mathrm{A}, \mathrm{a} \pm} 0,00$ \\
8 & $4,33^{\mathrm{B}, \mathrm{b}} \pm 0,06$ & $5,00^{\mathrm{A}, \mathrm{a}} \pm 0,00$ & $5,03^{\mathrm{A}, \mathrm{a}} \pm 0,06$ \\
38 & $4,60^{\mathrm{A}, \mathrm{b}} \pm 0,00$ & $5,13^{\mathrm{A}, \mathrm{a}} \pm 0,12$ & $5,00^{\mathrm{A}, \mathrm{a}} \pm 0,00$
\end{tabular}

Médias de resultados seguidas por letras maiúsculas distintas na mesma coluna apresentam diferença estatística significativa a $\mathrm{p}<0,05$ pelo teste de Tukey. Médias de resultados seguidas por letras minúsculas distintas na mesma linha apresentam diferença estatística significativa a $\mathrm{p}<0,05$ pelo teste de Tukey.

Fonte: Própria autoria.

$\mathrm{Na}$ Tabela 28 pode-se observar os resultados de acidez titulável para as três formulações de bebida isotônica.

Tabela 28 - Resultados das determinações de acidez total titulável para as três formulações de bebida isotônica ( $\mathrm{I} 2=25 \%$ nanoemulsão $3 \mathrm{M}$ de $\mathrm{NaCl}$ e $\mathrm{I} 3=30 \%$ nanoemulsão $2,5 \mathrm{M}$ de $\mathrm{NaCl})$.

Acidez Titulável (g de ácido cítrico /100 mL)

\begin{tabular}{crrr}
\hline $\begin{array}{c}\text { Período de } \\
\text { estocagem (dias) }\end{array}$ & Controle & I2 \\
\hline 0 & $0,171^{\mathrm{A}, \mathrm{a}} \pm 0,007$ & $0,173^{\mathrm{A}, \mathrm{a}} \pm 0,000$ & $0,171^{\mathrm{B}, \mathrm{a}} \pm 0,004$ \\
8 & $0,164^{\mathrm{A}, \mathrm{a}} \pm 0,004$ & $0,175^{\mathrm{A}, \mathrm{a}} \pm 0,040$ & $0,169^{\mathrm{B}, \mathrm{a}} \pm 0,007$ \\
38 & $0,167^{\mathrm{A}, \mathrm{b}} \pm 0,000$ & $0,177^{\mathrm{A}, \mathrm{a}, \mathrm{b}} \pm 0,004$ & $0,184^{\mathrm{A}, \mathrm{a}} \pm 0,004$
\end{tabular}

Médias de resultados seguidas por letras maiúsculas distintas na mesma coluna apresentam diferença estatística significativa a $\mathrm{p}<0,05$ pelo teste de Tukey. Médias de resultados seguidas por letras minúsculas distintas na mesma linha apresentam diferença estatística significativa a $\mathrm{p}<0,05$ pelo teste de Tukey.

Fonte: Própria autoria.

A acidez total praticamente não apresentou nenhuma alteração durante o período de estocagem. Somente a formulação I3 apresentou diferença significativa $(p<0,05)$ pelo teste de Tukey.

De Marchi et al. (2003) produziram um isotônico natural de maracujá. Os autores realizaram determinações de $\mathrm{pH}$, acidez titulável e sólidos solúveis ( ${ }^{\circ}$ Brix) por um período de 66 dias para a bebida armazenada a temperatura ambiente e por 141 dias 
para a bebida armazenada sob refrigeração. Para a bebida armazenada a temperatura ambiente a média do $\mathrm{pH}$ foi de 3,06, a de acidez foi de $0,46 \mathrm{~g} / 100 \mathrm{~mL}$ e ${ }^{\circ}$ Brix de 8,2. Para a bebida armazenada sob refrigeração os valores encontrados, de acidez titulável e ${ }^{\circ}$ Brix, foram os mesmos resultados encontrados para a bebida armazenada a temperatura ambiente. Somente os valores de $\mathrm{pH}$ alteraram, os resultados variaram na faixa de 2,9-3,23.

Petrus e Faria (2005) produziram bebidas isotônicas sabor laranja e avaliaram algumas características físico-químicas como $\mathrm{pH},{ }^{\circ}$ Brix e acidez titulável por um período de 26 semanas. Os autores relataram resultados de determinações de sólidos solúveis entre 5,9-6,8, de acidez titulável em torno de $0,1 \mathrm{~g}$ de ácido cítrico/100 mL de amostra e de $\mathrm{pH}$ entre 3,2-3,5.

Cavalcanti et al. (2010) avaliou o pH, a acidez titulável e o teor de sólidos solúveis de nove bebidas isotônicas disponíveis comercialmente. Dentre elas estava o Gatorade ${ }^{\circledR}$ sabor tangerina. As médias dos resultados encontrados para esta bebida foram $\mathrm{pH}$ de 2,03, acidez titulável de $0,32 \mathrm{~g}$ de ácido cítrico/100 $\mathrm{mL}$ e sólidos solúveis $6,33 \%$ a $23{ }^{\circ} \mathrm{C}$ e de $6,66 \%$ a $9{ }^{\circ} \mathrm{C}$.

Santos et al. (2013b) desenvolveram uma bebida isotônica orgânica de tangerina. Os resultados encontrados foram de $5,91^{\circ}$ Brix, $0,21 \%$ de acidez titulável e 3,2 de $\mathrm{pH}$ para a bebida produzida com $15 \%$ de suco de tangerina orgânico. Para a bebida produzida com 5\% de suco de tangerina orgânico os resultados encontrados foram 5,79 Brix, $0,13 \%$ de acidez titulável e 3,1 de pH.

Desta forma, pode-se observar que os resultados físico-químicos encontrados no presente estudo estão em conformidade com os resultados dos outros estudos. Somente o teor de sólidos solúveis está um pouco abaixo do encontrado na literatura.

Na Tabela 29 pode-se observar os parâmetros colorimétricos para as três formulações de bebida isotônica. Com relação ao parâmetro L* (luminosidade) houve uma diminuição e com relação ao parâmetro a* (eixo vermelho (+)/verde(-)) houve um aumento para a formulação controle e entre o dia 0 e dia 8 para as formulações I2 e I3. Entre os dias 8 e 38 houve uma diminuição do parâmetro a* para as formulações I2 e I3. A diminuição do parâmetro $\mathrm{a}^{*}$ para estas formulações comprova a perda da coloração avermelhada das nanoemulsões, fato relacionado com a degradação do $\beta$-caroteno encapsulado. Já com relação ao parâmetro b* (eixo amarelo (+) /azul(-)) e C*(croma) houve um aumento para as formulações controle e I2. 
Os resultados encontrados no presente trabalho de Mestrado estão de acordo com os resultados encontrados por Rosso e Mercadante (2007). Estes produziram bebida isotônica com antocianinas extraídas da acerola e do açaí e relataram uma mudança na tonalidade da bebida de vermelho para amarelo. Tal mudança de tonalidade foi acompanhada pela perda dos valores do parâmetro $a^{*}$, acompanhada de um decréscimo na intensidade da cor observada pela diminuição do parâmetro $C^{*}$.

Com relação ao ângulo de Hue, o qual é um indicativo de tonalidade, observa-se que todas as formulações ficaram na faixa de 70 a $75{ }^{\circ} \mathrm{C}$, o que corresponde a uma coloração entre o amarelo e o amarelo laranja, conforme pode observar pela Figura 24.

Figura 24 - Diagrama CIELAB com sequência de nuances de cores e orientação do ângulo de Hue.

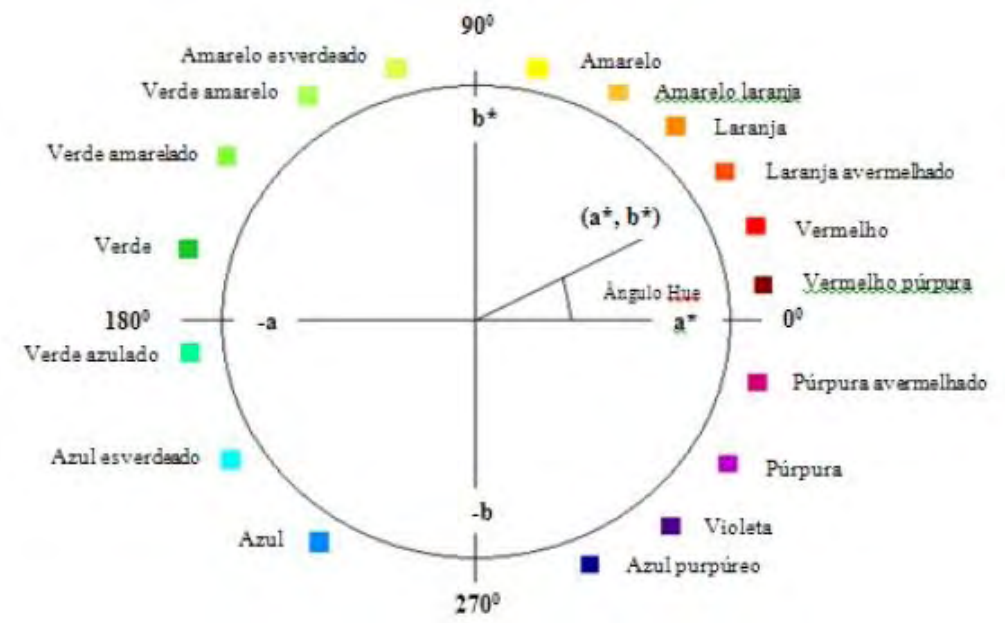

Fonte: ADRIANO, E. et al. Qualidade de fruto de aceroleira cv. Olivier em dois estágios de maturação. Revista Brasileira de Fruticultura, Jaboticabal, v. 33, 2011. 
Tabela 29 - Resultados das determinações de cor instrumental para as três formulações de bebida isotônica (I2 = $25 \%$ nanoemulsão $3 \mathrm{M}$ de $\mathrm{NaCl}$ e $\mathrm{I} 3=30 \%$ nanoemulsão 2,5 M de $\mathrm{NaCl})$.

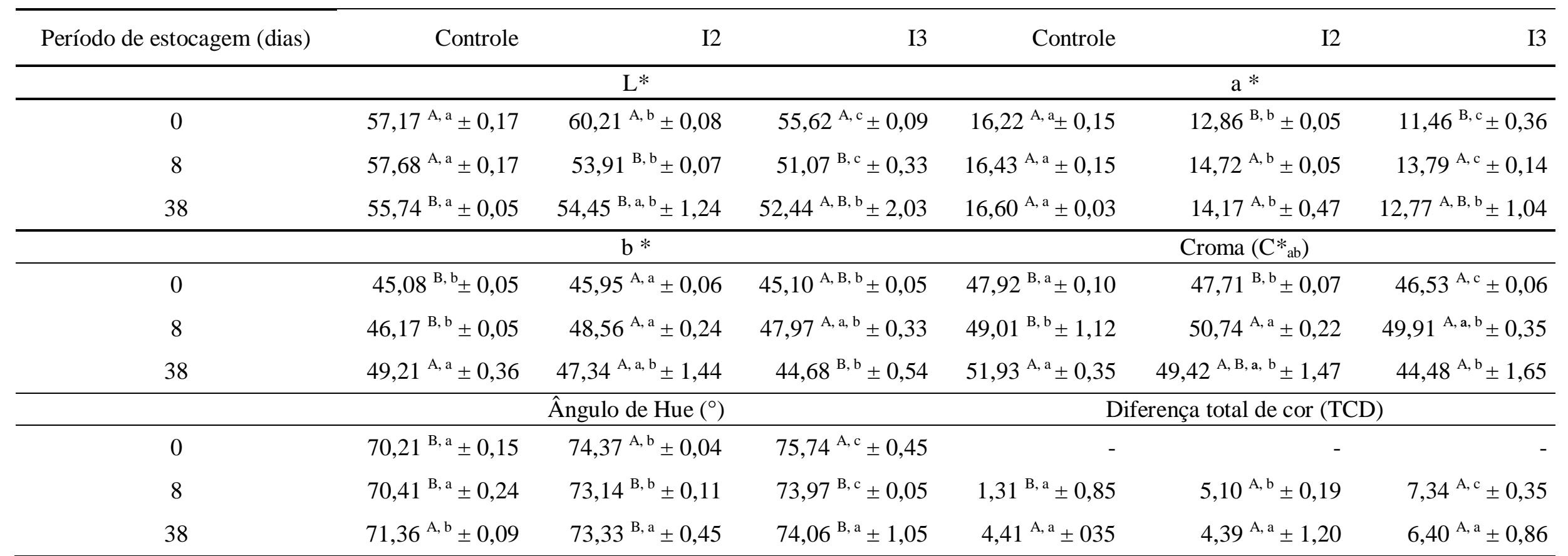

Médias de resultados seguidas por letras maiúsculas distintas na mesma coluna apresentam diferença estatística significativa a $p<0,05$ pelo teste de Tukey.

Médias de resultados seguidas por letras minúsculas distintas na mesma linha apresentam diferença estatística significativa a p $<0,05$ pelo teste de Tukey.

Fonte: Própria autoria 


\subsection{ANÁLISES MICROBIOLÓGICAS}

Segundo Monteiro e De Marchi (2010), bebidas isotônicas apresentam pH próximo de 3,5 e elevada acidez, condições estas que favorecem o crescimento de bolores e leveduras. Por esse motivo análises de fungos psicrotróficos da bebida isotônica foram realizadas. Além desta análise também foi feita a contagem total de aeróbios mesófilos uma vez que este é o método mais utilizado como indicador geral de populações bacterianas em alimentos (SILVA et al., 2010). Ambas as análises foram feitas com a finalidade de quantificar a população microbiana após o tratamento térmico e assim assegurar que a bebida isotônica estaria própria para ser consumida durante a realização da análise sensorial. As contagens de mesófilos aeróbios totais e de fungos psicrotróficos para a bebida isotônica foi ausente para todas as formulações, conforme mostrado na Tabela 30.

Tabela 30 - Resultados dos testes microbiológicos (I2 = 25\% nanoemulsão $3 \mathrm{M}$ de $\mathrm{NaCl}$ e I3 = $30 \%$ nanoemulsão $2,5 \mathrm{M}$ de $\mathrm{NaCl})$.

\begin{tabular}{lccl}
\cline { 2 - 4 } & \multicolumn{3}{c}{ Formulações } \\
\hline Análise & Controle & I2 & I3 \\
\hline Mesófilos aeróbios (UFC/ $\mathrm{mL})$ & Aus $/ 25 \mathrm{~mL}^{*}$ & Aus $/ 25 \mathrm{~mL}^{*}$ & Aus $/ 25 \mathrm{~mL}^{*}$ \\
Fungos psicrotróficos $(\mathrm{UFC} / \mathrm{mL})$ & Aus $/ 25 \mathrm{~mL}^{*}$ & Aus $/ 25 \mathrm{~mL}^{*}$ & Aus $/ 25 \mathrm{~mL}^{*}$
\end{tabular}

*Aus $/ 25 \mathrm{~mL}=$ ausência em $25 \mathrm{~mL}$ de bebida analisada

Fonte: Própria autoria.

Segundo Petrus e Faria (2005) para garantir estabilidade e segurança microbiológica da bebida isotônica quatro obstáculos podem ser considerados. A citar alta acidez, tratamento térmico, adição de conservantes e assepsia e adequação da embalagem. No presente estudo empregaram-se os quatro obstáculos conjuntamente, que contribuíram para obtenção de uma ótima qualidade microbiológica da bebida isotônica, sob as condições estudadas. Ainda de acordo com Monteiro e De Marchi (2010), bolores e leveduras apresentam baixa resistência térmica, de forma que estes são facilmente eliminados em temperaturas usuais de pasteurização. Fato esse que indica que o obstáculo do tratamento térmico foi essencial para garantir a qualidade microbiológica do produto.

Vale ressaltar que ainda não foram estabelecidos padrões microbiológicos para repositores hidroeletrolíticos. Entretanto a Resolução $n^{\circ} 12$ da ANVISA de 02 de janeiro 
de 2001 (BRASIL, 2001) apresenta especificações para contagem de bolores e leveduras em: sucos concentrados congelados, sucos e refrescos in natura, preparo líquido para refrescos e refrigerantes e sucos concentrados adicionados ou não de conservantes. Os valores máximos permitidos estão entre $10^{2}$ e $10^{4} \mathrm{UFC} / \mathrm{mL}$.

Petrus e Faria (2005) avaliaram a estabilidade microbiológica de 3 diferentes lotes de bebida isotônica estocados a $25^{\circ} \mathrm{C}$ por 26 semanas. As contagens de bolores e leveduras e mesófilos aeróbios totais foram de $<10 \mathrm{UFC} / \mathrm{mL}$ e $\leq 5,7 \mathrm{UFC} / \mathrm{mL}$ respectivamente para os três diferentes lotes. Os resultados encontrados por De Marchi et al. (2003) para contagem de bolores e leveduras em dois tipos de isotônico natural de maracujá, estocados a temperatura ambiente e refrigerada, apresentaram contagens inferiores a 10UFC/mL. Já para mesófilos aeróbios foi de $<40 \mathrm{UFC} / \mathrm{mL}$ para a bebida armazenada a temperatura ambiente por 66 dias e de $<60 \mathrm{UFC} / \mathrm{mL}$ para bebida armazenada sob refrigeração por 141 dias. Os resultados encontrados por Santos et al. (2013b) ao produzirem bebida isotônica orgânica de tangerina foram de valores inferiores a $2 \mathrm{UFC} / \mathrm{mL}$ para bactérias mesófilas aeróbias e contagens ausentes para bolores e leveduras para as três bebidas estudadas durante 30 dias e mantidas a $4{ }^{\circ} \mathrm{C}$

\subsection{AVALIAÇÃO SENSORIAL}

\subsubsection{Teste de diferença de controle}

Para a avaliação sensorial optou-se em analisar somente duas das três formulações processadas (controle e I2), pois percebeu-se que a formulação I3 estava com forte aroma e sabor residual, provavelmente devido ao uso do tensoativo Tween 80 .

A Tabela 31 mostra os resultados obtidos no teste de diferença de controle. O teste de diferença de controle permitiu verificar que há diferença significativa $(p<0,05)$ pelo teste de Tukey para todos os atributos estudados. Conforme pode-se observar o grau de diferença, para a amostra controle, foi de 1,76 para o parâmetro cor, de 1,86 para o parâmetro aroma e de 2,02 para o parâmetro sabor em uma escala de 5 pontos. Esse alto grau de diferença, para a amostra controle, também foi verificada em diferentes trabalhos que realizaram o teste de diferença de controle. Umbelino et al. (2001) por exemplo encontrou grau de diferença de 3,13, utilizando-se de uma escala de 9 pontos e com 30 provadores não-treinados. Nascimento et al. (2007) encontraram grau 
de diferença de 5,50, 5,20 e 5,60 para diferentes atributos, utilizando-se de uma escala de 9 pontos e com 10 provadores treinados. Tais estudos indicam que os resultados independem da escolha de provadores treinados ou não treinados

Os resultados indicam ainda que a diferença entre as médias da bebida controle e da formulação I2 foi de 0,94 para o atributo cor, de 1,60 para o atributo aroma e de 2,16 para o atributo sabor. Indicando que a maior diferença foi encontrada para o atributo sabor.

Tabela 31 - Teste diferença de controle realizado nas formulações controle e I2 (I2 $=25 \%$ nanoemulsão $3 \mathrm{M}$ de $\mathrm{NaCl})$.

\begin{tabular}{ccccccc}
\hline \multirow{2}{*}{ Atributos } & \multicolumn{2}{c}{ Cor } & \multicolumn{2}{c}{ Aroma } & \multicolumn{2}{c}{ Sabor } \\
\cline { 2 - 7 } & Controle & I2 & Controle & I2 & Controle & I2 \\
\hline Médias & $1,76^{\mathrm{A}} \pm 0,83$ & $2,7^{\mathrm{B}} \pm 0,98$ & $1,86^{\mathrm{A}} \pm 0,93$ & $3,46^{\mathrm{B}} \pm 1,19$ & $2,02^{\mathrm{A}} \pm 0,91$ & $4,18^{\mathrm{B}} \pm 0,95$
\end{tabular}

Médias de resultados seguidas por letras iguais na mesma linha, para um mesmo atributo apresentam diferença estatística significativa a $\mathrm{p}<0,05$ pelo teste de Tukey.

Fonte: Própria autoria.

\subsubsection{Teste de escala hedônica}

Os resultados obtidos no teste de aceitação, para as duas formulações de bebida isotônica, estão apresentados na Tabela 32. O teste de escala hedônica mostrou que há diferença significativa $(p<0,05)$ pelo teste Tukey entre a formulação controle e a I2, para todos os atributos avaliados. Esta diferença se deu principalmente com relação aos atributos aroma e sabor, indicando que o sabor residual das nanoemulsões é extremamente perceptível aos consumidores.

Tabela 32 - Resultados teste escala hedônica realizado nas formulações controle e I2 (I2 $=25 \%$ nanoemulsão $3 \mathrm{M}$ de $\mathrm{NaCl}$ ).

\begin{tabular}{ccccccc}
\hline \multirow{2}{*}{ Atributos } & \multicolumn{2}{c}{ Cor } & \multicolumn{2}{c}{ Aroma } & \multicolumn{2}{c}{ Sabor } \\
\cline { 2 - 7 } & Controle & I2 & Controle & I2 & Controle & I2 \\
\hline Médias & $7,3^{\mathrm{A}} \pm 1,1$ & $6,2^{\mathrm{B}} \pm 1,8$ & $6,3^{\mathrm{A}} \pm 1,3$ & $4,3^{\mathrm{B}} \pm 1,8$ & $6,3^{\mathrm{A}} \pm 1,7$ & $3,3^{\mathrm{B}} \pm 2,0$
\end{tabular}

Médias de resultados seguidas por letras iguais na mesma linha, para um mesmo atributo, apresentam diferença estatística significativa a $\mathrm{p}<0,05$ pelo teste de Tukey.

Fonte: Própria autoria. 
Os resultados indicam ainda que a diferença entre as médias da bebida controle e da formulação I2 foi de 1,10 para o atributo cor, de 2,00 para o atributo aroma e de 3,00 para o atributo sabor. Indicando que a maior diferença foi encontrada para o atributo sabor.

Para complementar o teste aceitação foi feito um teste de intenção de compra das duas formulações de bebida isotônica, tal resultado é mostrado na Figura 25.

Figura 25 - Intenção de compra das formulações de bebida isotônica sabor tangerina.

\section{Intenção de Compra}

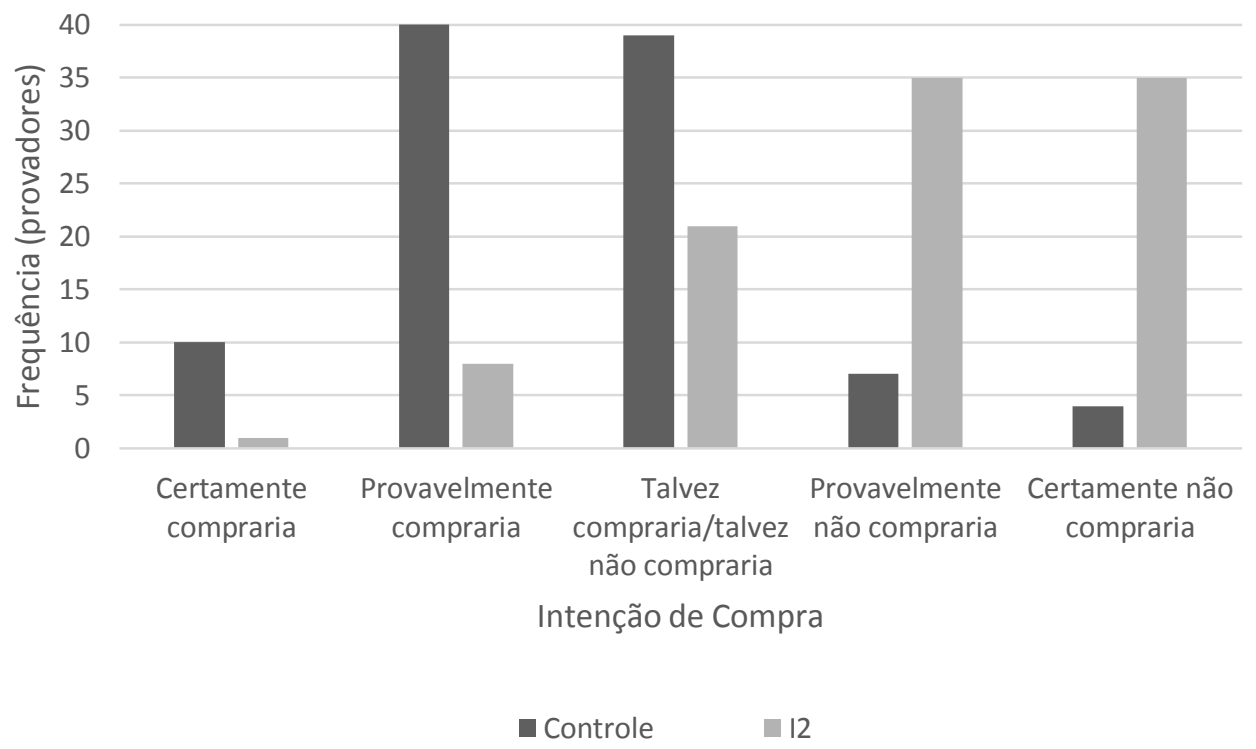

Fonte: Própria autoria.

O gráfico de intenção de compra revela uma preferência, por parte dos consumidores pela formulação controle. Apesar da aparente não-aceitação do produto, é interessante que mais testes sejam feitos com o intuito de mascarar o sabor residual deixado pela nanoemulsão. Conforme já mencionado anteriormente, a aplicação de nanoemulsão em produtos alimentícios é extremamente interessante uma vez que o mesmo pode atuar como sistema de entrega para compostos lipofílicos, tais como nutracêuticos e antioxidantes. 


\section{CONCLUSÕES}

Diante dos resultados experimentais obtidos foi possível concluir, com relação à estabilidade, que todas as formulações estudadas mostraram-se estáveis ao longo dos 60 dias de estocagem sob refrigeração. Através dos perfis de distribuição de tamanho e diâmetro hidrodinâmico, notou-se que as partículas apresentaram estabilidade relativa ao longo do período de estocagem. Os dados de TBARs indicaram que a oxidação lipídica não se mostrou significativa no sistema nanoemulsionado.

Com relação a incorporação de óleo de buriti nanoemulsionado em bebida isotônica, foi possível verificar que é possível a incorporação das nanoemulsões sem que haja separação de fases. Vale ressaltar que a bebida isotônica é um produto com diversas condições de stress, tais como pH em torno de 3 e altas concentrações de sal e açúcar, além de exigir o emprego de altas temperaturas durante o processo de produção.

Com relação às características físico-químicas da bebida isotônica, é possível afirmar que as bebidas apresentaram níveis adequados de sólidos solúveis, acidez e pH, assim como nas análises microbiológicas.

Por meio da realização de análise sensorial, observou-se que para uma primeira tentativa de incorporação de nanoemulsões em bebida isotônica os resultados se mostraram relativamente satisfatórios. Os resultados indicam que se modificações na formulação da bebida isotônica forem implementadas, por exemplo a utilização de sabores que necessitem de menos quantidade de corante, como laranja ou maracujá, a incorporação de nanoemulsões pode ser realmente bem-sucedida. 


\section{SUGESTÕES PARA TRABALHOS FUTUROS}

- Para mascarar o sabor residual deixado pelo Tween 80 (tensoativo utilizado para produção da nanoemulsão) na bebida isotônica sugere-se adicionar mais aroma na formulação e/ou testar diferentes formulações de nanoemulsão, como por exemplo utilizar outro tensoativo, como fosfolipídios ou uma mistura de tensoativos.

- O óleo de buriti nanoemulsionado pode ser testado em bebida isotônica de outros sabores, tais como laranja e maracujá, ou ser aplicado em outros tipos de produtos alimentícios.

- Novas formulações de óleo de buriti nanoemulsionado, com diferentes concentrações de sal, podem ser testadas visando a aplicação em outros produtos tais como em iogurtes e sorvetes.

- Comparação sensorial com a marca líder de mercado. 


\section{REFERÊNCIAS}

ADRIANO, E. et al. Qualidade de fruto de aceroleira cv. Olivier em dois estágios de maturação. Revista Brasileira de Fruticultura, Jaboticabal, v. 33, 2011.

AFONSO, S. R.; ÂNGELO, H. Mercado dos produtos florestais não-madeireiros do cerrado brasileiro. Ciência Florestal, Santa Maria, v. 19, n. 3, p. 315-326, jul./set. 2009.

ALBUQUERQUE, M. L. S. et al. Characterization of buriti (Mauritia flexuosa L.) oil by absorption and emission spectroscopies. Journal of the Brazilian Chemical Society, São Paulo, v. 16, n. 6A, p. 1113-1117, 2005.

ANTON, N. et al. Nano-emulsions and nanocapsules by the PIT method: an investigation on the role of the temperature cycling on the emulsion phase inversion. International Journal of Pharmaceutics, Amsterdam, v. 344, p. 44-52, 2007.

ANTON, N.; BENOIT, J. P.; SAULNIER, P. Design and production of nanoparticles formulated from nano-emulsion templates. Journal of Controlled Release, Amsterdam, v. 128, p. 185-199, 2008.

ANTON, N.; VANDAMME, T. F. The universality of low-energy nano-emulsification. International Journal of Pharmaceutics, Amsterdam, v. 377, p. 142-147, 2009.

AQUINO, J. S. et al. Refining of buriti oil (Mauritia flexuosa) originated from the Brazilian cerrado: physicochemical, thermal-oxidative and nutritional implications. Journal of Brazilian Chemical Society, São Paulo, v. 23, p. 212-219, 2012 a.

AQUINO, J. S. et al. Processamento de biscoitos adicionados de óleo de buriti (Mauritia flexuosa L.): uma alternativa para o consumo de alimentos fontes de vitamina A na merenda escolar. Revista de Nutrição, Campinas, v. 25, n. 6, p. 765-774, nov./dez. 2012 b.

BORRIN, T.R. et al. Curcumin-loaded nanoemulsions produced by the emulsion inversion point (EIP) method: an evaluation of process parameters and physicochemical stability. Journal of Food Engineering, London, (in press- accepted manuscript), 2015.

BOTTERI, R. L.; BOTTERI, M. K. An isotonic sports drink for female athletes fortified with iron, calcium and essential vitamins for use in rehydration and nutrition during exercise competition. US n. 2005/0095320, maio 2005. Disponível em:<http://www.google.com/patents/US20050095320>. Acesso em: 30 ago. 2015.

BOUCHEMAL, K. et al. Nano-emulsion formulation using spontaneous emulsification: Solvent, oil and surfactant optimization. International Journal of Pharmaceutics, Amsterdam, v. 280, p. 241-251, 2004. 
BRASIL ECONÔMICO. Ambev e Coca-cola agitam o mercado de isotônicos. São Paulo, 2014. Disponível em:<http://brasileconomico.ig.com.br/negocios/2014-0915/ambev-e-coca-agitam-mercado-de-isotonicos.html >. Acesso em: 04 jul. 2015.

BRASIL. Resolução no 44, de 25 de novembro 1977. Normas reguladoras do emprego de aditivos para alimentos. Disponível em: < http://www.anvisa.gov.br/anvisalegis/resol/44_77.htm>. Acesso em: 19 out. 2015.

BRASIL. Ministério da Agricultura. Metodologia de análise de bebidas e vinagres. Laboratório Nacional de Defesa Vegetal, Brasília, 1986. p. 67.

BRASIL. resolução no 12, de 02 de janeiro de 2001. Princípios gerais para o estabelecimento de critérios e padrões microbiológicos para alimentos. Disponível em:< hhttps://www.diariodasleis.com.br/busca/exibelink.php?numlink=1-9-34-2001-01-0212>. Acesso em: 17 out. 2015.

BRASIL. Resolução no 18, de 27 de setembro de 2010. Aprovação, regulamento técnico, alimento para praticante de atividade física, atleta profissional, composição dos alimentos, rotulagem, suplemento alimentar. Disponível em:< http://www.crn3.org.br/legislacao/doc/RDC_18_2010.pdf>. Acesso em: 29 ago. 2015.

BRASIL. Resolução no 382 a 388, de 09 de agosto de 1999. Regulamento técnico que aprova o uso de Aditivos Alimentares, estabelecendo suas Funções e seus Limites Máximos para a Categoria de Alimentos 19. Disponível em:< http://portal.anvisa.gov.br/wps/wcm/connect/76591a8047457c278903dd3fbc4c6735/RE SOLUCAO_388_1999.pdf?MOD=AJPERES>. Acesso em: 29 ago. 2015.

CARVALHO, C. O. et al. Características físicas, químicas e rendimento do óleo de buriti (Maurita flexuosa L..f. - Arecaceae). In: SANTOS-SILVA, E. N. et al. (Orgs.). BioTupé: meio físico, diversidade biológica e sociocultural do baixo Rio Negro. Manaus: Amazônia Central, 2011. v. 3, p. 123-134.

CASTRO, F. J.; SCHERER, R.; GODOY, H. T. Avaliação do teor e da estabilidade de vitaminas do complexo B e vitamina $\mathrm{C}$ em bebidas isotônicas e energéticas. Química Nova, São Paulo, v. 29, n. 4, p. 719-723, 2006.

CAVALCANTI, A.L. et al. Avaliação in vitro do potencial erosivo de bebidas isotônicas. Revista Brasileira de Medicina do Esporte, São Paulo, v.16, n. 6, 2010.

CERIANI, R. et al. Densities and viscosities of vegetable oils of nutritional value. Journal of Chemical and Engineering Data, Washington, v. 53, p. 1846-1853, 2008.

CONSTANT, P. B. L.; STRINGHETA, P. C.; SANDI, D. Corantes alimentícios. Boletim Ceppa, Curitiba, v. 20, n. 2, p. 203-220, jul./dez. 2002. 
CORNACCHIA, L.; ROOS, Y. H. Stability of $\beta$-carotene in protein-stabilized oil inwater delivery systems. Journal of Agricultural and Food Chemistry, Easton, v. 59, p. 7013-7020, 2011.

DE MARCHI, R.; MONTEIRO, M. Avaliação da vida-de-prateleira de um isotônico natural de maracujá (Passiflora edulis Sims.f.flavicarpa Deg.). Brazilian Journal of Food Technology, Campinas, v. 6, n. 2, p. 291-300, 2003.

DOWNHAM, A.; PAUL COLLINS, P. Colouring our foods in the last and next millennium. International Journal of Food Science and Technology, Oxford, v. 35, p. $5-22,2000$.

EMBRAPA. Buriti (Mauritia flexuosa L.). Centro de Pesquisa Agroflorestal de Rondônia. Porto Velho, 2005.

FRANÇA, L. F. et al. Supercritical extraction of carotenoids and lipids from buriti (Mauritia flexuosa), a fruit from the Amazon region. Journal of Supercritical Fluids, Amsterdam, v. 14, p. 247-256, 1999.

FRASER, P. D.; BRAMLEY, P. M. The biosynthesis and nutritional uses of carotenoids: a review. Progress in Lipid Research, Kidlington, v. 43, p. 228-265, 2004.

GALDINO, A. P. P. Estudo de mercado: Andiroba, Buriti/Miriti e Murumuru. Instituto do Homem e Meio Ambiente da Amazônia, 2007.

GANACHAUD, F.; KATZ, J. L. Nanoparticles and nanocapsules created using the ouzo effect: spontaneous emulsification as an alternative to ultrasonic and high-shear devices. ChemPhysChem, Weinheim, v. 6, p. 209-216, 2005.

GIRONÉS-VILAPLANA, A. et al. New isotonic drinks with antioxidante and biological capacities from berries (maqui, açaí and blackthorn) and lemon juice. International Journal of Food Sciences and Nutrition, London, v. 64, p. 897-906, 2013.

GOMES, G. V. L. Nanopartículas lipídicas produzidas por método de baixa energia: otimização das condições de processo, avaliação da absorção de bioativo encapsulado e estudo de digestibilidade in vitro. Tese (Doutorado) - Faculdade de Zootecnia e Engenharia de Alimentos, Universidade de São Paulo, Pirassununga, 2015.

GUINÉ, R. P. F.; HENRIQUES, F. O Papel dos ácidos gordos na nutrição humana e desenvolvimentos sobre o modo como influenciam a saúde. Millenium, Viseu, v. 40, p. 7-21, 2011.

HENRY, B. S. Natural food colours. In: HOUGHTON, J. D.; HENDRY, G. A. Natural food colorants. New York: Sringer, 1996. p. 40-79.

HEURTAULT, B. et al. A novel phase inversion-based process for the preparation of lipid nanocarriers. Pharmaceutical Research, New York, v. 19, n. 6, p. 875-880, 2002. 
IZQUIERDO, P. et al. Formation and stability of nano-emulsions prepared using the phase inversion temperature method. Langmuir, Washington, v. 18, p. 26-30, 2002.

LEE, S. J. et al. Protein-stabilized nanoemulsions and emulsions: comparison of physicochemical stability, lipid oxidation, and lipase digestibility. Journal of Agricultural and Food Chemistry, Easton, v. 59, p. 415-427, 2011.

LIMA, M. D. G. et al. Efeito do estresse salino sobre a concentração de pigmentos e prolina em folhas de arroz. Bragantia, Campinas, v. 63, p.335-340, 2004.

LIMA, A. L. S. et al. Avaliação dos efeitos da radiação gama nos teores de carotenóides, ácido ascórbico e açúcares do fruto buriti do brejo (Mauritia flexuosa L.). Acta Amazonica, Manaus, v. 39, p. 649-65, 2009.

MARIATH, J. G. R.; LIMA, M. C. C.; SANTOS, L. M. P. Vitamin A activity of buriti (Mauritia vinifera Mart) and itseffectiveness in the treatment and prevention of xerophthalmia. American Journal of Clinical Nutrition, Bethesda, p. 849-853, 1989.

MARTINS, R. C. et al. Avaliação da vida de prateleira de bebida isotônica elaborada com suco concentrado de frutas e hortaliças congelado por 30 dias. Alimentos e Nutrição, Araraquara, v. 22, n. 4, p.623-629, out./dez. 2011.

MASON, T. G. et al. Nanoemulsions: formation, structure, and physical properties. Journal of Physics: Condensed Matter, Bristol, v. 18, n. 41, p. 635-666, 2006.

McCLEMENTS, D. Food emulsions: principles, practice, and techniques. 2. ed. Boca Raton: CRC Press, 2005.

McCLEMENTS, D. J.; RAO, J. Food-grade nanoemulsions: formulation, fabrication, properties, performance, biological fate, and potential toxicity. Critical Reviews in Food Science and Nutrition, Boca Raton, v. 51, p. 285-330, 2011.

McCLEMENTS, D. J. Advances in fabrication of emulsion with enhanced functionality using structural design principles. Current Opinion in Colloid \& Interface Science, Kidlington, v. 17, p. 235-245, 2012.

McCLEMENTS, D. J. Lipid-based emulsions and emulsifiers. In: AKOH, C. C.; MIN, D. B. Food lipids: chemistry, nutrition, and biotechnology. 3. ed. Boca Raton: CRC Press, 2008. p. 63-97.

MEI, Z. et al. Preparation of positively charged oil/water nano-emulsions with a subPIT method, Journal of Colloid and Interface Science, New York, v. 361, p. 565-572, 2011.

MEILGAARD, M.; CIVILLE, G. V.; CARR, B. T. Sensory evaluation techniques. 3. Boca Raton: CRC Press, 1999.

MONTEIRO, M; DE MARCHI, R. Bebidas isotônicas in bebidas não alcoólicas. In: FILHO, W. G. V. F. Bebidas não alcoólicas: ciência e tecnologia. São Paulo: Blucher, 2010. v. 2, p. 81-88. 
MORAIS, L. R. B.; GUTJAHR, E. Chemistry of vegetable oils: valorization of amazonian biodiversity. Brasília: Agência de Cooperação Técnica Alemã (GTZ), 2009.

MORALES, D. et al. A study of the relation between bicontinuous microemulsions and oil/water nano-emulsion formation. Langmuir, Washington, v. 19, p. 7196-7200, 2003.

MOUTINHO, I. L. S.; BERTGES L. C.; ASSIS, R. V. C. Prolonged use of food dye tartrazine (FD\&C yellow n5) and its effects on the gastric mucosa of wistar rats. Brazilian Journal Biology, São Carlos, v. 67, p. 141-5, 2007.

NASCIMENTO, R. et al. Substituição de cloreto de sódio por cloreto de potássio: influência sobre as características físico-químicas e sensoriais de salsichas. Alimentos e Nutrição, Araraquara, v. 18, n. 3, p. 297-302, 2007.

OLIVEIRA, B. R. Desenvolvimento e avaliação de nanoemulsões com óleos de Carapa guianensis e Copaifera sp. e estudo da ação repelente frente a Aedes aegypti. 2008. 100 f. Dissertação (Mestrado) - Faculdade de Ciências Farmacêuticas de Ribeirão Preto, Universidade de São Paulo, Ribeirão Preto, 2008.

OLIVEIRA, D. L. Viabilidade econômica de algumas espécies medicinais nativas do cerrado. Revista UCG Estudos, Goiânia, v. 38, p. 301-332, 2011.

OSTERTAG, F.; WEISS, J.; MCCLEMENTS, D. J. Low-energy formation of edible nanoemulsions: Factors influencing droplet size produced by emulsion phase inversion. Journal of Colloid and Interface Science, New York, v. 388, p. 95-102, 2012.

PATHARE, P. B.; OPARA, U. L.; AL-JULANDA AL-SAID, F. Colour measurement and analysis in fresh and processed foods: a review. Food Bioprocess and Technology, New York, v. 6, p. 36-60, 2013.

PETRUS, R. R.; FARIA, J. A. F. Processamento e avaliação de estabilidade de bebida isotônica em garrafa plástica. Ciência e Tecnologia de Alimentos, Campinas, v. 25, n. 3, p. 518-524, 2005.

PIMENTEL, S. A. et al. Composição de ácidos graxos e tocoferóis em óleos especiais. In: II CONGRESSO BRASILEIRO DE PLANTAS OLEAGINOSAS, ÓLEOS, GORDURAS E BIODIESEL, 2, 2005, Varginha. Anais... Varginha, 2005.

PRADO, M. A.; GODOY, H. T. Corantes artificiais em alimentos. Alimentos e Nutrição, Araraquara, v. 14, n. 2, p. 237-250, 2003.

REGITANO-D'ARCE, M. A. B. Química básica dos lipídeos. In: OETERRER, M. et al. Fundamentos de ciência e tecnologia de alimentos. Barueri: Manole, 2006. p 197242.

RODRIGUES, A. M. C.; DARNET, S.; MELlER DA SILVA, L. H. M. Fatty Acid Profiles and Tocopherol Contents of Buriti (Mauritia flexuosa), Patawa (Oenocarpus bataua), Tucuma (Astrocaryum vulgare), Mari (Poraqueiba paraensis) and Inaja 
(Maximiliana maripa) fruits. Journal of the Brazilian Chemical Society, São Paulo, v. 21, n. 10, p. 2000-2004, 2010.

RODRIGUES-AMAYA, D. B.; KIMURA, M.; AMAYA-FARFAN, J. Fontes brasileiras de carotenoides: tabela brasileira de composição de carotenoides em alimentos. Brasília: MMA/SBF, 2008.

ROSSO, V. V.; MERCADANTE, A. Z. Evaluation of colour and stability of anthocyanins from tropical fruits in an isotonic soft drink system. Innovative Food Science and Emerging Technologies, Amsterdam, v. 8, p. 347-352, 2007.

RUOZI, B. et al. Atomic force microscopy and photon correlation spectroscopy: Two techniques for rapid caracterization of liposomes. European Journal of Pharmaceutical Sciences, Amsterdam, v. 25, p. 81-89, 2005.

SAMPAIO, M. B.; CARRAZZA, L. R. Manual tecnológico de aproveitamento integral do fruto e da folha do buriti (Mauritia flexuosa). Brasília, 2012.

SANTOS, R. D. et. al. I Diretriz sobre o consumo de gorduras e saúde cardiovascular. Arquivos Brasileiro de Cardiologia, São Paulo, v. 100, n. 1, jan. $2013 \mathrm{a}$.

SANTOS, E. S. M.; ALVES, R. M.; LIMA, C. S. Elaboração tecnológica e aceitação sensorial de bebida isotônica orgânica de tangerina (Citrus reticulata Blanco). Revista do Instituto Adolfo Lutz, São Paulo, v. 72, n. 1, p. 87-92, 2013 b.

SANTURIO, J. M. et al. Atividade antimicrobiana dos óleos essenciais de orégano, tomilho e canela frente a sorovares de Salmonella enterica de origem avícola. Ciência Rural, Santa Maria, v. 37, n. 3, p. 803-808, mai-jun, 2007.

SCHUMANN, S. P. A.; POLÔNIO, M. L. T.; GONÇALVES, E. C. B. A. Avaliação do consumo de corantes artificiais por lactentes, pré-escolares e escolares. Ciência e Tecnologia de Alimentos, Campinas, v. 28, n. 3, p.534-539, jul.-set. 2008.

SHINODA, K. The comparison between the PIT system and the HLB-value system to emulsifier selection. In: CONGRESS OF SURFACE ACTIVITY, 5, 1969, Barcelona. Proceeding of the $\mathbf{5}^{\text {th }}$ International Congress of Surface Activity, Barcelona, 1969. v. 2, p. 275-283.

SHINODA, K.; SAITO, H. The effect of temperature on the phase equilibria and the types of dispersions of the ternary system composed of water, cyclohexane, and nonionic surfactant. Journal of Colloid and Interface Science, Maryland Heights, v. 26, p. 70-74, 1968.

SIGMA-ALDRICH. Non-Ionic detergent. Saint Louis, 2015. Diponível em:< http://www.sigmaaldrich.com/life-science/biochemicals/biochemicalproducts.html?TablePage=14572924>. Acesso em: 29 ago. 2015.

SILVA, H. D.; CERQUEIRA, M. A.; VICENTE, A. A. Nanoemulsions for food applications: development and characterization. Food Bioprocess Technology, Braga, 2011. 
SILVA, N. et al. Manual de métodos de análise microbiológica de alimentos e água. 4. ed. São Paulo: Varela, 2010.

SILVA, S. M. et al. Characterization of oil extracted from buriti fruit (Mauritia flexuosa) grown in the Brazilian Amazon region. Journal of the American Oil Chemists Sociaty, Heidelberg, v. 86, n. 6, p. 11-616, 2009.

SOLANS, C. et al. Nanoemulsions. Current opinion in Colloid e Interface Science, Kidlington, v. 10, p. 102-110, 2005.

SOLANS, C.; SOLÈ, I. Nano-emulsions: formation by low-energy methods. Current Opinion in Colloid \& Interface Science, Kidlington, v. 17, p. 246-254, 2012.

SPERNATH, L.; MAGDASSI, S. A new method for preparation of poly-lauryl acrylate nanoparticles from nanoemulsions obtained by the phase in,version temperature processy Polymers For Advanced Technologies, New York, v. 18, p. 705-711, 2007.

TEO, B. S. X. et al. potential tocopherol acetate loaded palm oil esters-in-water nanoemulsions for nanocosmeceuticals. Journal of Nanobiotechnology, London, v. 8, n. 4, p. 1-12, 2010.

UMBELINO, D. C. et al. Aspectos tecnológicos e sensoriais do "iogurte" de soja enriquecido com cálcio. Ciência e Tecnologia de Alimentos, Campinas, v. 21, n. 3, 2001.

VIDOTTI, E. C.; ROLLEMBERG, M. C. R. Espectrofotometria derivativa: uma estratégia simples para a determinação simultânea de corantes em alimentos. Química Nova, São Paulo, v. 29, n. 2, p. FA230-233, 2006.

ZANATTA, C. F. et al. Photoprotective potential of emulsions formulated with Buriti oil (Maurixia flexuosa) against UV irradiation on keratinocytes and fibroblasts cell lines. Food and Chemical Toxicology, Oxford, v. 48, p. 70-75, 2010. 


\section{APÊNDICE}

APÊNDICE A Termo de consentimento e livre esclarecido para o teste diferença do controle.

\begin{tabular}{|c|}
\hline TERMO DE CONSENTIMENTO E LIVRE ESCLARECIDO \\
\hline 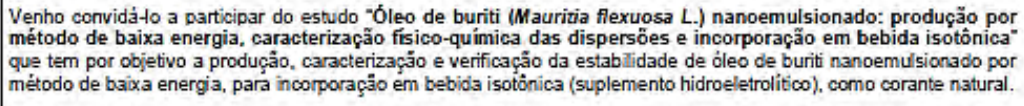 \\
\hline 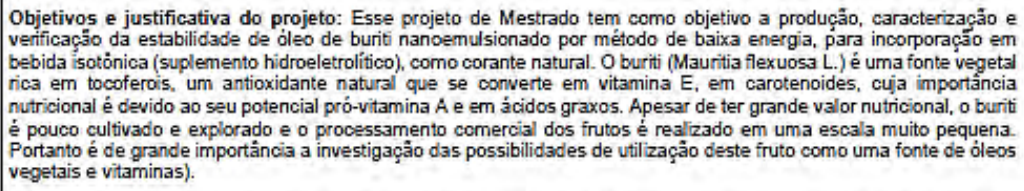 \\
\hline $\begin{array}{l}\text { Possiveis benefícios: Disponiblizaçăo de uma bebida segura, de qualidade e que promove uma rápida hidrataçäo de } \\
\text { praticantes de atividades física que perdem água e eletrólitos durante a transpiraçăo. Se bem aceito sensorialmente, a } \\
\text { bebida isotônica com aplicaçáo de nanoemulsôes contendo óleo de buriti pode trazer beneficios a saúde humana por } \\
\text { conta dos componentes nutricionais presentes no óleo de burit, e ainda, pode ser uma substituiçăo viável para corantes } \\
\text { artificiais, especialmente o amarelo tartrazina e amarelo crepussculo. }\end{array}$ \\
\hline 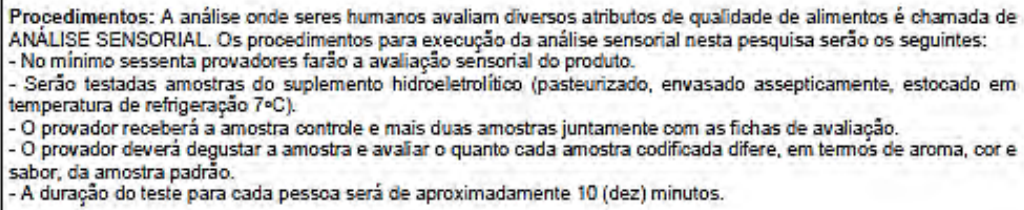 \\
\hline 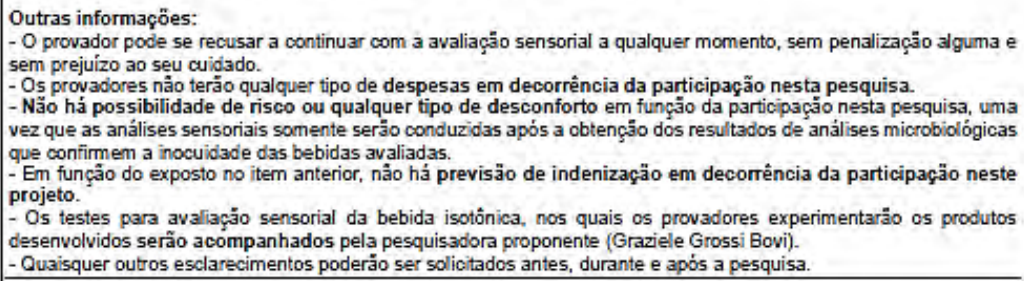 \\
\hline 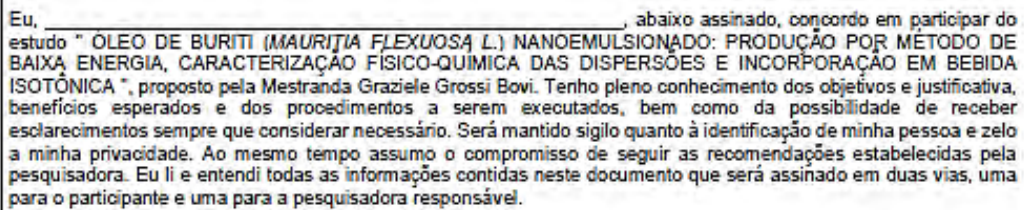 \\
\hline $\begin{array}{l}\text { Pesquisadora responsável: Graziele Grossi Bovi - Programa de Pós-graduçâo en Engenharia de Alimentos - } \\
\text { FZEA - USP. Contato: graziele.bovi@usp.br. } \\
\text { CEP da Escola de Enfermagem da USP:-Tel:(11) 3061-7548; e-mail: edipesg Qusp.br }\end{array}$ \\
\hline
\end{tabular}

APÊNDICE B Modelo da ficha de avaliação sensorial utilizada no teste de diferença do controle.

FICHA DE AVALIAÇAO SENSORIAL DE ISOTONICO SABOR TANGERINA Nome:

Data:

Vocé está recebendo uma amostra padrảo (P) e duas amostras codificadas de isotônico sabor tangerina. Prove o padrão e em seguida, cada uma das amostras codificadas e avalie, na escala abaìco, o quanto cada amostra codificada difere, em termos de aroma, da amostra padrão.
(0) Nenhuma đfierença
(1) Ligeiramente diferente de $P$
(2) Moderadamente diferente de $P$
(3) Muito diferente de P
(4) Extremamente diferente de P

Amostra Grau de diferença 
APÊNDICE C Termo de consentimento e livre esclarecido para o teste de escala hedônica.

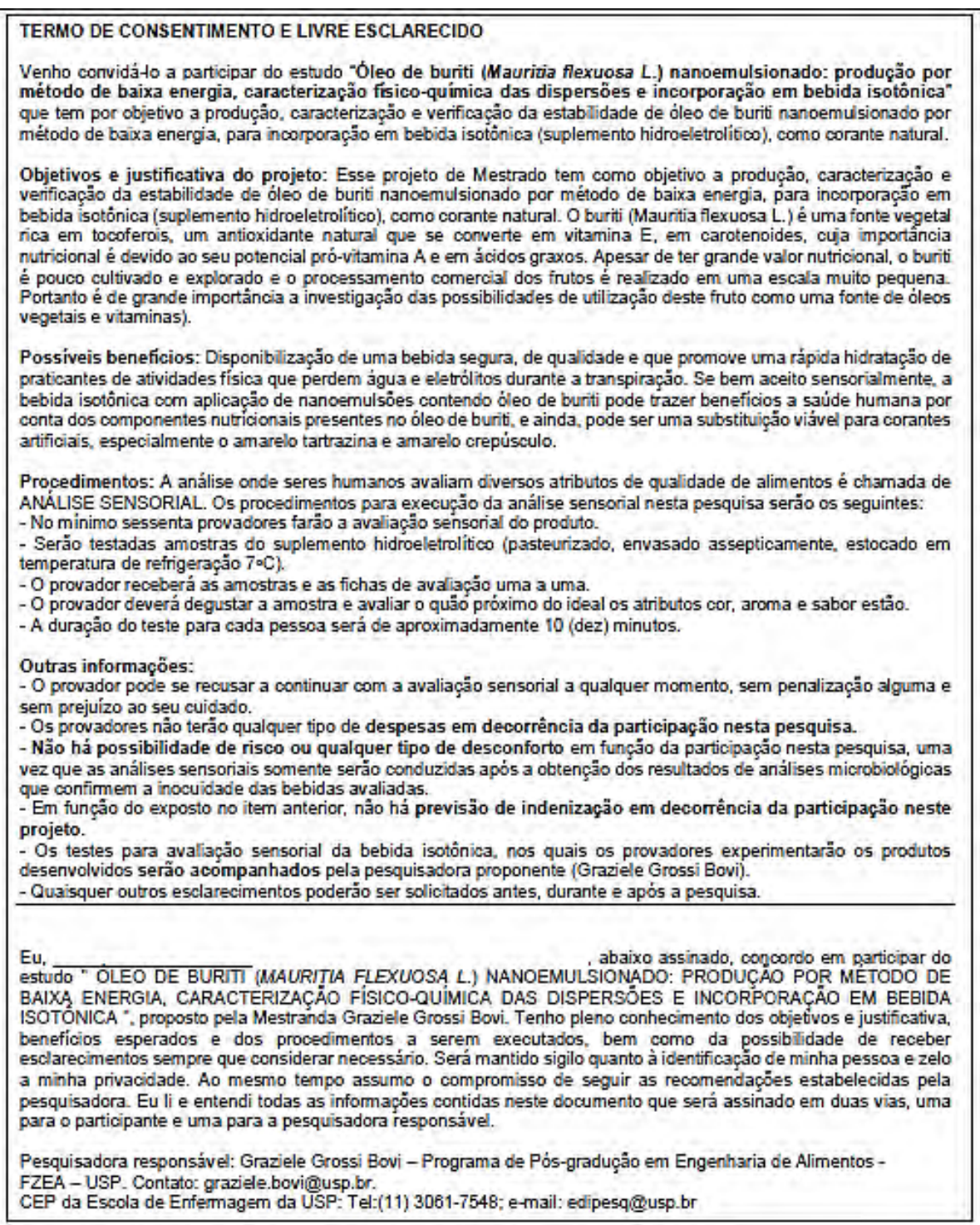

APÊNDICE D Modelo da ficha de avaliação sensorial utilizada no teste de escala hedônica.

FICHA DE AVALLACAO SENSORIML DE ISOTONICO SABOR TANGERINA

Nome;

Data

Por favor, avalie a amostra de isoldonico sabor tangerina e indique, uticicando a escala abaicio, o quanto vock gostou ou desgostou em relaçăo aos atribuhos indicados.
1. Desgostei muitissimo
6. Costei Iigeiramente
2. Desgostei multo
3. Despostei moderadamente
7. Gostei moderadamente
4. Detgostei ligeiramente
8. Gostei mutco
9. Gostei muitissimo

5. Nem gosteinem despostei

\begin{tabular}{|c|c|c|c|}
\hline AMOSTRA & Cor & Aroma & Sabor \\
\hline \multicolumn{4}{|c|}{ Se vocb encontrasse este produlo no mercado: } \\
\hline \multicolumn{4}{|c|}{ ) Certamente compraria } \\
\hline \multicolumn{4}{|c|}{ ) Provarveimente compraria } \\
\hline \multicolumn{4}{|c|}{ ) Talvez comørariatalvez nà compraria } \\
\hline \multicolumn{4}{|c|}{ ) Provaveimente nào compraria } \\
\hline ) Cert & comp & & \\
\hline
\end{tabular}




\section{ANEXO}

ANEXO A Laudo do óleo de buriti utilizado neste trabalho de Mestrado (fornecido pelo fabricante).

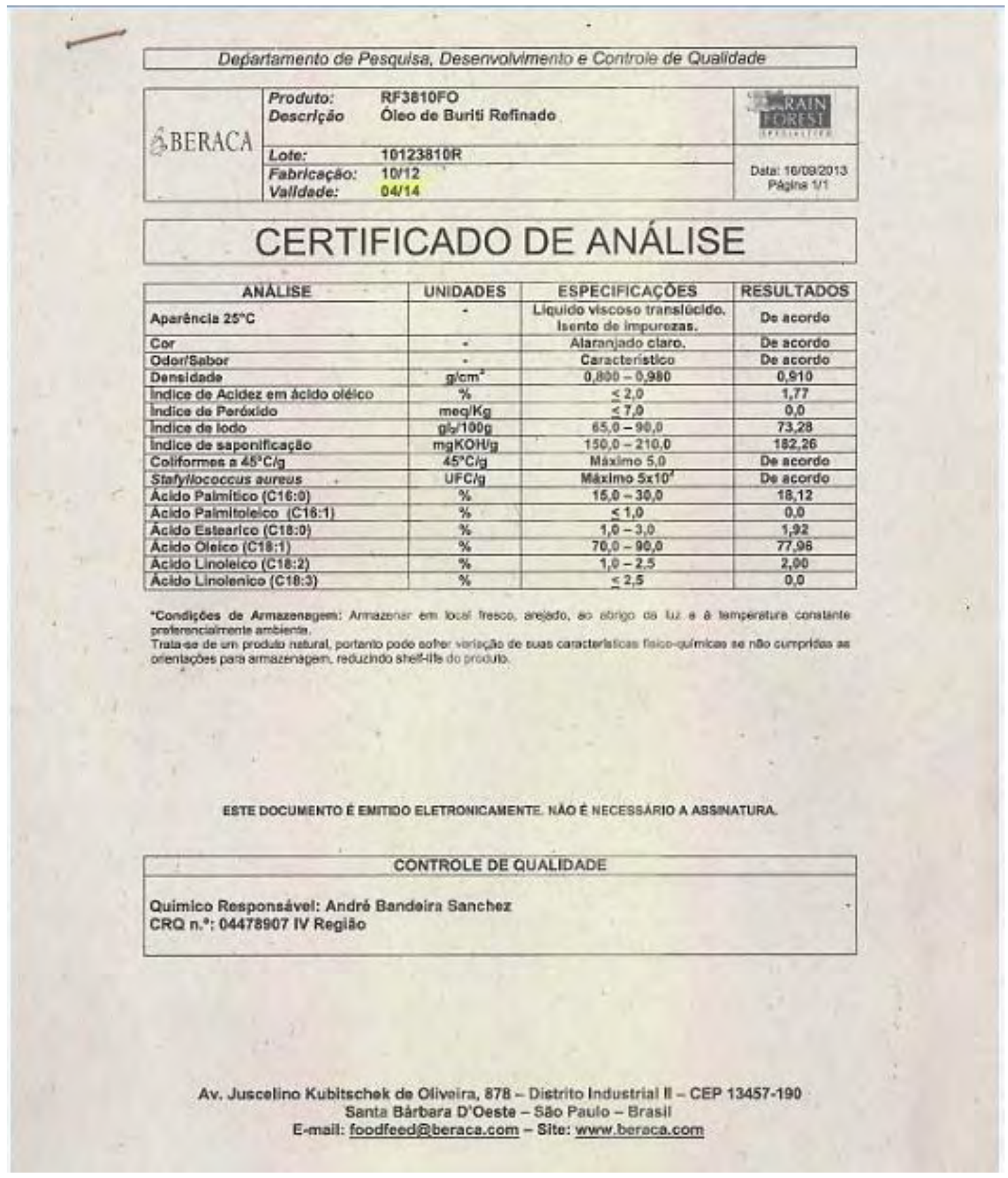


ANEXO B Laudo do aroma de tangerina utilizado neste trabalho de Mestrado (fornecido pelo fabricante).

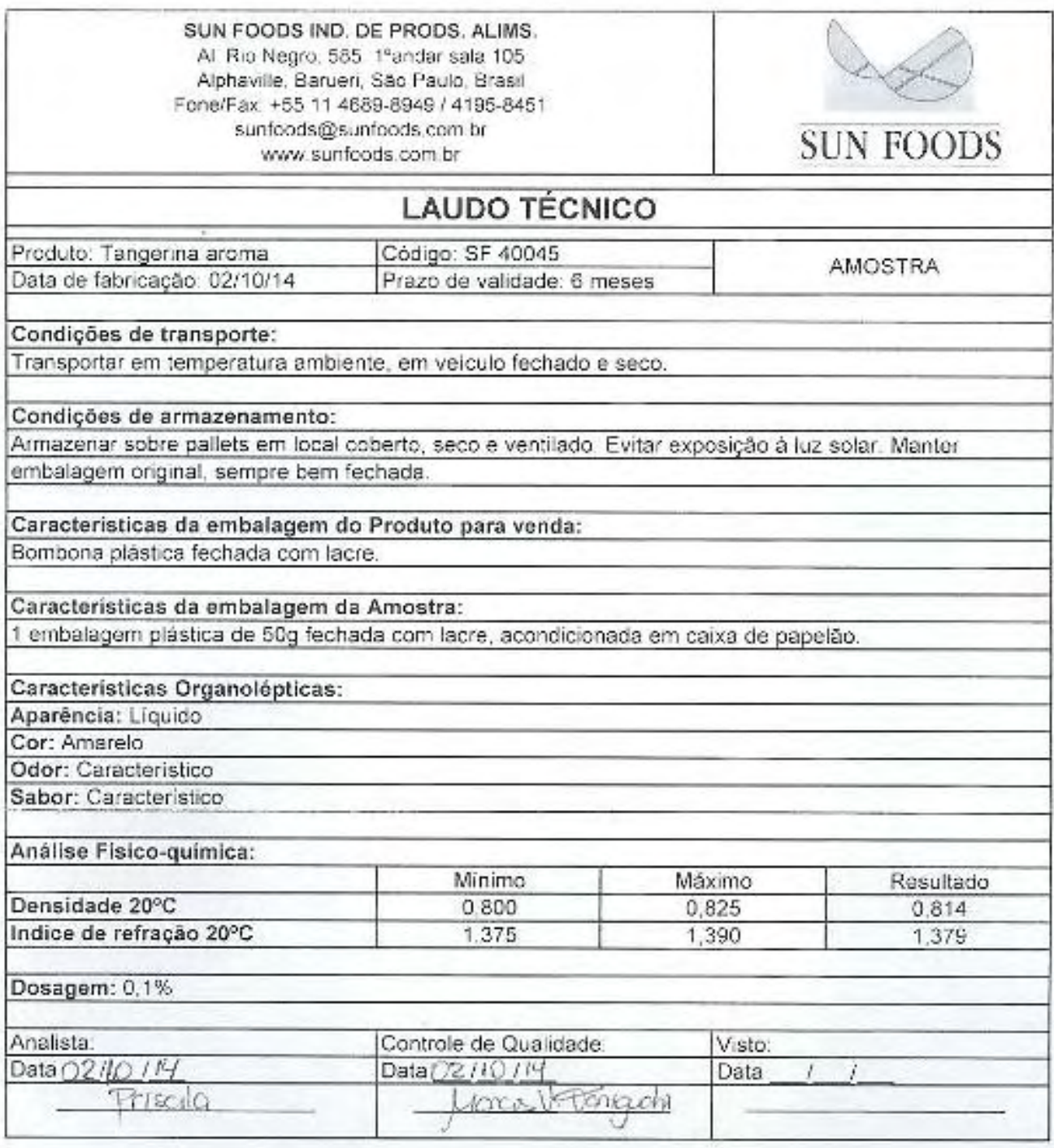


ANEXO C Parecer do Comitê de Ética em Pesquisa da Escola de Enfermagem da Universidade de São Paulo (EEUSP)

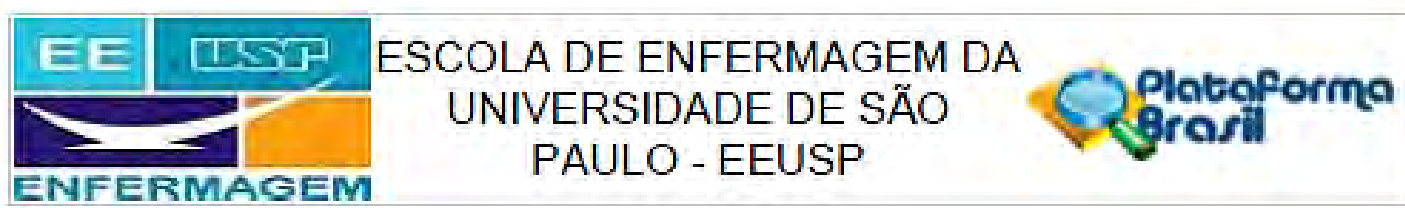

Contsnuaço do Farecer. 9es.4S0

Comentários e Considerações sobre a Pesquisa:

Trata-se de um projeto de mestrado. A metodologia apresenta detalhadamente todas as etapas para a produção da nanoemulsão de óleo de buriti e da bebida isotônica que o conterá, bem como os testes de segurança e qualidade do produto.

Consideraçőes sobre os Termos de apresentação obrigatória:

Foi apresentado o termo de consentimento livre e esclarecido que contém todos os itens da resolução $466 / 12$.

Recomendaçöes:

Não há.

Conclusões ou Pendências e Lista de Inadequaçőes:

As pendências foram atendidas. Pede-se para inserir a assinatura do pesquisador no TCLE.

Situaçäo do Parecer:

Aprovado

Necessita Apreciação da CONEP:

Não

Consideraçöes Finais a critério do CEP:

Este CEP informa a necessidade de registro dos resultados parciais e finais na Plataforma Brasil.

Esta aprovação não substitui a autorização da instituiçäo coparticipante, antes do inicio da coleta de dados.

Assinado por:

Marcelo José dos Santos

(Coordenador) 